\title{
Measurement of attitude toward educational use of the Internet in an English composition course with a comparison of traditional -aged and non-traditional-aged students
}

\author{
Diana Gail Duran \\ West Virginia University
}

Follow this and additional works at: https://researchrepository.wvu.edu/etd

\section{Recommended Citation}

Duran, Diana Gail, "Measurement of attitude toward educational use of the Internet in an English composition course with a comparison of traditional -aged and non-traditional-aged students" (2003). Graduate Theses, Dissertations, and Problem Reports. 2477.

https://researchrepository.wvu.edu/etd/2477

This Dissertation is protected by copyright and/or related rights. It has been brought to you by the The Research Repository @ WVU with permission from the rights-holder(s). You are free to use this Dissertation in any way that is permitted by the copyright and related rights legislation that applies to your use. For other uses you must obtain permission from the rights-holder(s) directly, unless additional rights are indicated by a Creative Commons license in the record and/ or on the work itself. This Dissertation has been accepted for inclusion in WVU Graduate Theses, Dissertations, and Problem Reports collection by an authorized administrator of The Research Repository @ WVU.

For more information, please contact researchrepository@mail.wvu.edu. 
Measurement of Attitude Toward Educational Use of the Internet in an English Composition Course with a Comparison of Traditional Aged and Non-traditional Aged Students

\title{
Diana G. Duran
}

A dissertation submitted to the College of Human Resources and Education

at West Virginia University in partial fulfillment of the requirements for the degree of

\section{Doctor of Education}

in

Educational Psychology

\author{
Anne H. Nardi, Ph.D., Chair \\ Richard T. Walls, Ph. D. \\ Samuel F. Stack, Ph.D. \\ Neal R. Shambaugh, Ph.D. \\ Laura Brady, Ph.D \\ Department of Advanced Educational Studies
}

Morgantown, West Virginia 2003

Keywords: Attitude, Internet, Writing Copyright 2003 Diana G. Duran 


\begin{abstract}
Measurement of Attitude Toward Educational use of the Internet in an English Composition Course with a Comparison of Traditional Aged and Non-traditional Aged Students
\end{abstract}

\title{
Diana G. Duran
}

Attitude is tied to behavior, and writing behaviors seem to be affected by using a computer. Technological advances have forever changed the way educators view the process of writing, including the way students learn, how they feel about the way they are learning, and their subsequent behaviors. Numerous studies have indicated that using computers to write changes the way students write, what they write, and the quantity and quality of that writing. However, studies disagreed about how these changes occur, whether they are positive or negative (or neither), and what psychological dynamics, such as attitude, are involved, to what degree, and how they relate to each other. Affect in general and specifically toward computers has been studied, with several computer attitude scales developed during the 1980s and 1990s. However, these scales did not measure attitude nor subsequent behaviors toward complex computer applications, such as the Internet; moreover, none existed for use in English composition. This study measured attitudes toward educational use of the Internet (ATEUI), along with selected behavioral correlates, among English composition students to examine the relationships between attitude and behavior, age, sex, and academic rank. Further, the students were categorized by age to determine any differences between those who were traditional aged $(<25)$ and those who were non-traditional aged $(\geq 25)$. 


\section{Dedication}

This dissertation is dedicated to my mother, Ruth Allen Duran, who convinced me at an

early age that education is the way out of poverty. I wish you were here to share this achievement with me and the rest of our family. 


\section{Acknowledgements}

While one writes a dissertation, it seems a solitary business, and in fact, that is often the case. However, no one reaches the final goal without a host of people supporting the writer in one way or another and, more often, in many ways. I would like to acknowledge the many people who have supported me as I pursued the doctoral degree, especially during the writing of this document.

First, I thank Björn Söderberg for his moral and financial support. Without him, I am certain I would never have reached this point in my education.

Next, I thank my committee members who are without doubt among the very best, and perhaps most patient, teachers - anywhere. The value of your guidance, knowledge, and expertise is immeasurable. I thank you for working with me and teaching me. As a group and individually, you have every right to feel superior and perhaps to flaunt that superiority; however, I can honestly say that your professionalism is equal to, if not surpassed by, your humility. I am fortunate to have known and worked with such a select group of educators.

As anyone who knows me realizes, I am very proud of my family. We grew up in poverty; resources were scarce. I don't really feel that this degree is "my" degree at all; rather, I feel that it is my family's degree, a symbol of one's ability to beat tremendous odds and to succeed in this country. So, to my parents, Virgil and Ruth Duran, my siblings - Richard, David, Jerry, Kathryn, Dennis, Ginger, Mike, and Teresa - this is for you and for us. Thank you for your love and support.

Another group of people are to be acknowledged - my colleagues in the Technical Assistance Department of the National Small Flows Clearinghouse-Peter, Andrew, Ed, Tricia, 
Jeff, Crystal, and Dolly. I thank you for the financial support through my years as a Graduate Research Assistant. As importantly, I thank you for your friendship, the camaraderie, and the laughter. Specifically, I thank Jennifer Hause, my supervisor, for giving me the opportunity to work at the NSFC and for being absolutely the best boss I ever had.

I would like to recognize a person who helped not only me, but countless others through the years, and that is Ann Crabtree. Ann paves the way, cuts through the red tape, and solves the problems. Thank you, Ann, you're truly a godsend.

Next, I want to thank the staff of the WVU Evansdale Library Interlibrary Loan Office for helping make the research process less painful and my literature review as complete as possible.

I thank Mark King, my physical therapist and friend, without whom I might not be able to walk. Thank you, Mark, for your expertise and caring, for being not only a physical therapist but also a psychologist, for helping me get my life back, for all the corny jokes, and your magic act — they made me laugh, some of the best medicine.

Finally, I thank all of my friends who encouraged and sympathized, listened to me and laughed with me. 
Table of Contents

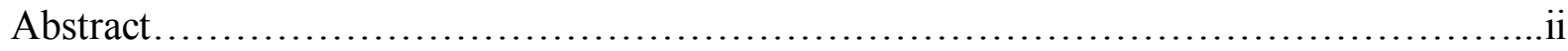

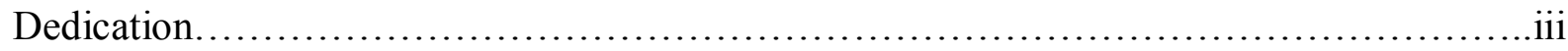

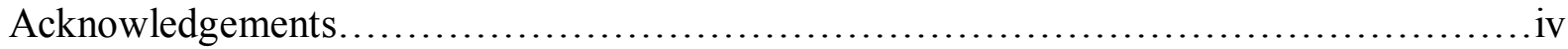

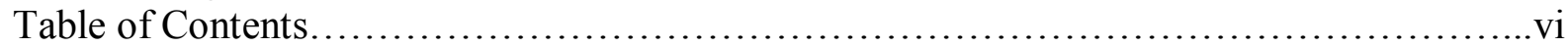

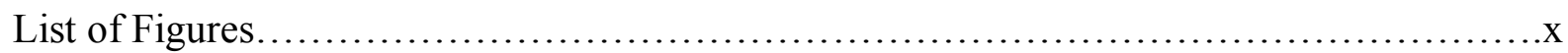

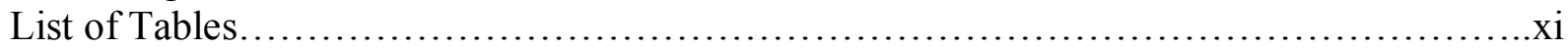

Chapter 1 - Introduction.............................................................

Chapter 2 - Literature Review and Research Question.................................... 3

Attitude as a component of the affective domain...............................4

Taxonomy of educational objectives: Cognitive and affective domains........4

Essentials of learning for instruction...................................... 4

Instrument development in the affective domain......................... 7

Summary............................................................ 11

Measurement of students' attitudes toward computers..........................12

Understanding gender differences in computer attitudes, aptitude, and use ....13

Reliability and factorial validity of computer attitude scales................16

The reliability and validity of an instrument for the assessment of computer attitudes...................................................... 17

Development of the attitudes toward computer usage (ATCUS) scale..........19

Testing the factor structure invariance of a computer attitude scale over two grouping conditions......................................23

Factorial validity of a computer attitude scale...........................24

Convergent validity of seven scales measuring computer-related attitudes.....25

Examination of the factor structures and concurrent validities for the computer attitude scale, the computer anxiety rating scale, and the computer self-efficacy scale...................................29

Antecedents of student attitudes toward computers.........................30

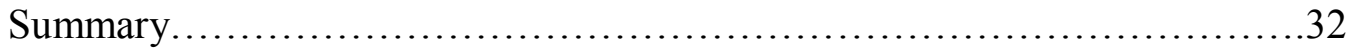

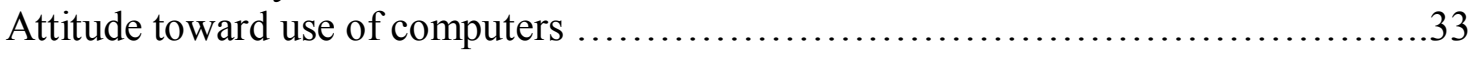

The effect of computer-and-writing instruction on prospective English teachers' attitudes toward and perceived uses of computers in computers in writing instruction...................................36

Challenges of the new information age curriculum: Computers and the liberal arts...............................................40

Teacher education students and computers: Gender, major prior computer experience, occurrence, and anxiety ............................. 42

Attitudes toward computers, science, and technology.....................44

An attitudinal comparison toward computers between underclassmen and graduating seniors............................................47

Gender differences in student attitudes toward computers...................49 
A longitudinal study of student attitudes toward computers: Resolving an attitude decay paradox............................................51

Changes in student attitudes and student computer use in a computer-

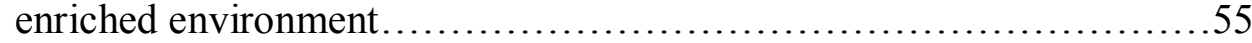

Effect of student attitude to course format on learning performance: An empirical study in Web vs. lecture instruction.......................58

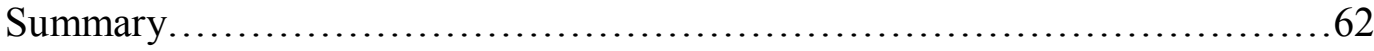

Using computers for English composition (computer-assisted composition)............63

Research and recommendations for computers and composition...............67

Critical perspectives on computers and composition instruction................69

Technology and literacy in the twenty-first century: The importance of paying attention............................................69

Opening spaces: Writing technologies and critical research practices............71

The computers-and-effective-writing movement: Computer-assisted composition.................................................... 71

When pens are passé: Students reflect on written composition.................72

Researching electronic networks.....................................76

The flashlight project and an introductory writing course sequence:

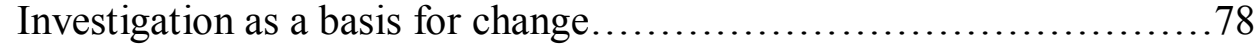

Critical computer literacy: Computers in first-year composition as topic and environment............................................... 81

What happens when machines read our students' writing?...................83

A synthesis of studies on computer-supported composition, revision,

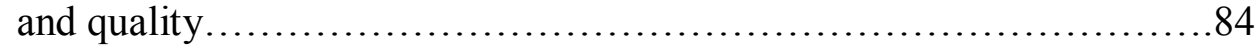

Assessing the impact of computer-based writing instruction....................85

Computer-assisted instruction...........................................86

Student attitudes and academic background as predictors of achievement in college English................................................87

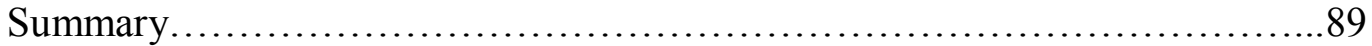

Measurement of students'attitudes toward educational use of the Internet (ATEUI) ...91

Information technology and education: Student perceptions of computer and Web-based environments..................................91

Student attitudes toward Web-enhanced instruction in an introductory

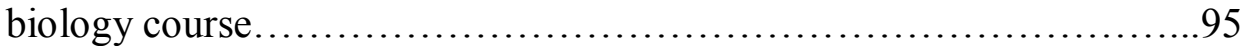

Measuring students' attitude toward educational use of the Internet..............98

Summary......................................................... 101

Non-traditional aged students compared to traditional aged students..................101

I became clueless teaching the GenXers: Redefining the profile of the adult learner.................................................... 102

The adult learner challenge: Institutionally and administratively..............103

Comparing teacher and student responses to the mixed age classroom..........106 
The one-to-one survey: Traditional versus non-traditional student satisfaction with professors during one-to-one contacts................108

Classroom age composition and academic achievement in college.............110

A model of college outcomes for adults..................................112

Adult undergraduates in higher education: A review of past research perspectives...............................................113

Adult students' academic and intellectual development in college..............114

Differential prediction of adult student performance from Miller Analogies test scores....................................................116

Facilitating adult learning in a liberal education context.....................116

Summary........................................................ 118

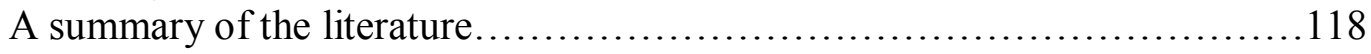

Research questions .......................................................... 119

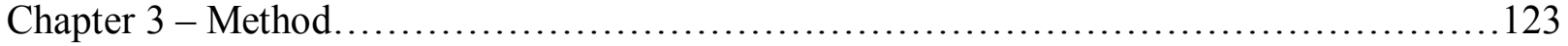

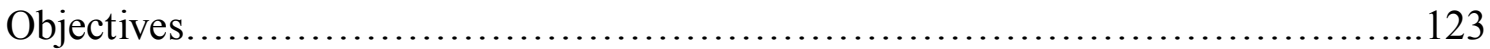

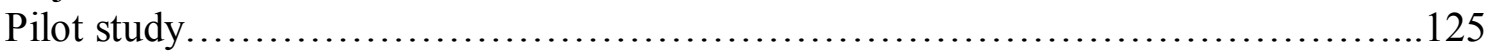

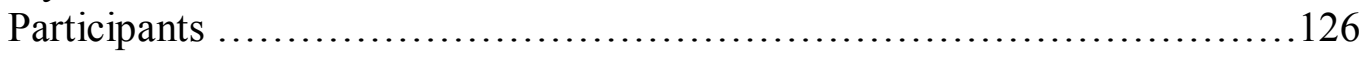

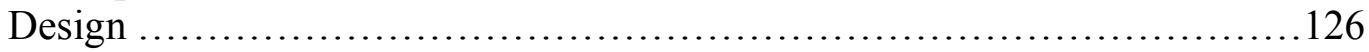

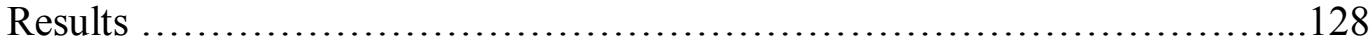

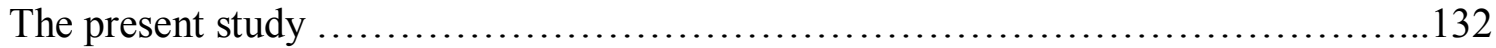

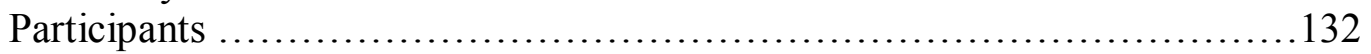

Participant recruitment procedure..............................133

Research design .................................................... 134

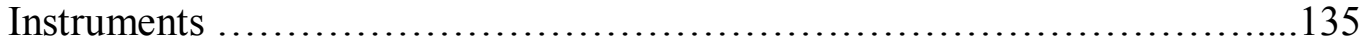

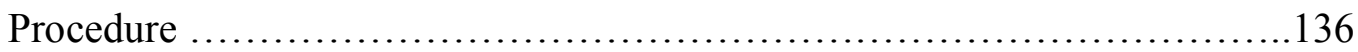

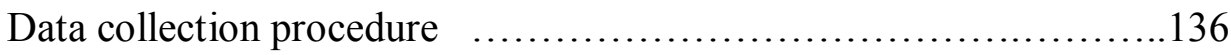

Setting..........................................................

Measurement ....................................................138

Hypotheses................................................140

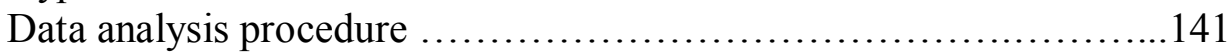

Chapter 4 - Results......................................................... 145

Participants............................................................ 145

Participant descriptive statistics...................................... 146

Hypotheses............................................................... 148

Quantitative data analysis .......................................... 148

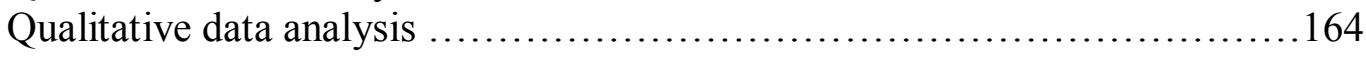

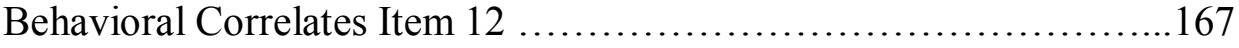

Behavioral Correlates Item 20 ................................169

Instructor Interviews ......................................... 170

Chapter 5 - Discussion and Conclusion........................................... 180

Measurement of ATEUI scores ........................................... 181

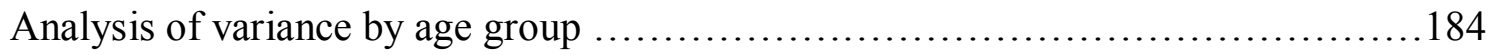


Correlation of ATEUI total scores with selected Behavioral Correlates

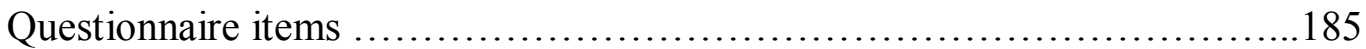

Response frequencies for the Behavioral Questionnaire items......................187

Correlations for ATEUI total scores with age group, academic rank,

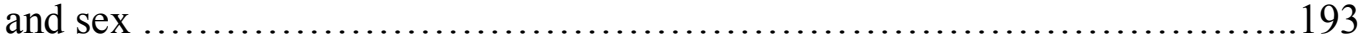

Correlations for Behavioral Correlates Questionnaire items with age group,

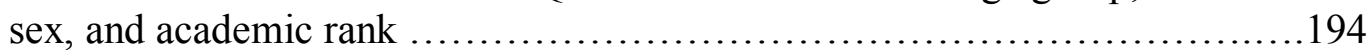

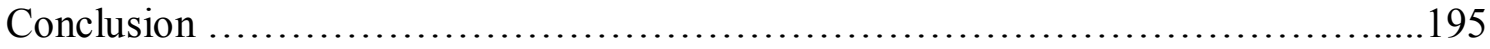

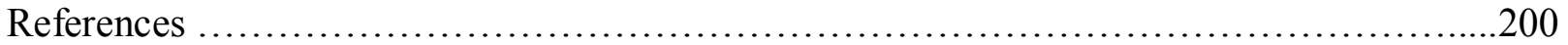

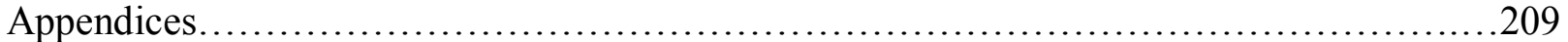

Appendix A - Attitudes Toward Educational Use of the Internet Scale ................210

Appendix B - Behavioral Correlates Questionnaire ................................211

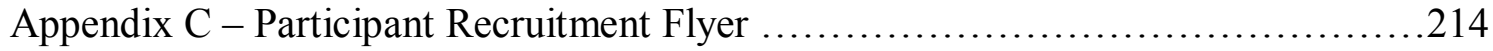

Appendix D - Script for Study .................................................215 


\section{List of Figures}

Figure 1: The Data Collection Procedure ......................................... 131 
List of Tables

Table 1: Summary of Research for Attitude as a Component of the Affective Domain...........5

Table 2: Summary of Research for Computer Attitude Scale Development and Testing........14

Table 3: Summary of Research for Attitude Toward Use of Computers.......................34

Table 4: Summary of Research for Computer-assisted Composition.........................64

Table 5: Summary of Research for Measurement of Students' Attitudes Toward Educational Use of the Internet..........................................92

Table 6: Summary of Research for Traditional Versus Non-Traditional Students..............104

Table 7: Data Analysis Procedure................................................ 142

Table 8: Demographic Frequencies and Percentages for Age Group, Sex, and Academic Rank.......................................................... 147

Table 9: Item Means and Standard Deviations for the Attitude Toward Educational Use of the Internet (ATEUI) Scale Based on Likert Format.........................150

Table 10: Results of ANOVA of ATEUI Mean Scores by Age Group for ATEUI

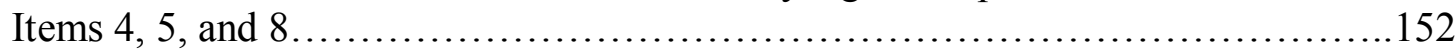

Table 11: Correlations for ATEUI Total Scores with Selected Behavioral Correlates Questionnaire Items................................................ 154

Table 12: Number (Percent) of Response Frequencies for Behavioral Correlates Questionnaire Items............................................... 156

Table 13: Correlation Matrix of ATEUI Total Score, Age Group, Academic Rank,

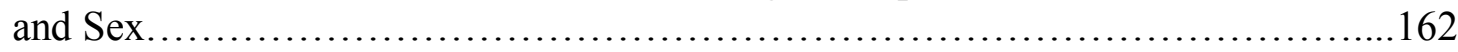

Table 14: Correlations for Behavioral Correlates Questionnaire Items with Age Group, Sex, and Academic Rank. 165 


\section{Chapter 1}

\section{Introduction}

Christopher Latham Sholes would surely be proud that, since the late 1860s, people have been tapping away on his patented QWERTY keyboard (Montgomery, 1982). With the exception of function and other specialty keys and peripherals like the mouse, it now appearsrelatively unchanged — on the most sophisticated microcomputers. Sholes would, however, be unable to fathom how we use that keyboard.

From the days of storing information on punched paper and thousands of vacuum tubes in the 1940s, and the first computer-assisted instruction (CAI) projects in the late 1950s, computer technology has increasingly been used for instructional purposes. Today, those students without access to a microcomputer, the latest software, and the Internet are disadvantaged.

Since the introduction of the microcomputer in the 1970s, no one has wanted to stem the tide of increasing computer use. Now it is not unusual for universities to offer an array of courses in a variety of disciplines either completely online or in combination with classroom meetings and/or conferences with the instructor-including writing courses. As far as education is concerned, specifically instruction in English composition-from basic CAI to incorporation of the Internet into a class_-from word processing, the drill and practice of grammar and spelling tutorials, text editors, and style checkers to e-mail, networks, and online courses - technological advances have forever changed the way educators view the process of writing, not to mention the way it is taught and learned. They may also have changed the way students feel about writing and the technology they use to write, and changed their subsequent writing behaviors.

To learn what students' attitudes are toward using the Internet for educational purposes in an English Composition course, and to examine ways in which students' attitudes and behaviors 
may have changed, this study examined five areas of research: (1) attitude as a component of the affective domain, (2) measurement of students' attitudes toward computers, including the variety of attitude scales developed and tested during the 1980s; (3) attitude toward use of computers, (4) using computers for English composition (computer-assisted composition), including the World Wide Web and the Internet; (5) measurement of students' attitudes toward educational use of the Internet, and (6) non-traditional aged students compared to traditional aged students.

The study of attitude in general evolved from its initial recognition as a viable domain of human learning with cognitive and psychomotor outcomes, to the development of scales to measure level of affect. As the instruments were developed, tested, and refined, the measurement of attitude became more specific, including the measurement of attitude toward computers and their use. Microcomputers proliferated, and the technology became more sophisticated as new applications became available and were used. The study of attitude toward these applications paralleled the technological advances, becoming more sophisticated and more specific, examining not only the use of computers and their various applications, but also targeting specific users in particular educational settings. Today, the continuing study of the affective domain of learning requires such studies as the present one to measure attitude toward educational use of the Internet in an English composition course along with possible corresponding behaviors. 


\section{Chapter 2}

\section{Literature Review and Research Questions}

The purpose of this study was to measure English composition students' attitudes toward educational use of the Internet and to study selected behavioral correlates to those attitudes using the Attitude Toward Educational Use of the Internet (ATEUI) scale developed by Duggan, Hess, Morgan, Kim, and Wilson (2001). Relationships between attitude, behavior, age, sex, and academic rank were also examined. Further, students were categorized by age to determine any differences between those who were traditional aged $(<25)$ and those who were non-traditional aged ( $\geq 25$ ) (WVU Extended Learning, 2002).

The computer attitude scales emerging during the mid-to-late 1980s and into the early 1990s did not measure student affect or subsequent behavior for computer applications such as the Internet. Scales to measure students' attitudes toward these applications were needed. Recently Duggan et al. (2001) published the Attitude Toward Educational Use of the Internet (ATEUI) scale along with a questionnaire eliciting selected behavioral correlates to use of the Internet for educational purposes.

To follow the evolution of the study of attitude from its initial recognition as a viable domain of human learning with cognitive and psychomotor outcomes, to the development of scales to measure level of affect and on to more sophisticated and specific measurement, several areas of literature were reviewed. This study examined six (6) areas of research: (1) attitude as a component of the affective domain, (2) measurement of students' attitudes toward computers, including the variety of attitude scales developed and tested during the 1980s; (3) attitude toward 
use of computers, (4) using computers for English composition (computer-assisted composition), including the World Wide Web and the Internet; (5) measurement of students' attitudes toward educational use of the Internet, and (6) non-traditional aged students compared to traditional aged students.

\section{Attitude as a Component of the Affective Domain}

Although attitude had been studied and measured at least since the 1920s (Thurstone \& Chave, 1929), it was during the 1970s that affective objectives were recognized to be important as both ends and means in the overall school process, and were no longer considered as merely acceptable outgrowths of an emphasis on the cognitive domain (Gable, 1986; Gable \& Wolf, 1993). Attitude, a component of the affective domain, is significant for a number of reasons, the most important of which is that it is related to motivation and is closely tied to behavior (Kay, 1992). A summary of the literature reviewed in this section can be found in Table 1 (below).

Taxonomy of educational objectives: Cognitive and affective domains. Bloom, Engelhart, Furst, Hill, and Krathwohl (1956) were among the first instructional theorists to accept the idea of domains of humans' learned capabilities, including the affective domain, and proposed a taxonomy of cognitive outcomes ranging from lower level (knowledge) to higher level skill (evaluation). Krathwohl, Bloom, and Masia (1964) later developed a taxonomy of outcomes within the affective domain, including receiving, responding, valuing, organization, and characterization by value, with the latter four defined in behavioral terms.

Essentials of learning for instruction. Gagné (1974) was the first to propose an integrated taxonomy of learning outcomes that included not only the affective but also cognitive and psychomotor. He identified five major categories of learning outcomes, including verbal 
Table 1

Summary of Research for Attitude as a Component of the Affective Domain

Study

Findings

Thurstone \& Chave

(1929)

The Measurement of Attitude:

A Psychophysical Method and Some Experiments with a Scale for Measuring Attitude toward the Church
Bloom et al.

(1956)

Taxonomy of Educational Objectives, Handbook I:

Cognitive Domain

Krathwohl et al.

(1964)

Taxonomy of Educational Objectives, Handbook II:

Affective Domain

Gagné

(1974)

Essentials of Learning for Instruction
Conceded that social phenomena are exceedingly difficult to describe in objective terms, but believed that attitude was related to motivation. Tried to devise a method whereby the distribution of attitude of a group on a specified issue may be represented in the form of a frequency distribution, now known as a maximum probability type scale. Recognized that there is some discrepancy, some error of measurement between the opinion and overt action that they used as an index and the attitude that they inferred from such an index. Stated that "truth is inferred only from the relative consistency of several indices since it is never directly known." Sought to create several indices that were internally consistent.

Among first to accept the idea of domains of humans' learned capabilities, including the affective domain, and proposed a taxonomy of cognitive outcomes ranging from lower level (knowledge) to higher level skill (evaluation).

Developed a taxonomy of outcomes within the affective domain, including receiving, responding, valuing, organization, and characterization by value, with the latter four defined in behavioral terms.

First to propose an integrated taxonomy of learning outcomes including affective, cognitive, and psychomotor. verbal information, intellectual skills, cognitive strategies, motor skills, and attitudes. 
Table 1 (continued)

Study

Findings

Fuchs

(1980)

Evaluating Education Research

Gagné

(1985)

The Conditions of Learning

Gable

(1986)

Instrument Development in the Affective Domain

Baker \& O'Neil

(1987)

Assessing Instructional Outcomes

Kay

(1992)

Understanding gender differences

in computer attitudes, aptitude, and

use: An invitation to build theory
Defined construct validity (that an instrument indeed measures what it says it does) as how well a test measures a theoretical construct (usually a phenomenon that is not observable, for example, intelligence, feelings, and attitudes. Believed that well organized and conducted survey studies are valuable and can be useful to those involved with planning and evaluating learning.

Defined attitudes as acquired internal states that influence the choice of personal action toward some class of things, persons, or events.

Reported definitions of attitude from researchers, e.g., Bloom, Anderson, Thurstone, Wagner, Aiken. No single definition has emerged. Construction and testing of affective instruments, including validity and reliability. Measured reliability using reliability coefficient. Used factor analysis to identify clusters of variables that share variation; inter-item correlation as a data reduction technique, including eigen values and vectors, orthogonal/varimax and oblique rotation. Discussed limitations of affective instruments including situational factors and sample size.

Cautioned that all measurement is imprecise; everything we infer is exactly that: inferencing about learning that occurred (or is potential) in the learner.

Believed that attitude is related to motivation and is closely tied to behavior. 
Table 1 (continued)

Study

Findings

Gable \& Wolf

(1993)

Instrument Development in the Affective Domain: Measuring Attitudes and Values in Corporate and School Settings
Extension of work by Gable (1986). Pointed out that all affective characteristics must have three attributesintensity, direction, and target. Believed that students approach learning tasks with prior affective entry characteristics as well as cognitive behaviors, and that the dynamic interaction between these overlapping cognitive and affective domains during the instructional process results in both cognitive learning outcomes and associated affective outcomes.

Stated that the effective implementation of technology depends on users' having a positive attitude toward it, that perceptions and attitudes are fundamentally important because they usually accompany effective learning.
(2000)

Information technology and education: Student perceptions of computer and Web-based environments information, intellectual skills, and cognitive strategies (cognitive domain); motor skills (psychomotor domain); and attitudes (affective domain).

Gagné (1985) later defined attitudes as acquired internal states that influence the choice of personal action toward some class of things, persons, or events. Given this definition, the connection between a student's attitude and performance seemed apparent. However, Gable and Wolf (1993) pointed out that there was some disagreement about the connection between attitude and behavior, and cautioned that behavior should be considered a function of one's attitude in the context of the particular situation.

Instrument development in the affective domain. Whatever the significance of attitude, its measurement and effect on motivation, learning, and performance (behavior) remained 
problematic. First, there was the matter of defining affective characteristics, of which attitude is one. Citing several sources, Gable (1986) and Gable and Wolf(1993) observed that there was no single definition of attitude, but that most authorities agreed attitude involves intensity of positive or negative affect for or against a psychological object and that it is composed of affective, cognitive, and behavioral components corresponding to one's predisposition to act toward the object of the attitude. They pointed out that all affective characteristics must have three attributes - intensity, direction, and target. Intensity refers to the degree or strength of the feeling (e.g., strong versus mild); direction reflects the positive, neutral, or negative aspect of feeling. The final attribute, the target, identifies the object, behavior, or idea at which the feeling is being directed, such as using the Internet to meet course requirements.

Gable and Wolf (1993) believed that students approach any learning task with prior affective entry characteristics (e.g., attitudes, self-esteem, interests, and values), as well as cognitive behaviors. It is the dynamic interaction between these overlapping cognitive and affective domains during the instructional process that results in both cognitive learning outcomes and associated affective outcomes. These affective outcomes help guide future feelings about course content and issues (attitudes), feelings of personal worth and success (selfesteem), desire to become involved in various activities (interests), and personal standards (values).

Others also believed that these predispositions to respond are learned. As far as attitudes toward computers were concerned, Liaw (2000) stated that the effective implementation of technology depends on users' having a positive attitude toward it, that "perceptions and attitudes 
toward hypermedia-based or Web-based environments are fundamentally important because they usually accompany effective learning" (p. 12).

Thurstone and Chave (1929) had earlier conceded that social phenomena are exceedingly difficult to describe in objective terms, but they believed that attitude was related to motivation. They tried to devise a method whereby the distribution of attitude of a group on a specified issue may be represented in the form of a frequency distribution, now known as a maximum probability type scale. They used the concept "attitude" to denote "the sum total of a man's inclinations and feelings, prejudice, or bias" (p. 6), and used the concept "opinion" as a verbal expression and a symbol of attitude. The authors admitted that there is uncertainty when using an opinion as an index of attitude. People may unintentionally misrepresent their real attitudes, modify their expressions for reasons of courtesy, or even lie.

Thurstone and Chave (1929) recognized that there is some discrepancy, some error of measurement between the opinion or overt action that they used as an index and the attitude that they inferred from such an index. They also conceded that opinions can be multidimensional (a scale is unidimensional); all opinions cannot be represented in a linear continuum. However, they observed that in almost every situation involving measurement-whether it is of volume or temperature, for examples — an abstract continuum is postulated, and the allocation of the thing measured to that continuum is accomplished usually by indirect means through one or more indices. Truth, they stated, is inferred only from the relative consistency of several indices since it is never directly known. They believed they were dealing with the same type of situation in attempting to measure attitude, and their goal was to find one or more indices that were internally consistent. 
They took for granted that people's attitudes were subject to change and pointed out that the measurement of attitudes expressed by a person's opinions does not necessarily mean the prediction of what he or she will do. They believed it was important to measure even intentionally distorted attitudes, that they measured at least the attitude that subjects tried to make people believe they had.

Attitude was defined, but its measurement remained a challenge. Baker and O’Neil (1987) cautioned that "all measurement is imprecise. Everything we infer is exactly that: inferencing about learning that occurred (or is potential) in the learner. We must remember we are dealing with people, not plastics. People are dynamic; they all change from second to second" (p. 344).

Gable (1986) and Gable and Wolf (1993) noted that measurement errors may arise from certain situational factors, such as fatigue, mood, or motivation, among others, and took these caveats into consideration as they outlined the steps to instrument development in the affective domain, a process very similar to that proposed by Thurstone and Chave (1929). They pointed out that Likert scales, employing a set of statements presented on a 5-point, agree-disagree format with responses summed across items to generate a score, had been frequently used because they were relatively easy to construct, could be highly reliable, and had been successfully adapted to measure many types of affective characteristics. Gable and Wolf(1993) stated that 5-point or 6-point scales were most reliable; a larger number of categories appeared to have no psychometric advantage, and fewer than five categories could result in a lack of response discrimination. 
During instrument development, they emphasized the importance of testing both the validity and reliability of the instrument and described factor analysis, including an orthogonal rotation called a varimax rotation. They considered reliability an indication of the proportion of variation in test scores, which could be considered true variance as opposed to error variance. To increase reliability, they advocated a sample size of 6 to 10 times the number of people as items, noting, however, that a few items with a high average interitem correlation will have a higher alpha reliability than a lot of items with a low interitem correlation. Gable and Wolf(1993) felt that good affective instruments reflected a minimum of .70 alpha reliability.

Fuchs (1980) defined construct validity (that an instrument indeed measures what it says it does) as how well a test measures a theoretical construct. A construct is usually a phenomenon which is not observable, for example, intelligence, feelings, and attitudes.

Although attitude is difficult to measure, he believed that well organized and conducted survey studies are valuable because they give information on a group's attitude toward a topic and that such information can be useful to those involved with planning and evaluating learning.

Summary. In summary, attitude as a component of the affective domain has been studied and measured at least since the 1920s (Thurstone \& Chave, 1929). As theorists defined attitude, their definitions bore more resemblance than differences. Attitude has been defined as an internal state influencing choice of personal action (Gagné, 1985) in a particular context (Gable \& Wolf, 1993), that it involves intensity, direction, and target (Gable \& Wolf, 1993), and that a positive attitude accompanies effective learning (Liaw, 2000). Thurstone and Chave (1929) made a distinction between attitude and opinion. And although theorists admitted attitude may be difficult to measure or may be imprecise for varying reasons (Baker \& O'Neil, 1987; Gable, 
1986; Gable \& Wolf, 1993; Thurstone \& Chave, 1929), they believed it is tied to behavior (Gagné, 1985; Kay, 1992; Krathwohl et al., 1964; Liaw, 2000) as well as other aspects of cognitive, affective, and psychomotor domains of learning (Bloom et al., 1956; Gagné, 1974; Krathwohl et al., 1964). With these caveats to attitude measurement, theorists offered ways to improve its accuracy and value, such as Thurstone and Chave's (1929) maximum probability type scale, Likert scales (Gable, 1986), testing instrument validity (Fuchs, 1980) and reliability, factor analysis, adequate sample size, and ratio of sample size to scale items (Gable \& Wolf, 1993).

\section{Measurement of Students' Attitudes Toward Computers}

After the microcomputer was developed in the early 1970s and became available to (and affordable by) the general public, personal computers (PCs) began to proliferate, and by 1980, about a million computers were sold annually. Now the computer is a standard fixture in offices and in many homes, not to mention in educational settings, such as schools and universities. As computer skills and knowledge became increasingly important, so did the teaching of those skills and knowledge. There was concern that not all students had equal access (Selfe, 1999), nor did they bring equal motivation to the task of learning to use the technology. Initially, researchers were particularly interested in what seemed to be a gender-linked fear or anxiety among female students; in other words, their attitudes toward using computers affected their learning, thus their success academically and later, perhaps, in the workplace. Since attitude is part of motivation and behavior, such as successful class performance, researchers — primarily psychologists—were concerned about the possible negative attitudes students had toward using computers, particularly among females. 
Subsequent to these concerns, in the mid-to-late 1980s, researchers sought to measure students' level of affect through the administration of computer attitude scales (CAS) to collect data (Loyd \& Gressard, 1984a). Attitude toward computers can be defined as the level of affect one has for computers. As Divine and Wilson (1997) pointed out, research had shown attitude toward computers to be positively linked to computer experience, computer instruction, education, external locus of control, and class length and number of class meetings per week, while attitudes have been negatively linked to age, class size, and math anxiety. Much of the research in this area had focused on the effects of computer anxiety, generally referring to the level of apprehension a person has with regard to using a computer. Computer anxiety has been positively linked to math anxiety and age, and negatively linked to computer experience, computer knowledge, computer ownership intentions, math experience, internal locus of control, education, analytical problem-solving style, GPA, and SAT quantitative score. Studies incorporating gender as a variable reflected mixed results as far as correlating anxiety and/or attitude to one gender or the other. Attitude and anxiety are not synonymous although some researchers used the terms interchangeably. Attitude covers a much broader conceptual domain. Attitudes toward computers have been defined in at least 14 different ways, including acceptance, affect, cognition, comfort, confidence, courses, interest, liking, locus of control, motivation, programming, training, case scenarios, and stereotypes. And researchers continue to maintain that attitudes are closely tied to behavior (Kay, 1992). A summary of the literature reviewed in this section can be found in Table 2 (below).

Understanding gender differences in computer attitudes, aptitude, and use. As part of a theoretical critique of the methods used by researchers to examine gender differences and/or 
Table 2

Summary of Research for Computer Attitude Scale Development and Testing

Study

Loyd, \& Gressard

(1984a)

Reliability and factorial validity

of computer attitude scales

Loyd \& Loyd

(1985)

The reliability and validity of an instrument for the assessment of computer attitudes

Popovich, et al.

(1987)

The development of the attitudes toward computer usage scale
Bandolas \& Benson (1990)

Testing the factor structure invariance of a computer attitude scale over two grouping conditions

Massoud

(1990)

Factorial validity of a computer attitude scale
Findings

Developed Computer Attitude Scale (CAS), 3 subscalesliking, confidence, anxiety; factorial analysis. Alpha coefficient $=.95$ for scale .

Revised CAS, added fourth subscale (perceived usefulness); anxiety and confidence measure same trait; attitude toward computers related to experience.

Developed and revised Attitude Toward Computer Usage Scale (ATCUS); factorial analysis; alpha coefficient $=$ .88 ; females more negative reactions; significant correlation between (1) positive reactions to computers and number of college computer courses, hours/week on a computer, and college math courses; (2) negative reactions to computers and college computer courses, hours/week on a computer, and computer anxiety.

Identified factor structure of Computer Attitude Scale (CAS) to test invariance across 2 subsamples (male/female) and graduate/undergraduate); alpha coefficient $=.96$; factor structure remained invariant, thus is multidimensional construct with highly correlated factors.

Tested validity and reliability of CAS, subscales and total score; alpha coefficient high; total scale represented general attitude toward computers; low literate adults have fairly positive attitude toward computers. 
Table 2 (continued)

Study

Zakrajsek \& Waters

(1990)

Convergent validity of scales measuring computer-related attitude scales

Harrison \& Rainer

(1992)

An examination of the factor structures and concurrent validities for the computer attitude scale, the computer anxiety rating scale, and the computer self-efficacy scale

Divine \& Wilson (1997)

Antecedents of student attitudes toward computers
Findings

Examined convergent validity of 7 computer-related attitude scales published between 1982-1987: ZOL12, ZOL23, ATCUS, CATT, Bannon et al., NCAS, and CARS; reliability estimate of $>.80$ on CATT, CARS, NCAS, ATCUS (consistent with authors' findings); intercorrelations for ZOL12, CATT, CARS, NCAS, ATCUS ranged from .66-.79; all had alpha coefficients $>.70$.

Evaluate factor structures for reliabilities of the empirically derived variables and intercorrelations among factors to examine concurrent validity of CAS, CARS, CSE in a field setting; positive correlation between attitude toward computers and computer skill level, negative correlation between anxiety toward computer use and computer skills, negative correlation between attitude and anxiety (significant at the .001 level). Each scale exhibited construct validity and reliability, and intercorrelations provided support for concurrent validity.

Causal impact of hypothesized antecedents of student attitudes toward computers; used CAS with four subscales; confirmed Loyd \& Loyd's exploratory factor analysis - anxiety and confidence measure same trait; fours subscales measured three factors: liking, usefulness, and anxiety/confidence; alpha reliabilities $=.779, .898$, and .948 , respectively; attitude positively linked to experience, instruction, education, external locus of control, class length, and number of classes/week; attitude negatively inked to age, class size, and math anxiety.

Kay (1992) answered, "It depends.” It depends on what attitudes one measures, what skills one assesses, and what use is being made of the computer, a set of variables confirmed as computer disparities in behavior toward computers, Kay (1992) saw a need for more process- 
oriented research focusing on how attitudes, ability, and dispositions for using computers develop, that is, qualitative or descriptive research versus quantitative or survey.

Research had centered on eight relatively distinct subpopulations: preschool students, primary school students (K-3), middle school students (Grades 4-8), high school students (9-12), university students, teachers, adults at work, and media advertisements. General patterns emerged: as a subpopulation got older, disparities increase. With respect to attitudes, males and females were most alike. In general, when asked which sex has more positive attitudes toward computers, has more aptitude in using computers, and is more likely to use computers, attitude scales were designed and tested and as studies used those scales to measure attitude among a variety of students.

Reliability and factorial validity of computer attitude scales. In the early to late 1980s, several computer attitude scales were developed and validated. In 1984a, Loyd and Gressard developed a scale to measure attitude toward computers. What they called the computer attitude scale (CAS) seemed to set the standard against which later scales would be tested. Their study examined the reliability and factorial validity of the CAS and its three subscales (Liking, Confidence, and Anxiety). The data suggested that this instrument was an effective, reliable, and convenient means of measuring student attitudes toward learning about and using computers.

The CAS, a Likert-type instrument of 30 items, presented statements of attitudes toward computers and the use of computers. Three main types of attitudes were represented: (a) anxiety or fear of computers; (b) liking of computers or enjoying working with computers, and (c) confidence in ability to use or learn about computers. In response to the statements, subjects indicated which one of six ordered responses, from strongly agree to strongly disagree, most 
closely represented the extent to which they agreed or disagreed with the ideas expressed. Positively and negatively worded statements were included for each of the three areas.

Subjects were 155 students in grades 8 through 12 involved in a computer-based education program in a large school district. Ages ranged from 13 to $18 ; 51(32.9 \%)$ were males and $104(67.1 \%)$ females. Students were administered the CAS by their classroom teachers. Item responses were coded so that a higher score indicated a higher degree of liking or confidence and a lower degree of anxiety. The total score was the sum of the three subscale scores. A higher score on any of the subscales or on the total scale indicated a more positive attitude toward using or learning about computers.

Means, standard deviations, and estimates of internal consistency (alpha coefficients) were calculated for each of the three subscales and for the total score. Correlations among the three subscales were also computed and a 30 x 30 matrix of item intercorrelation was formed. The coefficient alpha (Cronbach's Alpha) reliabilities were .86, .91, .91, and .95 for the Anxiety, Liking, Confidence subscales, and the Total Score, respectively. The three-factor solution accounted for $55 \%$ of the total variation.

The reliability coefficients of the three subscales and the findings of the factor analysis suggested that the scores of the three subscales were sufficiently stable to be used as separate scores. The total score based on the three subscales could reasonably be interpreted to represent a general attitude toward working with computers that reflected liking, confidence, and freedom from anxiety.

The reliability and validity of an instrument for the assessment of computer attitudes. In Loyd and Gressard's 1984a study, the CAS's validity was examined in relation to high school 
students, but not teachers. Thus, the next year, Loyd and Loyd (1985) conducted a study to obtain estimates of the reliability of the now four subscales of the CAS (perceived usefulness was added), to gain information concerning the factorial validity of the subscales, and to provide evidence about the differential validity of the scores (i.e., to ascertain the ability of the CAS to differentiate among three groups with different amounts of computer experience)—specifically in relation to classroom teachers.

The CAS used in this study was a Likert-type instrument of 40 items that presented statements of attitudes toward computers and the use of computers. Four main types of attitudes were represented:

1. Anxiety or fear of computers,

2. Confidence in ability to use or learn about computers,

3. Liking computers or enjoying working with them, and

4. Perceived usefulness of computers in present or future work.

Corresponding to these four categories were four subscales of 10 items each, distributed throughout the instrument. Each subscale included both positively and negatively worded items.

Subjects were 114 teachers of children in grades K-12 who were enrolled in one of six classes involving use of microcomputers in education. Ages ranged from 23-60; 33 were male, and 81 were female. Instructors administered the CAS to subjects at the beginning of the respective courses. Higher score indicated lower anxiety and higher degree of liking, confidence, and usefulness. The sum of the four subscales equaled the total score. Means, standard deviations, and estimates of internal-consistency reliability (alpha coefficients) were 
calculated for the four subscales and for the total score. Correlations among the four subscales were also computed.

Differential validity was assessed by four analysis of variance (ANOVA) procedures. Four one-way ANOVA procedures were conducted, one for each of the four subscales. The independent variable in each ANOVA was amount of computer experience, measured in three levels: less than six months, six months to a year, and more than a year.

Coefficient alpha reliabilities were $.90, .89, .89$, and .82 , respectively for Anxiety, Confidence, Liking, and Usefulness scales. Significance ranged from $<.02$ to $<.05$. The correlation between Anxiety and Confidence of .82 (.92 when corrected for attenuation) and the results of the factor analysis suggested that for the group of teachers, these two subscales measured the same trait. The other two subscales also had high correlations but reflected enough unique variance to support an interpretation of a separate score. All four subscales were related closely enough to support the use of the Total Score as a measure of general anxiety. The results of the ANOVA procedures suggested that attitudes can be demonstrated to be different for groups that reasonably would differ; attitudes toward computers seemed to be related to amount of computer experience. The results indicated that the CAS can be used reliably and validly to assess computer attitudes of adults who are similar to the group of teachers tested in this study.

Development of the attitudes toward computer usage (ATCUS) scale. In two studies using undergraduate general psychology students, Popovich, Hyde, Zakrajsek, and Blumer (1987) developed an instrument, the Attitude Toward Computer Usage Scale (ATCUS), to assess how people react to using computers and computer-related mechanisms, such as ATMs and price scanners. The first study involved item development and included estimates of internal 
consistency and test-retest reliability for a 40-item scale. The ATCUS was used to determine the relationship between attitudes toward computer usage and gender, a relationship that had been assumed, but had only recently begun to receive empirical support. For the second study, results of a factor analysis were used to reduce the length of the ATCUS to 20 items. Mean sex differences on this shorter version of the scale were more fully investigated.

The first study used 365 undergraduate students enrolled in general psychology courses at a medium-sized Midwestern university. Forty-one percent (41\%) were male; the average age was 18.8 years. Subjects volunteered in exchange for course credit. Responses were made on a 7-point Likert-type scale with anchors from strongly disagree (1) to strongly agree (7). Items were worded in negative as well as positive ways to preclude response sets.

In addition to the 40-item ATCUS, the study used two questionnaires developed by Zoltan and Chapanis (1982) that were used to assess attitude toward computers. The first questionnaire, commonly abbreviated as ZOL12, included 12 statements about computers (reactions to, beliefs about, features of, and uses of) on a 7-point Likert type scale with anchors similar to the ATCUS. The second Zoltan and Chapanis questionnaire contained a list of 22 pairs of bipolar adjectives separated by a 7-point semantic differential using descriptors such as extremely, quite, slightly, and neutral. Subjects were also asked for age and gender.

The internal consistency (alpha) estimate was .88 for the entire ATCUS, .49 for the 12item and .84 for the 22-item Zoltan and Chapanis scales. The test-retest correlation for the ATCUS with a sample of 44 retest subjects was .84. Significant correlations were found between total scores on the ATCUS and total scores on the 22 -item semantic differential, $\underline{r}=.62$, $\mathrm{p}<.001$, and the 12-item computer attitudes scale, $\underline{\mathrm{r}}=.2, \underline{\mathrm{p}}<.001$. 
A breakdown by sex for the ATCUS revealed a significant difference, $\underline{F}(1,360)=12.90$, $\underline{p}<.001$, with female participants exhibiting more negative reactions to computer usage than males. A significant sex difference was also found for the 22-item Zoltan and Chapanis semantic differential scale, $\underline{\mathrm{F}}(1,354)=9.26, \underline{\mathrm{p}}<.003$, with females giving more negative semantic differential ratings than males. There was no significant sex difference for the 12-item Zoltan and Chapanis scale, $\underline{\mathrm{F}}(1,354)=1.03, \underline{\mathrm{p}}=.31$.

The first study showed the 40-item ATCUS to be a reliable scale with some evidence of convergent validity provided by its significant relationship with other existing scales of attitudes toward computers. However, the large number of factors (12) and particularly the number of one and two-item factors, indicated that the scale could be refined, and a second study was initiated.

The second study used 351 undergraduate students in general psychology at a mediumsized Midwestern university. Of the sample, $39 \%$ were male, and the average age 18.75 . The revised ATCUS consisted of 20 items, selected by identifying those items that loaded highest on the five major factors from the original 40-item ATCUS and removing redundant items. This version included a demographics section, including questions about age, sex, and level of education, college level computer courses, mathematics courses, and computer usage. Subjects were also asked to estimate their anxiety toward computers and computerized machines, using a 5-point rating scale from very anxious to not anxious at all. The internal consistency (alpha) reliability estimate for the 20 -item version of the ATCUS was .84 .

Scores on the ATCUS were correlated with several background characteristics. There was a significant negative relationship between total scores on the ATCUS and the hours of computer use of participants (more time using computers, less negative reaction to computers, 
etc.). The number of college computer courses and the number of hours per week spent using a computer were significantly related. Finally, there was a small but significant correlation between total scores on the ATCUS and a self-report rating of computer anxiety, strongest for factors one (negative reactions to computers) and two (positive reactions to computers).

Significant sex differences were found for the ATCUS overall, with females responding more negatively to computer usage than males $(\underline{p}<.02)$. In an effort to determine other ways in which the sexes may have differed, the various sample characteristics were examined separately by sex. Results showed significant sex differences for number of college-level computer courses taken ( $\mathrm{p}<.001)$; number of hours per week spent using a computer $(\underline{p}<.001)$; and number of college-level mathematics courses taken $(p<.001)$. Comparison of mean scores indicated that males participated more than females. There were no significant sex differences in self-report ratings of computer anxiety $(\underline{p}=.64)$.

Overall, the study found the ATCUS to be a reliable instrument especially when assessing the reactions of undergraduate students to computers and examples of computer-related technology. Corresponding sex differences may also show that computer usage may join the list of areas that includes mathematics, science, and other related disciplines, as those that are more popular among males than females. However, it is possible that these sex differences in reactions to computers may not be pervasive and persistent. The study also showed that females were more positive than males about certain new technology items, indicating that the differential reactions of the sexes to computers may not be true for all computer uses. The results of the present study provided some support for this suggestion since female reactions to 
some familiar computer-related mechanisms (such as automatic banking machines, electronic price scanners) were actually seen as more positive than male reactions.

Testing the factor structure invariance of a computer attitude scale over two grouping conditions. In 1990, Bandalos and Benson conducted a study to identify the factor structure of the computer attitude scale and to test the invariance of this factor structure across two subsamples: male/female and graduate/undergraduate students. A determination of factor structure invariance across the subsamples would lend support to the hypothesis that the same construct was being measured in these subsamples. As computer literacy became required of college students, it was evident that not all students were comfortable using them; many students experienced varying degrees of anxiety. Former studies suggested there was a relationship to math anxiety when males and females were compared, but with mixed results; comparison of older and younger subjects also produced mixed results. This study hoped to get a clearer explication of computer anxiety dimensions, thus a more nearly precise measurement.

Data were collected from 375 graduate and undergraduate students enrolled in three courses in educational measurement and statistics. Of these, 187 were undergraduate, 188 were graduates, 136 were men, and 236 women. The study used the Computer Anxiety Scale (CAS) designed by Loyd and Gressard (1984a), which measured computer anxiety, confidence, and liking. It was believed that this scale more so than any other instruments available attempted to define specific components of computer anxiety. The internal-consistency reliability—as estimated by coefficient alpha reported by the authors - was $.86, .91$, and .91 , respectively to the three subscale items above, and .95 for the total scale. 
The study found that the factor structure of the revised 23-item CAS remained largely invariant when the goodness-of-fit (GOF) of the model was assessed simultaneously over groups in each of two grouping conditions of gender and student status. The results suggested that the 23-item CAS was measuring the same construct to a similar degree for males, females, graduates, and undergraduates. These results suggested that computer anxiety was a multidimensional construct with highly correlated factors.

Bandalos and Benson's (1990) analysis of Loyd and Gressard's (1984a) model differed somewhat from what the designers purported. The reliabilities for these authors' three subscales and the revised 23-item total scale, as estimated by coefficient alpha, were $.90, .93, .90$, and .96, respectively. The three-factor model resulted in a statistically significant chi-square fit statistic of 642,227 degrees of freedom $(\mathrm{GOF}=.861$, mean square residual $=.048)$. A two-factor model was used because factors 2 and 3 especially were highly intercorrelated, chi-square statistic $=$ $748,229 \mathrm{DOF}, \mathrm{GOF}=.835$, mean square residual $=.051$.

Factorial validity of a computer attitude scale. That same year, Massoud (1990) also conducted a study to test the validity and reliability of the Computer Attitude Scale (CAS) and its subscales (anxiety, confidence, and liking). Participants were adult basic education students ( $\underline{\mathrm{n}}=$ 59) pursuing their GED certificate. Ages of the participants ranged from 16 to 45 or over; 23 were males and 36 females. Each participant was asked to fill in the Participant Inventory that has information about the participant's characteristics and then was asked to complete the CAS.

The coefficient alpha reliabilities were extremely high $(.91, .78, .82, .75)$ indicating that the scales are highly reliable, as found by Loyd and Gressard (1984a). The reliability coefficients of the three subscales and the findings of the factor analysis suggested that the scores 
of the three subscales were sufficiently defined to be used as separate scores. The magnitudes of the intercorrelations among the three subscales indicated that they share a large amount of common variance. Therefore, it was reasonable to assume that the total scale score represented a general attitude toward computers and the use of computers that reflected liking, confidence, and freedom from anxiety. These findings supported those of Gressard and Loyd (1985) and Loyd and Gressard (1984a).

Results suggested that low-literate adults as a whole had fairly positive attitudes toward computers. On all subscales of the CAS, the mean scores ranged from 30-33 on a 40-point scale where a score of 25 would indicate a neutral attitude toward computers. It appeared likely that the population studied differed from those in earlier studies in terms of their age range.

Convergent validity of seven scales measuring computer-related attitudes. Following up on the development of such scales, Zakrajsek and Waters (1990) examined the convergent validity of seven computer-related attitude scales published between 1982 and 1987. These included scales designed for adults and were not occupation specific.

The seven scales examined by Zakrajsek and Waters (1990) included the:

- General Statements Questionnaire (ZOL12 and ZOL23) (Zoltan and Chapanis, 1982);

- Attitudes Toward Computer Usage Scale (ATCUS) (Popovich, Hyde, Zakrajsek, \& Blumer, 1987);

- Computer Attitude Scale (CATT) (Dambrot, Watkins-Malek, Silling, Marshall, \& Garner, $1985)$

- Cognitive and Affective Subscales (Bannon, Marshall, \& Fluegal, 1985);

- Computer Attitude Scale (NCAS) (Nickell \& Pinto, 1986); and 
- Computer Anxiety Rating Scale (CARS), (Heinssen et al., 1987).

The General Statements Questionnaire developed by Zoltan and Chapanis (1982), a 23item "general statements" questionnaire (ZOL23) to assess subjects' beliefs about and reactions to both specific features of computers and potential uses and applications of computers. The scale used a 7-point Likert-type response format. Of the original 23 items, 12 were shown to differentiate between attitudes of experienced and inexperienced computer users, and became a separate scale known as the ZOL12. Both the ZOL23 and ZOL12 scales were used in the Zoltan and Chapanis 1982 study.

In 1987, Popovich, Hyde, Zakrajsek, and Blumer developed the Attitudes Toward Computer Usage Scale (ATCUS) to measure general attitudes toward computers and computerized machinery. The original 40 -item scale was factor analyzed and revised to a 20 item scale. Popovich et al. (1987) reported a significant correlation between their 40-item scale and the 12-item scale of Zoltan and Chapanis $(\underline{r}=.52, \underline{p}<.001)$. No relationship between their revised 20-item scale and the scale by Zoltan and Chapanis (1982) was reported. Those authors did report significant relationships between the 20-item attitude scale and hours of computer use $(\underline{\mathrm{r}}=-.30, \underline{\mathrm{p}}<.001)$, number of college computer courses $(\underline{\mathrm{r}}=-.16, \underline{\mathrm{p}}<.001)$, and self-reported computer anxiety $(\underline{\mathrm{r}}=.16, \underline{\mathrm{p}}<.001)$. An alpha coefficient of .84 was reported for the ATCUS. Zakrajsek and Waters (1990) examined three computer attitude scales:

1. Dambrot, Watkins-Malek, Silling, Marshall, and Garner (1985) developed the 20-item Computer Attitude Scale (CATT). Item responses were recorded on a 5-point Likert-type scale. The CATT was significantly related to math anxiety $(\underline{\mathrm{r}}=-.24, \underline{\mathrm{p}}<.001)$, math experience $(\underline{r}=-.09, \underline{p}<.01)$, computer experience $(\underline{r}=-.19, \underline{p}<.001)$, math aptitude $(\underline{r}=-.14$, 
$\underline{\mathrm{p}}<.001)$, high school achievement $(\underline{\mathrm{r}}=-.07, \underline{\mathrm{p}}<.01)$, and $\operatorname{sex}(\underline{\mathrm{r}}=-.12, \underline{\mathrm{p}}<.001)$. Higher scores on the CATT reflected more negative attitudes toward computers and males were coded higher on the gender variable. An alpha coefficient of .84 was reported.

2. Also in 1985, Bannon, Marshall, and Fluegal developed a 14-item computer attitude scale composed of two subscales, cognitive computer attitudes and affective computer attitudes, each employing a 5-point Likert-type response format. Coefficient alpha reliabilities of .93 and .90 were reported for cognitive and affective subscales, respectively.

3. Nickell and Pinto (1986) developed the Computer Attitude Scale (NCAS) consisting of 20 items with a 5-point Likert-type response scale. A coefficient alpha of .81 was reported.

Two years later, Heinssen, Glass, and Knight (1987) reported the development of the Computer Anxiety Rating Scale (CARS), a 19-item measure with a 5-point Likert-type response format. The reported alpha coefficient was .87. Several of the variables Heinssen et al. (1987) correlated with the CARS included (a) a self-rating of how uneasy or anxious the person would feel sitting down to work on a computer $(\underline{\mathrm{r}}=.48, \underline{\mathrm{p}}<.001)$ and when having difficulty getting a job to run $(\underline{\mathrm{r}}=.37, \underline{\mathrm{p}}<.001) ;(\mathrm{b})$ prior computer experience $(\underline{\mathrm{r}}=-.33, \underline{\mathrm{p}}<.001)$; (c) math anxiety $(\underline{\mathrm{r}}$ $=.26, \mathrm{p}<.001) ;(\mathrm{d})$ trait anxiety $(\underline{\mathrm{r}}=.20, \mathrm{p}<.001) ;(\mathrm{e})$ mechanical interest $(\underline{\mathrm{r}}=-.48, \mathrm{p}<.001) ;(\mathrm{f})$ SAT-verbal $(\underline{\mathrm{r}}=.32, \underline{\mathrm{p}}<.001)$, and $(\mathrm{g})$ SAT-quantitative $(\underline{\mathrm{r}}=.32, \mathrm{p}<.001)$.

In their study to examine the several scales, Zakrajsek and Waters (1990) used 95 male and 119 female undergraduate college students enrolled in sections of an introductory psychology course at a Midwest public university who participated in exchange for course credit. The seven computer-related attitude scales were administered in booklet form to groups of 25-50 
students in 30-minute sessions. The order of presentation of the seven scales was randomized across booklets.

As a preliminary analysis, all scales and subscales were correlated with the gender of the respondent. These coefficients ranged from -.05 to .17 , with a median absolute value of .08 . Dambrot et al. (1985) found significant gender differences on the CATT scale, but this result was not replicated for this sample. As gender accounted for less than $3 \%$ of the variance for any of the attitude scales, correlations among the scales were computed on the combined-gender sample of 214 students. All scales were scored so that high values reflected negative attitudes toward computers or computerized equipment.

Reliability estimates of over .80 were obtained for four of the seven scales: CATT, CARS, NCAS, and ATCUS. These findings were consistent with previously reported estimates provided by the authors/researchers. Coefficient alpha values for the two subscales of the computer attitude scale developed by Bannon et al. (1985) were somewhat lower than those reported earlier, but both the total scale and the cognitive subscale yielded alpha coefficients above .70. No comparison reliability data were available for the other scales or subscales. Intercorrelations for five of the seven computer attitude scales (ZOL12, CATT, CARS, NCAS, and ATCUS) ranged from .66 to .79. Four of these scales also had reliability estimates of over .80 , and the correlations among these scales were all in the .70 s.

The correlations of the total score on the Bannon et al. (1985) scale with the five scales just described ranged from .45 to .64 . The cognitive and affective subscales correlated .23 with each other, which supported the differentiation of cognitive and affective components of computer-related attitudes. 
The correlations among the five global measures of computer-related attitudes provided strong evidence for convergent validity. It would also appear that a differentiation can be made between cognitive and affective reactions to computers, with some scales (e.g., Bannon et al., 1985) measuring both, and others (Nickell \& Pinto, 1986; Popovich et al., 1985) assessing one more than the other. A choice of scales to be used by either researchers or practitioners should be made with this distinction in mind, and future scale development should reflect this distinction.

Examination of the factor structures and concurrent validities for the computer attitude scale, the computer anxiety rating scale, and the computer self-efficacy scale. The validity of computer attitude scales continued to be examined, and in 1992, Harrison and Rainer collected data from 693 university personnel to evaluate the factor structures (for reliabilities of the empirically derived variables) and intercorrelations among the factors to examine the concurrent validity of the Computer Attitude Scale (CAS) (Nickell \& Pinto, 1987), the Computer Anxiety Rating Scale (CARS) (Heinssen et al., 1987), and the Computer Self-Efficacy Scale (CSE) (Murphy, Coover, \& Owen, 1989) in a field setting. They also investigated the psychometric properties of the three computer scales, i.e., affective behaviors (attitudes and anxiety) and perceptions of computer skill or ability.

Based on the literature, there were expected relationships among computer attitudes, anxiety, and skill:

1. A positive correlation was expected between attitude toward computers and computer skill level. 
2. A negative correlation was expected between anxiety toward computer use and computer skills.

3. A negative correlation was expected between attitude and anxiety.

A survey designed to elicit data on a variety of aspects of end-user computing was mailed to 3,488 salaried personnel on the main campus of a large university. Seven hundred and seventy-six responses $(776)$ were received for a response rate of $22.3 \%($ sample size $=693)$. The CAS, CARS, and CSE were embedded in the questionnaire.

The relationships among the three instruments' derived factors were used to examine the concurrent validity of each instrument. All correlations were significant at the .001 level and were in the expected directions as postulated in the literature. Factor analyses for each of the CAS, CARS, and CSE resulted in satisfactory internal-consistency reliability coefficients. Each instrument exhibited construct validity and reliability, and intercorrelations among each instrument's factors provided support for concurrent validity. Therefore, it was concluded that the resulting forms of the three instruments held promise for their use in further research and evaluation.

Antecedents of student attitudes toward computers. In 1985, Loyd and Loyd had identified three dimensions of attitude toward computers besides anxiety: liking, usefulness, and confidence, so four in all. They considered liking the bottom-line indicator of attitude toward computers, with anxiety, usefulness, and confidence more perceptual in nature and as factors that influence, but are not part of, the attitude (liking). So in 1997, Divine and Wilson conducted a study to examine the causal impact of different hypothesized antecedents of student attitudes toward computers. The results indicated that, although student attitudes toward computers are 
significantly affected by both confidence/non-anxiety and perceived usefulness, confidence/nonanxiety has a stronger relationship. The authors believed that positive attitudes greatly facilitated the learning of computer skills (students who like computers are more likely to become more involved, use them more, etc., thus develop their computer skills more so than those students who dislike computers). They also thought positive attitudes give students the proper mental framework to accommodate the learning of future computer skills and that this is extremely important, given the rapid pace of innovation in the computer industry. The study's main objective was to identify which perceptual and demographic factors are the most important determinants of student attitudes toward computers.

Data were collected from 362 undergraduate students enrolled in either a marketing principles course or a capstone marketing course at a Midwestern university with a large marketing program. The CAS instrument featured four subscales (Anxiety, Confidence, Liking, and Usefulness), with 10 questions per subscale. Response choices ranged from strongly agree to strongly disagree.

Before relationships could be tested between CAS subscale constructs, it had to be established that the subscales do, in fact, measure different traits, an observation not clearly demonstrated in prior research. Six discriminant validity hypotheses were tested on a pair-wise basis using a series of confirmatory factor analyses (CFA). The second discriminant validity test determined whether a significantly better fit to the data was provided when two subscales were treated as separate constructs (two-factor model) than when the items from those subscales were pooled together into a single construct (one-factor model). 
The results of both sets of CFA tests supported all of the discriminant validity hypotheses except H6 (there is discriminant validity between the Anxiety and Confidence scales). This finding mirrored Loyd and Loyd's (1985) own exploratory factor analysis in which the items from Anxiety and Confidence subscales loaded on the same factor; that is, they were measuring the same underlying trait. So their results indicated that the four CAS subscales represented three different factors: Liking, Usefulness, and Confidence/Anxiety. The Liking subscale was found to have discriminant validity from all of the other CAS subscales. Reliabilities for these three scales used the coefficient alpha measure of internal consistency: Usefulness $=.779$; Attitude $=.898 ;$ Confidence/Anxiety $=.948$.

The study produced five main findings:

1. Attitude toward computers can be modeled as a unidimensional construct.

2. The computer confidence and computer anxiety subscales in the Computer Attitude Scale appeared to be indicators of the same underlying trait.

3. Computer anxiety/confidence and perceived usefulness were found to have significant relationships with student attitudes toward computers.

4. Computer confidence/non-anxiety had a much stronger relationship with student attitudes toward computers than perceived usefulness.

5. Student attitudes toward computers and computer confidence/non-anxiety were affected by students' class standing but not by gender or major.

Summary. To summarize, the development of psychometric scales to gauge level of affect, specifically attitude, held toward computers began in 1984 with Loyd and Gressard's Computer Attitude Scale (CAS). Subsequent to the CAS, others tested the scale's reliability and 
validity (Bandolas \& Benson, 1990; Divine \& Wilson, 1997; Harrison \& Rainer, 1992; Loyd \& Loyd, 1985; Massoud, 1990), or modified it to create new scales (Bannon et al., 1985; Dambrot et al., 1985; Heinssen et al., 1987; Nickell \& Pinto, 1986; Popovich et al., 1987; Zakrajsek \& Waters, 1990). Because computers and their usage were relatively new, the scales measuring attitude or other levels of affect toward computers also were. Thus, during the period from 1984 to 1997 , they were refined through repeated factorial analysis and other tests to assure statistical accuracy, validity, and reliability.

Although the studies using attitude scales varied in their exact findings, in general, they found that females reacted more negatively toward computers and computer usage. They found that computer experience (hours per week/years of usage); instruction/education (number of courses, including computer and math); math anxiety, experience, and aptitude; high school achievement (SAT verbal and quantitative); mechanical interest, and age were important variables correlating with attitude toward computers. The study and testing of these scales then paved the way for new research as additional computer applications, such as word processing and the Internet, became available and were used.

\section{Attitude Toward Use of Computers}

Once scales for the measurement of attitude toward computers were designed, tested, and refined to include factors such as perceived usefulness as part of attitude, studies were conducted to examine attitude toward the use of computers more specifically. Primarily, researchers found that there was a consistent and positive correlation between computer experience, knowledge, and ownership and positive attitude toward their use. They also found that an initially positive attitude could change (decay) over time. In higher education studies, academic, rank, majors and 
Table 3

Summary of Research for Attitude Toward Use of Computers

Study

Findings

Reed

(1990)

The effect of computer-andwriting instruction on prospective English teachers' attitudes toward and perceived uses of computers

\section{Behar \& Hackett}

(1991)

Challenges of the new information age curriculum: Computers and the liberal arts

\section{Liu \& Reed}

(1992)

Teacher education students and computers: Gender, major, prior computer experience, occurrence, and anxiety

Sensales \& Greenfield (1995)

Attitudes toward computers, science, and technology

Walters \& Necessary (1996)

An attitudinal comparison toward computers between underclassmen and graduating
Investigated the effect of computer-and-writing instruction on attitudes toward and perceived uses of computers in writing instruction. Found that computer anxiety reduced from pre- to post-treatment (with exposure to computers). Uses and types of uses increased; greatest change in group with no prior computer experience.

Examined the relationship between computer experience and attitude, comparing experienced and non-experienced users in different majors. Determined that the more experienced users were the most frequent users. Business majors more frequent users than liberal arts majors, taken more college level courses. Sex was significant with males reporting a higher percentage of computer experience.

Found that gender, year, major, and prior experience had significant main effects on computer anxiety across four categories of prior computer experience. Two way interaction between year and major. Males showed significantly lower computer anxiety.

Field of study and gender differences in evidence, but lesser role in attitude than nationality (country). Students in psychology and the humanities, females, and Italians were significantly more negative about the computer's psychological and cognitive effects than were students in the sciences and engineering, males, and Americans.

Examined an attitudinal comparison between underclassmen and graduating seniors. All subjects had a positive attitude toward computers, but seniors were consistently more positive on almost every scale statement than were those of underclassmen. Consistent with other 
Table 3 (continued)

Study

Findings

Young

(2000)

Gender differences in student attitudes toward computers

McKinnon et al.

(2000)

A longitudinal study of student attitudes toward computers

Mitra \& Steffensmeier (2000)

Changes in student attitudes and student computer use in a computer-enriched environment knowledge, and experience, the more positive their attitudes toward computers. No significant results for gender.

Principle components analysis confirmed five expected factors: confidence, perception of computers as a male domain, positive teacher attitudes, negative teacher attitudes, and perceived usefulness of computers. Factors were related to several background variables, such as selfrating of computer skill, access to and use of computers at home and school, and family role models of computer users. Boys spent significantly ore time using computers; females reported finding the computers more useful for school and careers.

Found that computer attitude changed (decayed) over time. Compared performance of integrated curriculum project students (IS) with that of peers in the parallel traditional school program (non-IS), and evaluated students' performance. Although IS students held a significantly more positive attitude than their non-IS peers, attitudes toward computers (mean scores) became significantly less positive over three years of the study, a change that was attributed to the diminishing novelty of using computers.

Examined changes in students' attitudes toward the use of computers in a computer-enriched higher education environment, to reveal changes in student us of computers. Longitudinal study of five years. From year one of the study, students were provided with personal computers (laptops). Results indicated that there were more significant differences between Year 1 and Year 2 as compared to Year 2 and Year 3 students in comfort with use of computers, apprehension regarding the use of computers, concern that computer use in teaching was making the teaching process too impersonal, how computers enabled them to interact with teachers, whether 
Table 3 (continued)

Study

Findings

computers were effective for communicating with teachers about non-course-related material, and whether communicating with professors by e-mail was generally gratifying. There were also significant differences in attitude and use of computers across different groups of students, specifically between students who were provided computers and those who were not.

Sankaran et al.

(2000)

Effect of student attitude to course format on learning performance: An empirical study in Web vs. lecture instruction
Investigated student attitudes about Web vs. lecture formats and how they affected learning outcome. The relationship between attitude toward course format and the student's learning strategy was also studied. Differences in attitudes toward formats among various ethnic groups and ESL students were also examined.

fields of study were compared, with underclassmen and liberal arts majors consistently holding more negative attitudes toward the use of computers and a higher level of anxiety. Results were mixed in relation to gender and ethnicity. As far as Web versus traditional instruction format, research showed that students enrolled in courses that best fit their learning strategy preference. Table 3 (above) summarizes the literature for research of attitude toward the use of computers.

The effect of computer-and-writing instruction on prospective English teachers' attitudes toward and perceived uses of computers in writing instruction. In a 1990 study, Reed investigated the effect of computer-and-writing instruction on prospective English teachers' attitudes toward and perceived uses of computers in writing instruction. After an 11-week course focusing on computers and writing, 23 English education undergraduates' attitudes 
toward and perceived uses of computers were measured. The group was divided into three smaller groups:

1. Those entering with no computer experience,

2. Those entering with word processing experience, and

3. Those entering with both word processing and programming language experience.

It was found that computer anxiety for the entire group reduced from pre- to posttreatment. Not only did the number of computer uses listed at the onset increase- from 94 to 143, an increase of 52\%--but also the types of uses departed from the early focus on isolated skills (via drill and practice) to the later dominating of writing process uses. In all analyses, the subgroup experiencing the greatest changes was that entering with no prior experience with computers.

The research questions were: (a) What uses of computers do prospective English teachers perceive as appropriate for the classroom? (b) What is their degree of anxiety toward computers? and (c) What kinds of concerns do they have about computer use? The study set up a pretest-posttest design to look at significant changes in their perceived uses of computers in the English classroom, their computer anxiety, and their concerns about computer use.

Of the 23 participants enrolled in an undergraduate English education methods course entitled “Approaches to Teaching Writing” at West Virginia University, 20 were females and three were males. No age demographic was noted. The three-stage approach of the composing process - prewriting, writing, and rewriting - served as the instructional framework for this course. 
In summary, the 11-week treatment involved weekly class meetings, each a 3-hour block of time during which the readings related to prewriting, writing, revision, and computers and writing were discussed. Participants also had weekly writing assignments that were wordprocessed; they spent an average of 2 hours and 23 minutes of actual computer time on their word processing assignments. They also developed rough drafts of preliminary activities to promote prewriting, writing, and rewriting, which they revised, based on the instructor's recommendations, for the comprehensive writing unit.

Three dependent measures included (1) computer uses (students were asked at the beginning and end of the semester to list 10 uses of computers in the English classroom and rank them based on importance), (2) computer anxiety, and (3) stages of concern toward an innovation. For computer uses, frequencies of uses and rankings, both pre- and post-test, were tabulated. Rankings were calculated for those uses cited five or more times. To analyze computer anxiety, a paired t-test was conducted to determine pretest/posttest differences in computer anxiety during the course of instruction. Seven paired t-tests were conducted to determine pretest/posttest differences in stages of concern for the entire sample, with scores for each stage as the dependent measures. Seven one-way ANOVAs were conducted to determine differences in stages of concerns of the three subgroups. Both pretest and posttest scores were compared in these analyses, with scores for a particular stage as the dependent measure.

Results for computer uses in the classroom showed that all 23 students listed drill and practice, but its ranking differed with groups. Writing papers was the second most often cited use with the fourth highest ranking average, followed by revision of papers as the third most 
often cited, and the second highest ranking average. Prewriting was cited as the fifth most often cited use, but the third highest ranking average.

The anxiety of the 23 English education students toward computers significantly decreased $(\mathrm{p}<.002)$. The pretest mean was $40.96(\underline{\mathrm{SD}}=12.83)$; the post-test mean was 33.91 $(\underline{\mathrm{SD}}=9.38)$. Although the computer anxiety of the three groups of levels of use decreased, those entering with no prior experience with computers reduced the most dramatically_-from a pretest of $51.83(\underline{\mathrm{SD}}=9.24)$ to $38.23(\underline{\mathrm{SD}}=5.93)$.

There was significant decrease in the awareness concerns of the 23 students. A one-way ANOVA of all scores for the stage of awareness indicated there were significant differences when comparing pretest and posttest scores of all three levels of use $(\mathrm{p}<.01)$. There was not a significant change in the information or personal concerns; however, management concerns respectively. Both collaboration and refocusing concerns showed significant increases ( $\mathrm{p}<.01)$.

Overall, computer uses increased. As in much of the research conducted prior to this study, decreases in anxiety after varying types of exposure to computers usually occurred, an unsurprising result given the time of exposure they had to computers. The investigator expressed some concern over the number of statistical analyses; it is common knowledge that the more procedures a researcher conducts on his or her data the greater the likelihood of finding significant differences at some point; however, rationale for the tests was given.

Results indicated that there were more significant differences between Year 1 and Year 2 as compared to Year 2 and Year 3 in comfort with use of computers, apprehension regarding the use of computers, concern that computer use in teaching was making the teaching process too impersonal, how computers enabled them to interact with teachers, whether computers were 
effective for communicating with teachers about non-attitudes toward and perceived uses of computers in writing instruction

Challenges of the new information age curriculum: Computers and the liberal arts. Behar and Hackett (1991) conducted a study that also examined the relationship between computer experience and attitude, comparing experienced and non-experienced users in different majors. Their survey results indicated significant variations in student experiences, competence, orientations, and level of satisfaction using computers. Grouping students by major provided a basis for the analysis of generalized and distinctive results, with business and preprofessional students responding more favorably to existing curricula opportunities in computing than students in the liberal arts and humanities.

The research was conducted at a private, liberal arts college in the New York metropolitan area where, two years prior to the study, the college had introduced and established an academic computing center for general student use. The questionnaire was designed to survey student responses in relation to varying levels of computer experience, and particularly to study and compare experienced users with the non-experienced. Additionally, students in the humanities and social sciences were targeted and studied for their use and knowledge of computer applications. Researchers also inquired about student attitudes and values relating to the personal, educational, professional, and social impact of computers. A total of 518 undergraduates were included in the final study.

At the time of Behar and Hackett's (1991) study, others had demonstrated that a majority of entering freshmen on many campuses had used a computer before entering college; however, students varied tremendously in how much experience they had using computers, how frequently 
they used computers, the kinds of applications employed, and their attitudes about computers. Several demographic variables were significantly related to computer experience among students, including class standing, level of parents' education, and self-reported grade point average. A majority (58.8\%) of the students required to use the computer academically indicated that the computer helped them learn the subject matter.

The study compared experienced and inexperienced computer users. Students were grouped according to their frequency of computer use: (1) using the computer less than three times a month and (2) using it at least once a week. Then frequencies were computed for years of experience on one of three levels: 1-3 years, 4-6 years, and 7-15 years. Differences between the two groups of users were tested using the Chi-square analysis. Significant differences emerged between the two groups of computer users $\left(\chi^{2}=73.10, \mathrm{df}-6, \mathrm{p}<.01\right)$, and it was determined that the more experienced users were also the most frequent users.

Experienced users were further categorized by major in relation to frequency of types of computer use. Three computer use variables were examined: (1) percent of computer use in each of different situations, (2) percent who had taken a course in computer programming, and (3) percent who were required to use a computer in a college course (not designed to teach computing). First, a Chi-square analysis showed that frequency of use in varying situations, for example, word processing, spreadsheets, differed significantly for experienced users who were business majors compared to those who were liberal arts majors $\left(\chi^{2}=7.35, \mathrm{df}=1, \underline{p}<.01\right)$. Further, more business majors had taken at least one computer programming course, and those results were also significant $\left(\chi^{2}=19.50, \mathrm{df}=1, \underline{\mathrm{p}}<.01\right)$. A third Chi-square analysis revealed that the percent of business majors required to use a computer in a college course not designed to 
teach computing was significantly different from that of liberal arts majors $\left(\chi^{2}=15.07, \mathrm{df}=1\right.$, $\mathrm{p}<.01$ ). In this study, parents' education and self-reported GPA were not significant. Sex was significant at the .05 level with a higher percentage of males reporting computer experience $\left(\chi^{2}=\right.$ 4.89, $\mathrm{df}=1, \mathrm{p}<.05)$.

With a business and technology model of academic computing predominating, the most common computer use for liberal arts students involved word processing as a kind of automated typing; however, these students were generally not experienced with other more advanced textprocessing activities involving file management, note keeping, bibliographic databases, desktop publishing, or hypertext. Yet students pursuing the traditional liberal arts reported significant interest in learning to be computer literate and expected to use computers in their future work.

The researchers believed that in consideration of the differences between business/technical and liberal arts students, computer associated instruction should be specifically designed to help students overcome negative expectations and experiences, and promote a constructive intelligent and meaningful use of computers.

Teacher education students and computers: Gender, major prior computer experience, occurrence, and anxiety. In 1992, Liu and Reed published the results of a study that compared groups of teacher education students to identify patterns of computer experience and attitudes. Their goals were to identify and analyze differences - with respect to computer anxietybetween the groups of students in terms of occurrence and type of prior computer experience, major, and gender. Data were collected over a four-year period during which time 914 teacher education students participated in this study when they were enrolled in a required undergraduate educational psychology course. 
All students responded to the instrument materials when they enrolled in a mandatory Computer Awareness Module. They indicated gender, major, and prior computer experience versus using word processing, database, and/or spreadsheets software versus programming languages. The students also responded to a computer anxiety instrument, a modified version of Spielberger's Self-Evaluation Questionnaire, a 20-item, 4-point Likert-type scale.

Liu and Reed (1992) found that gender, year, major, and prior experience all had significant main effects on computer anxiety. There were significant differences in computer anxiety across four categories of prior computer experience. There was also a significant twoway interaction between year and major. Males showed significantly lower computer anxiety than females, a finding that agreed with some studies (Behar \& Hackett, 1991), but disagreed with others (Jones, 1994; Loyd \& Gressard, 1984b).

A 2 (Gender: male, female) x 7 (Major: English education, science education, social studies education, elementary education, mathematics education, special education, physical education) x 4 (Year: 1, 2, 3, 4) x 4 (Prior Computer Experience: none, CAI, CMI, programming) analysis of variance was conducted. Results revealed that males $(\mathrm{N}=277)$ had significantly lower computer anxiety than did females $(\mathrm{N}=637) ; \underline{\mathrm{F}}(1,738)=21.94, \underline{\mathrm{p}}<.0001$.

As far as computer use, there were significant differences in computer anxiety across the four categories of prior computer experience: (a) none, (b) computer-assisted instruction (CAI), (c) computer-managed instruction $(\mathrm{CMI})$, and (d) programming languages $[\underline{\mathrm{F}}(3,738)=110.31$, $\mathrm{p}<.0001]$. There also were significant differences in computer anxiety across the seven majors $[\underline{F}(6,738)=7.92, \underline{p}=.0001]$. Based on Scheffé post hoc tests, two majors were significantly 
different from the others: math education and science education majors consistently felt less anxiety toward computers than did those majoring in the remaining five majors.

Additionally, there were significant differences in computer anxiety across the four years: $\underline{F}(3,738)=4.15, \underline{p}=.006$. Based on Scheffé post hoc tests for sources of effect, it was found that there were significant differences (a) between Years 1 and 2, (b) between Years 1 and 3, and (c) between Years 1 and 4. It was interesting that those in Year 1 had significantly lower computer anxiety. Given the ongoing use of computers, it was suspected that the results would be more favorable in the later years, which was not the case.

Attitudes toward computers, science, and technology. Field of study and gender differences also were in evidence in a later study by Sensales and Greenfield (1995), but played a lesser role in attitude than other factors. A comparative study of the structure of attitudes toward computers, science, and technology was carried out with 320 university students equally distributed by country (Italy and the United States), by field of study (humanities, psychology, science, and engineering), and by gender. The instrument used was a Likert-type scale of 56 statements. First, individual items were analyzed for cross-national differences. From items showing a range of values within both national groups, the researchers extracted three factors that, together, accounted for $39 \%$ of the variance: attribution to the computer of negative effects, both at an individual psychological level (Factor 1) and at a social psychological level (Factor 2) and the attribution to science, to technology, and to the computer of positive effects at an instrumental and organizational level (Factor 3). Attitudes toward computers, science, and technology were generally more positive than negative in both countries. Nevertheless, against this background of cross-national similarity, sociocultural factors produced attitudinal 
differences. In particular, the nationality of the subjects made the greatest difference; whereas, gender showed a less important influence than did field of study, although female subjects were less positive than males.

However, the type of secondary school attended exerted an even greater influence. Students with humanities education, when compared to those with a scientific background, showed less positive or more negative attitudes; those with a technical education clustered somewhere in between.

Subjects were second and third year students at the University of Rome La Sapienze; in the U.S. they consisted of juniors and seniors at the University of California, Los Angeles (UCLA). In each country the subsample was subdivided according to academic field of specialization: humanities, psychology, sciences, and engineering. Each group consisted of 20 males and 20 females. Consequently, there were 160 subjects from each country, and 320 subjects in all.

The analysis focused on a Likert-type scale of 56 items, a questionnaire that explored attitudes toward computers, computer science, and technology (SACCST). Items were balanced between positive and negative ( 28 of each), and represented attitudes toward 12 aspects of computers and technology. The scale had six points ranging from 1 "disagree very much," to 6 "agree very much."

In order of increasing effect, students in psychology and the humanities, females, and Italians were significantly more negative about the computer's psychological and cognitive effects than were students in the sciences and engineering ( $\mathfrak{p}<.01$, Duncan's post hoc test), males, 
and Americans. Country and field of study, but not gender, yielded significant main effects on Factor 2, negative attitudes toward social effects of computers.

In an effort to identify variables that predict attitudes toward computers, Jones (1994) investigated the relationship between the Myers-Briggs Type indicator (MBTI) codes, computer attitude, and computer use among 140 university students. Participants were solicited from upper-division undergraduate and graduate courses taught by the investigator in a college of education at a university in the western U.S. They earned extra point credits for participating. The investigator administered the MBTI along with questions designed to elicit attitudes about computers and probability of computer use. Demographics (sex and age category) were given. The primary instrument was the 50 -item abbreviated form of the MBTI. A computer attitude scale adapted from Kay (1989) was prepared. Participants chose between polar adjectives, the word that seemed more closely associated with computer use, e.g., uncomfortable-comfortable, empty-full, and natural-artificial. Kay (1989) used a 7-point semantic differential scaling for 10 adjective pairs, which was labeled as an affective scale. The responses were binary, thus possible scores on the attitude scale could range from 10 (selected each negative term) to 20 (selected each positive term). Cronbach's alpha coefficient for the adapted scale was .89 , suggesting satisfactory reliability.

Overall, participants reported highly positive attitudes toward computers $(\mathrm{M}=17.6$ of 20 possible score). Differences between female $(M=17.7)$ and male $(M=17.3)$ participants were significant on only one of seven questions designed to elicit probability of computer use. On the 4-point scale, females were more likely to report probable use of a word processor $(\mathfrak{p}<.05)$. 
The probability of computer use was assessed with a scale also adapted from Kay (1989). Participants used a 4-point Likert-type scale, with options ranging from very likely to unlikely to respond to individual questions regarding computer use. For seven items selected from Kay's behavior scale, participants were asked to indicate the likelihood of performing the behavior during the next six months. Higher computer use scores were associated with certain MBTI preferences —Extrovert, Sensing, Thinking, and Judging. Also, a more positive attitude toward technology was associated with the MBTI N (Intuitive) and Thinking preferences. Differences on the computer attitude scale among participants with clear or very clear MBTI preferences were not significant.

In 1992 Kay concluded that, although researchers had examined a broad age range of subjects from preschoolers to adults, the diversity of age groups gave little insight into the development of computer attitudes, aptitude, and use. Researchers either focused on a single age group or failed to dissect large composites. One final goal for researchers in human-computer interaction was to address some of the basic assumptions, e.g., do attitudes predict or cause behavior?

An attitudinal comparison toward computers between underclassmen and graduating seniors. Concerned with the issue of negative attitudes toward computers, Walters and Necessary (1996) helped answer this question with a study of 204 business students that examined an attitudinal comparison toward computers between underclassmen and graduating seniors. No age demographics were given, only the students' class status. The study statistically tested the effectiveness of the 24-item Attitude Toward Computers Scale (ATCS) developed by Francis (1993) for measuring college students' attitudes toward computers. 
The ATCS was tested on the data for reliability using Cronbach's alpha, and yielded a coefficient reliability of .96, which was similar to that found by Francis. Hence, the statistics from both populations were good indicators of the homogeneity and unidimensionality of the ATCS. All 24 items were treated as part of a single scale to measure students' attitudes.

All subjects had a positive attitude toward computers, but seniors were consistently more positive $($ Mean $=98.97, \mathrm{~N}=101, \mathrm{SD}=13.73)$ on almost every statement in the ATCS than were those of underclassmen $($ Mean $=92.07, \mathrm{~N}=103, \mathrm{SD}=12.88)$. Analysis of variance revealed significant differences for several demographic variables used with the ATCS. A significant attitude toward computers difference existed between the two groups of underclassmen and seniors $(\mathrm{p}=.0003)$, with the seniors' attitude toward computers consistently more positive. In accordance with other studies (Koohang, 1989; Loyd \& Gressard, 1984b), as individuals gained computer experience, the more positive their attitudes toward computers, with this study showing a significant positive correlation between students' computer experiences and attitudes toward the computer $(\mathrm{p}=.0001)$. This study revealed a significant difference between students' attitudes and their overall knowledge of computers $(\underline{p}<.0000)$. Specifically, computer knowledge was found to have a statistically significant relationship to the development of more positive attitudes toward computers. In addition, those students who own a computer $(\underline{N}=82)$ have more positive attitudes toward computers than those $(\underline{\mathrm{N}}=122)$ who did not $(\underline{\mathrm{p}}=.0037)$.

This study found that ATCS scores for university students were predictably related to number of university computer courses completed, years of computer experience, overall computer knowledge, and ownership of a personal computer. However, no significant 
differences were found relative to gender, as was the case in studies with similar populations by Francis (1993) and Loyd and Gressard (1984b).

Gender differences in student attitudes toward computers. Despite-or perhaps because of - earlier findings of little or mixed results for gender differences, in 2000 Young developed a student computer attitude survey to examine gender differences in student attitudes toward computers among 462 middle and high school students (220 girls and 242 boys). The principal components analysis confirmed five expected factors: confidence, perception of computers as a male domain, positive teacher attitudes, negative teacher attitudes, and perceived usefulness of computers. These factors were related to several background variables, such as self-rating of computer skill, access to and use of computers at home and school, and family role models of computer users. The study had two main objectives: (1) to report the results of the survey instrument development, and (2) to examine patterns of gender differences for the group of participants who took the pilot survey. The main gender differences related to greater confidence among males and the perception of computers as a male domain was supported by males and rejected by females.

The research literature on computer education has examined gender difference since the early 1980s. There had long been an equity concern related to the low level of female participation or persistence in courses and careers related to computer technology. By 1996, the percentage of women attaining degrees in computer science had consistently been less than $20 \%$. Thus, this undesirable outcome was perceived to have its roots in earlier experiences of females. In the educational research literature, various factors associated with gender differences had been explored. The computer gender gap begins early as children, teachers, and parents act 
on the perception of computers as a male domain. Children at all levels perceive computers as a male domain with belief more pronounced in the adolescent years (Koohang, 1989). Some studies have found a tendency for females to be unsure of their own abilities to use computers but to believe that women in general are as capable as men in their use.

The effect of experience on the development of positive attitudes had been identified in several studies, though some had found that the nature of computer experiences affect attitude, with some experience contributing to negative attitudes that persist over time. Boys had substantially more computer exposure at both home and school and were more likely to participate in activities such as computer camps or after-school computer clubs.

The instrument developed to assess students' attitudes toward computers was the Computer Attitude Survey (CAS), which contained 48 items rated on a 5-point Likert-type response format, with " 1 " representing strongly disagree and "5" representing strongly agree. The CAS was adapted from the short version of the Fennema-Sherman Mathematical Attitude Scale, which assessed gender differences in attitudes toward mathematics. The CAS contained 12 questions (6 negative and 6 positive) related to each of four dimensions:

- Confidence in using computers,

- Perception of computers as a male domain,

- Perceived usefulness of computers, and

- Teachers' attitudes.

Additionally, 10 background questions were included to determine gender, access to and weekly use of computers, a self-rating of computer skill, who else in the student's family used computers, and whether the student was planning to go to college. 
Independent sample t-tests of the mean scores for boys and girls were done for the five scales that emerged in the factor analysis. Finally, the association between the self-report of computer skill level and the five scales, along with several background variables, were examined using stepwise multiple regression analysis (for the total group and for each sex group separately to test for gender differences in the predictive models).

The reliability analysis of each of these scales produced the following alpha coefficients: confidence $=.87$; male domain $=.87 ;$ positive teacher attitude $=.64 ;$ negative teacher attitude $=$ .74 ; and usefulness $=.87$. Thus the reliability coefficients are respectable for all but the teacher attitude factors.

Ninety-five percent (95\%) of the students planned to go to college. There was no significant difference in self-ratings of computer skills; slightly more than half rated themselves "great" or "pretty good." Boys spent significantly more time using computers, mostly because of the difference in home computer use. The perceived usefulness of computers indicated that females reported finding the computers more useful for school and careers (mean difference $=$ $.093 ; \mathrm{p}=.007)$.

Although the results of this study require more detailed data to more accurately interpret the survey results, the CAS could be considered an effective barometer of gender attitudes toward computers across large groups of students, and it was successful in getting teachers to look at computer use in terms of gender differences.

A longitudinal study of student attitudes toward computers: Resolving an attitude decay paradox. As the previous research documented, attitude toward computers and their use can be measured; however, at least one study found that attitude changed (or decayed) over time. 
McKinnon, Nolan, and Sinclair (2000) conducted a longitudinal study of student attitudes to examine their motivations and attitudes toward the use of computers in New Zealand. They compared the performance of integrated curriculum project students (IS) with the performance of peers in the parallel traditional school program (non-IS) and evaluated students' performance during their junior high school careers with the goal being some implication for the design and implementation of curriculum programs.

The researchers found that although IS students performed significantly better than peers in the parallel traditional school program, non-IS student attitudes toward computers became significantly less positive during their junior high careers, a finding that concerned the researchers because contemporary literature states, by and large, the opposite. The integrated program created conditions in which students became enthusiastic computer users to the point of regarding the computer as indispensable as pens and pocket calculators. Students persistently worked on computers to complete class assignments, frequently during lunch hours and after school. At the end of three years, results in the nationwide school certificate examination showed that the IS students had performed significantly better than non-IS peers. Yet during the three years of their junior high school careers, student attitudes toward computers became significantly less positive.

A key message for educators was that even though modern computer technology may be both fascinating and compelling to teachers and students alike, it was the quality of the curriculum programs in which the technology is used that made the real difference to students' attitudes, motivation, and performance. 
The research setting was a typical New Zealand coeducational secondary school (grades 8-10). Results were generated from data gathered for five years on three cohorts of students who elected to participate in the integrated studies project and in traditional instruction. In all, 415 students were involved.

Two main instruments were used to collect attitude and motivation data. A modified version of the Bath County Computer Attitudes Scale, and the Adolescents' Theories of Education questionnaire, respectively. Student achievements in English, mathematics, and science were obtained from their results in the external New Zealand school certificate examinations conducted at the end of Grade 10. In addition, two forms of qualitative data were collected: students' written comments each time questionnaires were administered, and focused interviews to probe students' responses to the integrated studies and traditional programs.

The scales were validated as unidimensional using a two-factor structure. Internal consistency (Cronbach's alpha) was .9009 on the expressive scale (enjoyment and personal aspects, use computers as a source of excitement, interest, and fun), and .8578 for the instrumental scale (the value of computers in helping students perform tasks, solve problems, and work more productively).

Fourteen (14) items probed student attitude toward out-of-class activities using the same format as the Bath County Computer Attitudes questionnaire. Two factors emerged: students' enjoyment of out-of-class activities and students' attitudes toward the role of these activities in the curriculum. Reliability analysis (Cronbach's alpha) revealed internal consistencies of .8143 for the enjoyment scale and .7239 for the curriculum scale. A 4-item scale measuring student attitudes toward subject integration possessed an internal consistency of .6919. 
The three scales on achievement motivation, satisfaction with school, and task orientation were used to illuminate students' underlying attitudes toward the learning environments in which they were working. The three scales possessed good internal reliabilities, $.7896, .7335$, and .7467 , respectively.

The decline in positive student attitudes toward the expressive dimension of computer use was indicated by the decreasing mean scores on each successive occasion. There was a significant main effect due to program group membership. The IS students had a significantly more positive attitude toward the expressive dimension than their peers in the non-IS program. The within-subject effect showed that the mean score for all students decreased significantly over the three testing occasions ( $\mathrm{p}<.0005$.). It increased from Occasion 1 to 2 and 3 before decreasing at Occasion 4. Similar results were evident for the instrumental dimension of learning with and about computers; within-subject effect showed that the mean score for all students decreased significantly over the three testing occasions $(\underline{p}<.0005)$.

One outcome of major importance illustrated the computer-use paradox: Although attitude scores for the two computer scales showed a significant decline for all groups of students over the testing occasions, the scores for the remaining six scales showed no significant decrease. Indeed, the scale scores were notable largely for their stability or slight increase. Academically, the IS students performed better, and their attitudes were more positive than the non-IS students; however, their attitude became significantly less positive over time. The paradox of computer use reported here might be explained as a product of emerging student, and to some extent, teacher habituation; they may have begun to take computers for granted (they weren't new any more). The researchers commented that in the IS project, computer use perhaps lost its 
fascination after the halo effect had worn off. Moreover, such programs are more likely to engage and sustain student interest and help them learn better if attention is paid to the content and pedagogy rather than the technology.

Changes in student attitudes and student computer use in a computer-enriched environment. Where the McKinnon et al. (2000) study used junior high students to examine changes in attitude toward computers, Mitra and Steffensmeier's (2000) study used Wake Forest University students to determine the changes in student attitudes toward the use of computers in a computer-enriched higher education environment, and to reveal changes in student use of computers in a computer-enriched higher education environment.

The study was designed as a longitudinal survey spanning five years, with the first year being the baseline year. The process of enrichment involved several different initiatives, including extensive networking of student residence halls, classrooms, the library, and most office buildings, as well as providing all incoming students (beginning in the fall of 1996) with an IBM ThinkPad computer. Thus, by fall 2000 , every student at the university would be equipped with mobile computing that would provide easy access to a local area network and the Internet. The survey design used a questionnaire constructed after extensive use of focus group discussions to explore and uncover the various issues surrounding the computer-enrichment process at the university. Over the years, the response rates varied among the different administrations to the incoming class; however, the composition of the samples was comparable, allowing statistical comparison between the respondents.

A one-way ANOVA was used to test for differences between groups, and a Scheffé post hoc test for homogeneity was used to identify the specific groups that were significantly 
different. The results indicated that there were more significant differences in attitude between Year 1 and Year 2 as compared to Year 2 and Year 3. There were significant differences $(\mathrm{p}<.05)$ in the ways students expressed:

- Comfort with the use of computers: The attitude mean increased consistently from Year 1 students to Year 3 students,

- Apprehension regarding the use of computers: The attitude mean for this item consistently decreased from Year 1 to Year 3 students,

- Concern that computer use in teaching was making the teaching process too impersonal: The attitude mean consistently decreased from Year 1 to Year 3 students,

- How computers enabled them to interact with teachers: The attitude mean consistently increased from Year 1 to Year 3 students,

- Whether computers were effective for communicating with teachers about non-course-related material: Attitude means consistently increased from Year 1 to Year 3 students, and

- Whether communicating with professors by e-mail was generally gratifying: The attitude means consistently increased from Year 1 to Year 3 students.

The question of attitude change also was explored by comparing specific groups of students and the changes and differences in their attitudes toward the use of computers in education. A oneway ANOVA was used to compare Year 1 freshmen, Year 2 sophomores, and Year 3 juniors. Year 2 and Year 3 students felt that the use of computers did not make the learning process easier.

Another comparison was made between Year 2 freshmen and all other Year 2 students. This test represented a comparison between ThinkPad and legacy students (those enrolled prior 
to 1996) in Year 2 using a t-test statistic with Levene's test of equality of variance. Significant differences $(\mathfrak{p}<.05)$ were observed:

1. ThinkPad students felt that the introduction of computers made learning easier.

2. ThinkPad students preferred taking classes where they could use the computer.

3. Legacy students felt that computers can make the learning process too impersonal.

4. ThinkPad students felt that computers are effective for communicating with faculty about non-course-related work.

5. ThinkPad students felt that communicating with teachers by e-mail was generally gratifying.

6. ThinkPad students perceived that computers enabled them to interact more with teachers.

There were, thus, several instances in which significant differences were observed between the first group of ThinkPad students and legacy students. Significant differences were observed over the three years in (1) attitude and use, and (2) across different groups of students.

These results suggested that three elements of attitudes toward computers - attitudes toward computers in general, the role of computers in teaching, and how computers facilitate the communication process - tended to become more favorable as an institution makes itself computer enriched. Over the length of the study, the students felt that the use of computers in the college environment can be perceived to make the process of learning easier.

A key implication of these findings was that longitudinal exposure to a computerenriched learning environment might not necessarily change the attitudes toward computerenhanced learning unless the development of the computer-enriched environment is supplemented with the tools for connecting with the environment. In this study, the legacy students were those who never felt the empowerment of access and, thus, continued to maintain 
either a negative attitude or did not alter their attitudes in a positive way even when placed in a networked and computer-enriched environment. On the other hand, the ThinkPad students entered the environment with a personal laptop computer and felt immediately connected to the environment. This conclusion has certain far-reaching implications, and it points to a fundamental difference between the notions of being in a networked environment and having access to a network. Furthermore, it can be inferred from these findings that instead of attempting to measure learning from traditional perspectives of grades and test scores, it might be better to measure how students perceive the changes brought forth in the learning environment with the introduction of computers.

Effect of student attitude to course format on learning performance: An empirical study in Web vs. lecture instruction. One way that the learning environment has changed with the proliferation of computers and the later development and availability of the Internet has been the offering of Web-based versus lecture or traditional instruction. Because attitude affects learning performance, measurement of student attitude toward course format is helpful. One such study (Sankaran, Sankaran, \& Bui, 2000) investigated student attitudes about Web vs. lecture formats and how they affected learning outcome in an accelerated four-week undergraduate business computer course. The relationship between attitude toward course format and the student's learning strategy was also studied. Differences in attitudes toward formats among various ethnic groups and ESL students were also examined. Attitudes toward Web format along with learning strategies were measured using a survey and learning performance by test scores.

Findings suggested that students tend to enroll in the format according to their attitude and learning strategies. When they did not enroll in accordance to preference, learning outcomes 
were adversely affected. There were no statistical differences in attitude to Web due to ethnicity. The conclusion was that matching course formats with students' attitudes and learning strategies enhanced learning performance. The effect of the student attitudes on the learning performance was inconclusive.

A survey instrument was developed to quantify the attitude of each student toward Webbased instruction vs. traditional lecture. An interval scale of 1 to 5 was used with 1 representing strong disagreement and 5 representing strong agreement. The attitude to Web subscale contained 13 items describing student preference for Web format, propensity to work independently as against in a classroom environment, access, and willingness to use technology, current inventory of Internet skills, strength of belief in the effectiveness of Web courses, and their willingness to enroll in them.

To detect possible agreement bias, some statements were reverse-scored. To test the internal consistency, the researchers used Cronbach's alpha coefficient, which was computed to be .83 . The mean score of all the items was computed for each student and assigned as an Attitude to Web Score (AWS). The statement and rating scales were designed so that a high AWS represented a positive attitude to Web format and low AWS a negative attitude to lecture.

The Learning Strategy Subscale contained 14 items to determine whether the student employed deep or surface learning strategy, as proposed by Hoeksema. A student using the deep strategy will put in longer study hours, make detailed notes from the text and class Web site, do extra exercises and assignments with corresponding good results in performance. A surface learning strategy, on the other hand, is directed to memorizing facts, disjointed pieces of data, examples, and illustrations. 
Of the 116 students in the sample, $46(39.7 \%)$ chose to take the course in the Web format, and $70(60.3 \%)$ chose the lecture format. To test the effect of attitude on choice of course format, the Attitude to Web Scores (AWS) were computed for the participants based on their responses to the survey questionnaire. The t-test used to verify if the AWS in the Web group and lecture group arose from independent samples. The AWS was significantly higher for the Web group $(\mathrm{p}=.004)$. Thus, the hypothesis $(\mathrm{H} 1)$ that students will have no preference to one course delivery format over another was rejected. If a choice were to be given, attitudes do play a role in the students' exercising their option.

As discussed earlier, learning performance was measured using the final test scores. The results of the t-test showed that the difference was not significant. Thus, $\mathrm{H} 2$, which stated that there would be no difference in learning performance in spite of variations in attitudes to course format, was supported. The amount of learning achieved by students in the course was computed by subtracting the pre-test score from the final score. There was no significant difference $(\mathrm{p}=.478)$ in the incremental scores achieved by students in the Web or lecture format. This implied that both groups learned equally.

It was seen from the discussion of $\mathrm{H} 1$ that students had a tendency to match their attitude to the format of the course. Further, H2 suggested that there was no difference in the incremental learning in the Web or lecture format. However, one would want to know how the performance was affected if there were a mismatch between attitude and format. To gain additional insight into this area, the AWS range of 1 to 5 was divided into three equal parts, less than 2.3, 2.3 to 3.7 , and greater than 3.7. Students with AWS of greater than 3.7 were considered Web-oriented, between 2.3 and 3.7 format-neutral, and those below 2.3 lecture-based. Their 
mean incremental test scores were then computed for each of these three categories. The most gains were made when the attitudes of the students toward Web and lecture were matched to the course formats they chose to be in. Conversely, when the attitudes and formats were mismatched, students made the lowest gain. This brought out a point that any one course delivery format may not be the optimum method for all students; hence, it would be beneficial to offer a course in multiple formats if possible.

$\mathrm{H} 3$, then, concerned the relationship between attitude to Web and learning strategies. H3 was tested using correlation analysis. Learning Strategy Scores were negatively related to attitude toward Web and significant at 10 level for the Web group. This implied that Weboriented students employed surface learning strategy and that lecture-oriented students employed the deep learning strategy. This was what one would expect because the Web format, with no direct verbal interaction, lends itself better to present course materials in a more sequential manner. Important points in the material can be more easily picked from the concise and organized Web materials. The Web format is very conducive to one using surface strategy that emphasizes memorization and reproducing ability.

Used to test H4: Attitude to Web and ethnicity, ANOVA showed no statistical differences in AWS among the different ethnic groups at the .05 level $(\underline{\mathrm{F}}=2.234 ; \mathrm{p}=.071)$.

Interestingly, one finding from H5: Attitude to Web and ESL students revealed that 65 of the ESL students chose the Web format and 38 the lecture format, almost 2:1. An explanation could be that these students had better reading skills and were hesitant to be in the interactive lecture environment due to language and cultural barriers. 
Overall, this study showed that when a course was offered in multiple formats, students tended to enroll in the one that is compatible with their attitude and learning strategies. Where students failed to make such a match, learning outcomes were adversely affected. The implication of this study for educators and administrators was that one-format-fits-all is not an effective course design. Every student learns differently. This study showed that the Web is not the panacea for instruction, nor is the lecture or any other format. Thus, it is important to develop and match innovative course designs that support a student's individual way of learning.

Summary. As studies continued to examine attitudes toward use of computers in the 1990 s and into the $21^{\text {st }}$ century, the research became more specific, painting a more detailed picture compared to the broader strokes of earlier attitude studies, such as those of Loyd and Gressard (1984a) and Loyd and Loyd (1985). Year in school and major or field of study were examined to determine relationship to computer attitude and use, with both variables significant, with seniors reflecting more positive attitudes than underclassmen, and those students in business, science, or technical majors more positive than those in the humanities or social sciences (Liu \& Reed, 1992; Sensales \& Greenfield, 1995; Walters \& Necessary, 1996). Negative attitudes toward computers were of particular interest to researchers, and gender issues were still researched with conflicting findings. Some studies found significant sex differences, with males generally having less anxiety and more positive attitudes than did females (Liu \& Reed, 1992; Young, 2000), but other studies did not (Jones, 1994; Sensales \& Greenfield, 1995). Researchers also wanted to learn whether attitude predicts behavior (in terms of learning performance), with findings indicating that computer knowledge, skill, use, and access to computers were positively related to attitude toward computers (McKinnon et al., 2000; Mitra \& 
Steffensmeier, 2000; Walters \& Necessary, 1996; Young, 2000). Interestingly, some studies found that students' highly positive attitude toward computers may change (decay) over time as they habituate to the use of computers (McKinnon et al., 2000), and others found that certain personality preferences were related to more positive attitudes toward computers (Jones, 1994). And as the millennium arrived, researchers turned their attention to the ways in which computer applications such as the World Wide Web might not only affect students' attitudes toward computers and their use, but also their choice of course format (Web-based versus lecture) depending on their preferred learning strategies, and academic success (Sankaran et al., 2000). Using Computers for English Composition (Computer-assisted Composition)

As microcomputers became popularized in the early 1980s, English composition programs began establishing computer labs where computers were loaded with certain software known as text editors, e.g., Bell Laboratories' Writer's Workbench that analyzed text for 15 programs plus gave readability scores (Collins, 1989). With the advent of the Internet about 1993, and its subsequent incorporation into educational settings, composition students and teachers relied more and more heavily on its use as an aid to learning in what may be called computer-assisted composition (CAC).

Technology—specifically, computers — provided a new and different writing environment for recording and presenting text, and offered new techniques for organizing writing. The ways in which these tools influenced writers' theories and practices merited examination, particularly student writers' attitudes toward computers and the possible resulting behavior related to their performance outcomes. The next step was to relate that information to the teaching and learning in a writing course using computers as a significant component. The literature in general 
Table 4

Research Summary for Computer-assisted Composition

Study

Findings

Sadler

(1987)

The computers-and-effectivewriting movement: Computerassisted composition

Hawisher \& Selfe

(1989)

Critical perspectives on computers and composition: Teaching and research in the virtual age
Erickson

(1992)

A synthesis of studies on computer-supported composition revision, and quality
Described and documented the history of the use of microcomputers and word processing software. Bennett College study with CAI and CAC, combination computer lab and class. Increased quantity of student writing; revision process resulted in qualitative change; grades rose progressively. There was an attitudinal change toward writing.

Comparative studies: Students seem to have positive attitudes toward writing and word processing after working with computers. Fewer mechanical errors and longer pieces. Conflicting results for revision and quality. Case studies: A writer's particular habits and strategies for composing seem to take precedence over the influence of the machinery.

Ethnographies: Context includes the social situation in which writing takes place and by which it is shaped is integral. Some influence on social interactions among students but conflicting results.

General observations: Lack of detail in research; not much consistency among studies, hard to compare them. Writing instruction is also important in shaping the influence of computers.

Recommendations: Build upon previous research; intersection of qualitative and quantitative needed; use a longitudinal approach to observe emerging patterns. Conclusions: Results seem to be confusing and contradictory but a research base is forming.

Study showed that the quality of compositions written on computers depends on many variables, including writer experience using the writing process, writer maturity, instruction in the writing process, editing instruction, and time to become familiar with keyboarding and editing programs. Results of studies are mixed. 
Table 4 (continued)

Study

Findings

Parr

$(1994 / 1995)$

When pens are passé: Students reflect on written composition

Eldred \& Hawisher

(1995)

Researching electronic networks

Reed

(1996)

Assessing the impact of computer-based writing instruction

Cotton

(1997)

Computer-assisted instruction
Year-long evaluation of a computer innovation in which students and their teachers received personal computers for use in class and at home. Students claimed to enjoy producing written work more when they used a word processor; quality increased; identified ways their writing behaviors changed, including planning and revising.

Defined empirical research as studies that entail some systematic observation and analysis of composition, quantitative (and qualitative) analysis. Compositionists have done little empirical research on computer-mediated communication. Five key concepts: (1) reduced social context cues, (2) decision making, (3) efficiency and quality of work, (4) task orientation, and (5) the equalization phenomenon.

Reviewed research on computer use in English language arts, predominantly since 1987 . Categorized research into three groups: (1) word processing use only, (2) modified word processing use, and (3) composing process software. Results favored older, more able students, especially those exposed to relatively lengthy treatments that wee well grounded in appropriate theoretical frameworks. Writing attitudes improved, but contradictory results from writing fluency and quality studies. Generally revise more and produce better papers, and some internalization of computer-based writing strategies.

Computer-assisted instruction, findings emerged from analysis of 59 research reports in CAI, CBE. Studies also focused on students' attitudes toward the content of courses in which computers were used. Traditional and computerbased delivery systems are of greatest value when complementing each other. Positive outcomes include longer samples, word and sentence variety, more accurate mechanics and spelling, more substantial revision, better attitudes toward writing. 
Table 4 (continued)

Study

Findings

Sullivan \& Porter

(1997)

Opening spaces: Writing

technologies and critical

research practices

House \& Prion

(1998)

Student attitudes and academic background as predictors of achievement in college English

Selfe

(1999)

Technology and literacy in the $21^{\text {st }}$ century: The importance of paying attention

\section{Duffelmeyer}

(2000)

Critical computer literacy:

Computers in first-year composition as topic and environment
Advocated a view of research as a set of critical and reflective practices (praxis) that are sensitive to the rhetorical situatedness of participants and technologies and that recognize themselves as a form of political and ethical action. Called for an integration of empirical research, including traditional positivistic and traditional naturalistic and "critical theory." Computers and composition has yet to explore the methodological implications of studying the computer as a writing tool.

Investigated the predictive relationship between student attitudes and their subsequent achievement in a freshman composition course. Results indicated that academic background and student attitudes were significantly correlated with subsequent grade performance in a freshman English course.

Cautions that access (or lack thereof) to computers is inequitable; ethnic and poor students have significantly less access to computer technology. Affects education, jobs, quality of life. Defined technological literacy. Meta-analysis of 254 studies: they lack the necessary scientific controls to make solid conclusions possible.

Article addresses how first-year students understand the computer's influence on them by virtue of cultural assumptions about technology. Defined critical literacy as awareness of the forces that affect conditions within which we acquire literacy and of how we view the uses and meaning of literacy. Categorized students' attitudes as hegemonic, oppositional, and negotiated. 
Table 4 (continued)

Study

Findings

Harrington

(2000)

The flashlight project and an introductory writing course sequence: Investigation as a basis for change

Herrington \& Moran

(2001)

What happens when machines read our students' writing?
Investigated the activities in the computer-assisted classrooms to evaluate the ways in which faculty were trained and supported in their uses of technology, and to evaluate ways in which students were learning with technology. Results: very few significant differences between computer-assisted sections and traditional sections - in students, overall faculty effort, teaching and learning practices. Students with low technological skills were much less likely to own or use a computer, GPAs tended to be lower, a sign of academic risk.

Detailed descriptions of two computerized writing evaluation programs to analyze the claims for their value to postsecondary education. Authors had serious concerns about the potential effects of machine grading of student writing on teaching, on students' learning, and on the profession of English.

reflected a positive outcome for computer-assisted composition (CAC), but there was some disagreement on the specific behaviors or outcomes. A summary of the research in using computers for English composition (computer-assisted composition) is contained in Table 4 (above).

Research and recommendations for computers and composition. Early studies were conducted on whether programs like Writer's Workbench improved the quality and/or quantity of students' compositions. These studies were primarily qualitative in nature, using verbal protocols and document analysis; quantitative research was relatively absent from the discipline 
of English composition. In fact, Hawisher (1989) observed that surprisingly few studies investigated the ways in which computer use affects or is affected by the wider instructional environment. By the latter part of the 1980s, microcomputers were being used in college composition programs, and compositionists began to document the dynamics of CAC. For example, Hawisher's (1989) meta-analysis of 42 studies conducted between 1981 and 1987 showed that students exhibited consistently positive attitudes toward revision when they used computers, attitudes that tended to contribute to a spirit of cooperation rather than competitiveness within a classroom. Each study regarded computers as tools for writing rather than as intact instructional systems, and included a variety of research methods, including survey, observation, and study. There were two categories: those that employed primarily quantitative methods of inquiry and those that relied largely on qualitative techniques (further categorized into case studies and ethnographies). Of the 42 studies, 26 were comparative (or quantitative), 16 naturalistic (qualitative). Of the 16 qualitative studies, 12 were case studies and 4 ethnographies. Undergraduate college students were sampled in 7 of the 26 quantitative studies.

Results of comparative and case studies showed that, after working with computers, students seemed to have positive attitudes toward writing and word processing. There were fewer mechanical errors, and many students wrote longer pieces; however, there were conflicting results for revision and quality.

There were several reasons why word processors facilitated the writing process. Students more easily engaged in all phases of the writing process, from prewriting through publishing. They took risks with their writing because the physical act of writing by hand was eliminated by 
computers, and changes could be made easily. Word processors helped students evaluate their own work because the work was presented in a form that was easy to read. Finally, they encouraged peer editing.

Hawisher (1989) saw a decided lack of detail in the research. She felt it ironic that the quantitative studies seemed to present a more complete description of context in which the research was conducted than the descriptive (qualitative) studies did. Another flaw of several studies was their failure to include and describe the word processing package, and there were differences in the definition of "composing at the computer." Some studies limited or prevented printouts, considering them part of the pen-and-paper province. In sum, there was little consistency among the studies so that it was hard to compare them. Given these limitations, Hawisher (1989) called for the profession to build upon previous research, to intersect qualitative and quantitative methods to form systematic research agendas in order to extend the emerging knowledge base, and to use a longitudinal approach.

Critical perspectives on computers and composition instruction. Prior to the advent of the Internet, Hawisher and Selfe (1992) saw the change that use of computer technology brought to the teaching (and learning) of composition, and saw the need for continuing scholarly work throughout the 1990s. Citing conflicting and mixed results of previous studies in the 1980s, Selfe (1992) reiterated the need for a variety of types of research in computer mediated composition (CMC), stating that "theory untested by . . . a systematic research program remains an intellectual exercise that has little to do with the real stuff of instruction" (p. 33).

Technology and literacy in the twenty-first century: The importance of paying attention. Selfe (1999) was also concerned that student access (or lack thereof) to computers was 
inequitable, and wrote that ethnic and poor students have significantly less access to computer technology. The phenomenon perpetuates the economic system currently in place, that is, that white and affluent students are favored, thus will get better educations, higher paying jobs, and a better quality of life. She stressed that "technological literacy-computer skills and the ability to use computers and other technology to improve learning, productivity, and performance-has become as fundamental to a person's ability to navigate through society as traditional skills like reading, writing, and arithmetic" (p. 3).

Selfe (1999) focused on a second definition of technological literacy that referred not only to what is often called "computer literacy," that is, people's functional understanding or basic familiarity with what computers are and how they are used. This second definition of technological literacy referred to the events that involve reading, writing, and communicating within computer-based environments, all of which have come to be socially identified as literate activities. These include understanding and valuing the uses of common computer applications for generating, organizing, manipulating, researching, producing, and distributing information, discourse, and texts (print, still graphics, moving images); and using such tools as databases, word-processing packages, multimedia production packages, e-mail, listserv software, bulletin boards, and graphics and line-art packages. At this level, the term technological literacy also referred to the activities associated with navigating online communication environments such as the Word Wide Web (WWW) and the Internet, activities that require, for example, the use of browsers and search engines in order to locate information and engage in online conversations. Like Hawisher (1989), she pointed to the need for conclusive, quantitative research. 
Opening spaces: Writing technologies and critical research practices. Sullivan and Porter (1997) proposed ways in which research into computers and composition could be improved, citing the lack of methodological design of studies of computer writing. They advocated a view of research as practical action (as opposed to the modernistic view of research as generating knowledge). To them, "good research has a practical aim; it does something good for somebody, and enables the end we all desire: better research practices serving the aim of better writing practices" (p. xvi). They agreed with Selfe (1999) that "electronic writing (including word processing, email, Internet file transfer, World Wide Web) is the key site for future writing. Very shortly, if not already, writing will mean 'electronic writing”" (p. 151).

Like Hawisher (1989) they called for an integration of empirical research, including traditional positivistic, traditional naturalistic, and "critical theory," whose aim is critique. They felt that new technology, in part, urges us to research new issues, or at least new technology. They found the divisions between the two main methodological camps in rhetoric and composition—between empirical research and critical/postmodern theory—unnecessary and counterproductive.

The computers-and-effective-writing movement: Computer-assisted composition. Sadler (1987) documented the history of the use of microcomputers and word processing software as well as other software packages, such as Writer's Workbench, Grammatik, Invent, drill and practice, and tutorials. Sadler cited the Bennett College experience with computer-assisted instruction (CAI) and computer-assisted composition (CAC). The study of predominantly black female students focused on a composition course combining use of a computer lab and a 
traditional class setting. Sadler (1987) and her partner, Wendy Greene, set up a computer laboratory and set out to familiarize their students with computer terminology.

The students took a mid-semester test on terminology and techniques and received another version of it as a final examination. The laboratory grade was based on these tests, on formatting, and on class participation. The letter grades awarded the compositions were part of the English grade. The first and most notable change was an amazing increase in the quantity of student writing; paragraphs and essays were approximately twice as long as previously. Second, the revision process that developed resulted in a qualitative change in student writing; now they were allowed as many opportunities as they wished to revise. The files had stacks of drafts in which the grade rose progressively from $\mathrm{F}$ to $\mathrm{B}$ or sometimes even to $\mathrm{A}$. The effect was to encourage both surface and deep-level revision.

Additionally, there was an attitudinal change toward writing. The researchers acknowledged that word processing enabled students to produce a beautiful product. The builtin revision process allowed some of them to achieve a sense of perfection or near perfection for the first time in their lives. Sadler (1987) and Greene believed that CAC not only encouraged revising but treated revision as a fact of the life of writing; it made the student, with teacher assistance, aware of writing as a process; it made writing a more communal activity, and enabled the writer to become both creator and critic, thus to use both right- and left-hemispheric powers.

When pens are passé: Students reflect on written composition. Parr (1994/1995) added to this body of work by studying how the theories writers build about writing are shaped, in part, by the tools they use, specifically, the theories and practices writers develop when they use a personal computer for writing. The data reported here were gathered during a year-long 
evaluation of a computer innovation in which 47 students (mean age, 13.5 years) and their teachers received personal computers for use in class and at home. Data were obtained from questionnaires, interviews, observations, and written work. Preference for word processing was related to the ease and speed with which work could be produced. In terms of a theory of writing, speed aided generation and recording of ideas. Preference was also related to the facility with which text could be arranged and altered. These factors were seen to enable the production of better quality written work. Students were able to reflect on writing as shown by their ability both to identify the features of word processing that facilitate writing and to pinpoint changes in the way they went about composing in different media.

Parr (1994/1995) examined students' attitudes toward writing and the theories they hold about writing when they used the computer for almost all of their written work. The study involved the evaluation of a computer innovation at a private secondary school for boys. Two classes received personal computers as part of the pilot project. One class had MS-DOS; one had MacIntoshes. Computers were available for use in all core subject lessons and for homework. The computers were used in a variety of ways, but predominantly for word processing. Schooling was essentially text based; only a small amount of information was obtained or exchanged electronically.

The students were in their first of five years of secondary schooling and ranged in age from 13 to 18 . One class was categorized as accelerated, one as having average academic ability; 13 teachers who taught core courses participated.

Baseline data were collected from questionnaires administered to teachers and the boys regarding the extent and type of their home and school computer use. Teachers were asked 
about professional development to date and for self-ratings of their knowledge and ability to carry out various computer operations, as well as personal and classroom use of computers. All boys and teachers were interviewed individually, using interviews structured by the researcher; about 15 minutes for boys, one-half to one hour for staff. Some questions asked for ratings, but most were open-ended.

Students were asked questions about their attitudes toward computer use, type and extent of computer usage, use of word processing functions, academic matters including written work, and writing by hand. Experience has been shown to have a positive impact on students' attitudes; for teachers, experience in classroom computing leads to different usage patterns. Research also suggested that keyboard skills may affect the perceived value of word processing. Informal observations were made in classrooms, and discussions took place with staff. Pieces of student written work were assessed, including composition and handwriting samples.

The students preferred word processing to handwriting as a writing medium; they produced remarkably little written work with pen and paper (about $10 \%$ of total output) even though they had a choice, possibly a result of their experience, knowledge of operations, and keyboard skills. Typing skill may have been a factor moderating the outcomes of word processing in terms of some of its perceived values.

Regarding processes of planning, generating, and transcribing material, students commented that they were able to work faster and produce more, longer, and more substantial assignments. The planning process was more overt; they used more structured organizational strategies. Most boys (70\%) clearly believed that their writing skills had improved as a result of using word processing. A number of students mentioned that when writing electronically, they 
felt they had a better chance of capturing their ideas as they occurred. This was especially evident when a student could type much faster than he could write (means were 44wpm:17wpm).

They felt no need to be concerned about mechanics, such as spelling. Other advantages included ability to generate more text and to revise the text they produced. One respondent said that the text was so clear and easy to read that more ideas just popped into his head. The structure of a written piece was easier to see when typed.

These students were like most novice writers, however, who tend to revise at the word level; at the end of the first term, fewer than $25 \%$ of the students had used the block-move or cutand-paste functions. At the end of the year, however, the majority talked of rearranging sections of their essays or reports and making changes to the text, in addition to revising at the sentence or word level.

When asked, about $80 \%$ of the students said they made changes in the way they went about handwriting the essay in the exam compared to when they wrote essays on the computer. Changes were harder to make on the handwritten exam. Some did not bother making changes even though they could see where changes needed to be made on the handwritten exam. They said that it was too much trouble and that they would have written more on the computer.

The tools used for writing not only influenced attitudes toward writing but also the theories formed about both product and process. Students in this study claimed to enjoy producing written work more when they used a word processor. Speed of production, one of the major reasons for their preference, was quite obviously related to keyboard facility. Another reason was the perceived increased quality of their written work. Students were able to identify characteristics of word processing that could potentially increase the quality of writing produced, 
e.g., speed of transcription, speed of recording, clarity of production, and the ease with which text could be changed, which encouraged revision.

Students were also able to identify the ways their writing behaviors had changed with the use of computers. The main changes involved planning and revising, improving the focus of attention, capturing ideas, and rereading in order to generate more text or review what was written. The students' ability to identify the features of word processing that facilitated writing and to pinpoint changes in the way they composed when using different media showed a degree of self-reflection about writing that, arguably, was shaped by the tool employed for writing.

Researching electronic networks. According to Eldred and Hawisher (1995), composition studies, as a field, has always depended on theoretical constructs and empirical methods from other disciplines. Thus, they looked at interdisciplinary work in the area of composition and computer-mediated communication (CMC), and reviewed the work of four groups conducting social psychological research on CMC. They found that the research advocated a dialogic relationship between research in computers and composition studies and social psychology.

Eldred and Hawisher (1995) followed Beach's definition of empirical research as studies that entail "some systematic observation and analysis of composition; although empirical research typically involves some sort of quantitative analysis, it may also include qualitative analysis" (p. 219). They observed that, with the exception of a few studies, compositionists had done little empirical research on CMC. They felt that composition has sustained its disciplinary economy through heavy importing of empirical studies, largely from the social sciences, and 
relied too heavily on one or two early studies from social psychology, primarily the work conducted at Carnegie Mellon University in the mid-1980s.

Eldred and Hawisher (1995) did not see interdisciplinary research or the work imported as a problem; rather, they found troublesome the unproblematic way such studies had been incorporated and the static readings these studies received. Researchers in computers and composition studies had accepted many of the early findings as givens rather than as hypotheses that fueled continuing research agendas. Moreover, these findings or results had been imported as universal "conclusions." In short, sufficient attention has not been paid to the problem of translating social psychological research into contexts never imagined by the empirical researchers - the arena of composition classrooms.

The authors attempted to produce a background study for composition researchers who might be persuaded to design empirical studies of writing on electronic networks. They felt such studies were necessary to determine the relationship between the questions asked by social psychological research and those generated within the specific context of composition classrooms. Their main concern was with "translating" social science discourse, particularly five key concepts: reduced social context cues, decision making, efficiency and quality of work, task orientation, and the equalization phenomenon.

The introduction of computers into the composition classroom changed class dynamics. At first, there was an absence of social cues revealing age, gender, race, ethnicity, status, and mood; empirical research on this difference, however, was not forthcoming.

Next, the computer networks' ability to reproduce and circulate texts and thus to deliver instruction efficiently first attracted writing instructors. Since then compositionists have been 
exploring new ways to tap into this efficiency — accessing library materials, circulating peer manuscripts, and distributing class news. Examinations of quality, on the surface, have seemed less forthcoming. Unlike the area of word processing and revision, which witnessed a flurry of reports boasting improved writing (Parr, 1993/94; Sadler, 1987), research on electronic networks has seen no comparable studies making claims about enhanced quality. Whatever the reason, the authors were unaware of any empirical work within composition studies pronouncing that electronic networks improve writing quality.

Eldred and Hawisher (1995) felt that other studies were needed to look carefully at faceto-face and online environments in which writing instructors and students were increasingly asked to participate. Very few studies had looked at the reciprocal relationship between CMC and the face-to-face contexts in which teachers and students met together. Without studies that emphasize the dynamic relationship of all elements within a social context-electronic or otherwise-inquiry into computers and composition remained inadequate.

The flashlight project and an introductory writing course sequence: Investigation as a basis for change. Both the social context and the interaction with the technology were studied by Harrington (2000) in what was called The Flashlight Project at Indiana University-Purdue University, Indianapolis (IUPUI). In the fall of 1995, the IUPUI English Department entered its $10^{\text {th }}$ year of computer-assisted composition instruction. Administrators decided to investigate the activities in the computer-assisted classrooms, to evaluate the ways in which faculty were trained and supported in their uses of technology, and to evaluate ways in which students were learning with technology. Since roughly half of the sections in the introductory writing sequence met in the computer classrooms for half their class meetings, the study compared computer- 
assisted classes to traditional classes and also allowed description of the activities in computerassisted classrooms.

The sections that met in the computer classrooms differed from the sections that met in traditional classrooms in significant ways. Computer-assisted sections had 23 students each, traditional sections 29 (based on the number of computers in the lab). The one piece of software bought specifically for writing classrooms was the Daedalus Integrated Writing Environment (DIWE), actually a suite of programs that offered a rudimentary word processor among other tools. That the computer-assisted classes were smaller than traditional classes and that different courses had access to computer rooms at different rates raised questions about the data generated by this research. It was possible, even probable, that some of the factors that appeared to be related to technology use were interrelated with factors stemming from the course curriculum or class size.

The researchers used the Current Student Inventory item bank to draft a questionnaire that was distributed to students in the three different writing courses: basic writing, first-year composition, and business and professional writing sections, taking account of the variety of times and places courses were scheduled: on and off campus, daytime, evening, and weekends. A total of 421 surveys were returned, divided more or less equally between computer-assisted and traditional sections.

Perhaps the most striking finding of this research effort was that there were very few significant differences between computer-assisted sections and traditional sections_-in students, overall faculty effort, and teaching and learning practices. On the whole, students in both sections reported great satisfaction with their courses and their teachers. Students in both 
sections reported remarkably similar relationships with technology: equivalent measures of technological expertise. There were similar overall GPAs, and neither group was inclined toward technology anxiety. They reported remarkably similar learning practices, that they were likely to review additional readings outside of class, revise assignments, study with other students, help other students with class assignments, and communicate with their instructors about their coursework. They spent about the same amount of time revising their work.

This similarity in survey results mirrored the perceptions of instructors, who had never reported noticeable differences between students in computer-assisted classes and traditional ones. Why? When students register for required courses like composition, they either do not or may not know the instructor when they are signing up, thus appear to sign up randomly or perhaps by time preferences. In class, students pursued the same curriculum. The department's writing curriculum emphasized conversation and collaboration, so they were not surprised to see these activities reflected in students' reports of how they spent their time out of class each week.

On the other hand, the Current Student Inventory questionnaire revealed three ways in which students in computer-assisted classrooms differed from their counterparts in traditional classrooms:

1. Students in computer sections reported that because their course required the use of electronic communication, they were more likely to put thought into their comments (this difference was statistically significant at the .05 level).

2. However, they were less likely to think that writing assignments encouraged their creativity. This finding was not statistically significant (.08) but was of concern because of the importance of creativity in a writing class. 
3. Students in the computer-assisted sections were more likely to feel that, compared to courses which did not require technology, they wasted time sorting through their email to find important messages (significant at .03), and more likely to feel that they spent too much time learning about technology (significant at .05).

Those students with low technological skills differed from their peers in terms of computer access. They were much less likely to own or use a computer. More distressingly, their GPAs tended to be lower, another sign that they may have been at relative academic risk. These students consistently reported that they were disadvantaged because of their low skills, the time spent learning the technology, and their poor levels of access to technology (all of these findings were significant at the .00 level).

Critical computer literacy: Computers in first-year composition as topic and environment. In a qualitative study concerning how the technological tools they use affected students' attitudes, Duffelmeyer (2000) addressed how first-year students understand the influence of computers by using cultural assumptions about technology. Duffelmeyer wanted to know the extent to which students in first-year composition support, challenge, or even demonstrate an awareness of prevailing discourses about technology. The results suggested clear implications for how computers and composition scholars incorporate computer technology into the pedagogy if one of the goals is to help students develop critical computer literacy.

Duffelmeyer defined critical literacy as an awareness of the forces that affect the microand macro-level conditions within which we acquire literacy and of how we view the uses and meaning of literacy. Critical ethnography attempts to provide clearer images of the larger picture of which we are a part. 
The study was conducted using a sample of 140 first-year composition students during one full academic year in the late 1990s at a large (25,000 students) Midwestern, land-grant university. Of the sample, $87 \%$ were white, and $78 \%$ from the state. Males comprised $57 \%$ of the sample. These demographics were reflected in 6 sections of first-year composition used for the study, conducted in computer-intensive sections of the second course of composition, which focuses on argument. The class met every session in a computer lab rather than in a traditional classroom. They were asked to write a technology narrative, recounting and reflecting on their defining and foundational experiences with computer technology.

Of the 140 students who completed the technology narrative, $37 \%$ could be described as being in the hegemonic ("comfortable oneness," sees and uses the text/technology primarily as it has been set in motion by unquestioned (perhaps unperceived) cultural forces) position; $11 \%$ in the oppositional (frustrated but resigned, understand the culturally accepted meanings of the text/technology, but deliberately choose an alternative perspective and are more comfortable with that than with the culturally approved hegemonic one); and 52\% in the negotiated position (tolerated ambiguity, although generally agreeing with the text's/technology's meanings on the abstract, macro-level, students may disagree with these meanings at an individual level based on contrary experiences or observations).

The computer as a medium of instruction in composition classes has largely received enthusiastic, almost utopian, praise in the classroom experiences its proponents detail and in the claims made about how the digital environment benefits student writing (Parr, 1993/94; Sadler, 1987). However, Duffelmeyer (2000) believed that computers are not neutral, transparent tools, as they are so easily and popularly assumed to be- that they do not unproblematically mediate 
between us and the tasks we undertake with them. Thus, she felt it is important for students and teachers alike to be able to think critically about the computer, since technology is a form of thinking that orients the person to approach the world in a particular way.

What happens when machines read our students' writing? As was Duffelmeyer (2000), Herrington and Moran (2001) were concerned about the ways in which the use of technological tools to write might shape not only the way we write but literally what we write, that we might begin to write to the machine. Their article detailed descriptions of two of the computerized writing evaluation programs, WritePlacer Plus and Intelligent Essay Assessor (IEA), and analyzed the claims made by their marketing people for their value to postsecondary education.

Each of the authors used one of the programs to respond to a topical prompt and had the program analyze and score/evaluate their responses. Herrington used Intellimetric, a component of WritePlacer Plus. She was told to "prepare a multi-paragraph writing sample of about 300600 words" in which she should "take a position on whether individuals are becoming more respectful of one another's differences." After rewriting twice (once seriously and once adding sarcasm and clichés) and receiving a "5" both times, she concluded that Intellimetric measured primarily length and mechanical conventions, such as syntax and fragments.

Moran used IEA and chose biology as his field. On the topic, "The Human Circulatory System," he earned a 4 of 6 . When he rewrote for a better score, heavily plagiarizing from another paper, he got a 3 and a "low confidence" comment when his piece was compared to the representative set of essays in the program used to evaluate his writing sample. He continued to play with the machine but without success, getting more negative comments. His fourth and further attempts, both at authorship and at plagiarism, brought him more $3 \mathrm{~s}$ but not a 4 or 5 , and 
he found himself not trying to explain what he knew to a human reader, but "trying to beat the machine."

The authors also had serious concerns about the potential effects of machine grading of student writing on teaching, on students' learning, and therefore, on the profession of English. For these authors, the final and overarching problem with these programs was that students were writing to a machine, not to human beings. They advocated the need to distinguish between writing on the machine and writing to the machine. To illustrate, they compared the use of email to the computer grader, noting that email is a highly personal medium, one in which people write on a computer to other people. The computer here mediated and facilitated communication between and among human beings. Writing to a machine, however, created what they saw as an unprecedented and unnatural rhetorical situation.

A synthesis of studies on computer-supported composition, revision, and quality. In 1992, Erickson wrote a synthesis of studies on computer-supported composition, revision, and quality. Erickson found that, as far as the learner was concerned, experience in the writing process itself was an important quality, and that learners brought writing style, including approach to composing, revision styles, proficiencies in keyboarding, eagerness for collaborative writing, and attitude toward writing, to the learning environment.

A total of 34 studies were cited, 12 of which involved college-level students, that compared and contrasted expert and novice writers use of revision (versus copy editing, mechanics). Results of studies were mixed. Findings were that, in general, the quality of compositions written on computers depended upon many variables, including writer experience using the writing process, writer maturity, instruction in the writing process, editing instruction, 
and time to become familiar with keyboarding and editing programs. Some of the studies' results were not encouraging: only four showed student improvements in quality of writing, only three showed more substantive revisions by students, five showed no differences in revisions among students, and two actually showed that students made fewer revisions.

Assessing the impact of computer-based writing instruction. Taking up where Erickson left off, Reed (1996) reviewed the research on computer use in the English language arts, predominantly writing, since 1987. The research was categorized into three groups: (1) word processing use only, (2) modified word processing use, and (3) composing process software. Fairly consistently, results favored older, more able students, especially those exposed to relatively lengthy treatments that were well grounded in appropriate theoretical frameworks.

Prior to and including 1987, general findings regarding computer-assisted instruction or skills software indicated that: students in a computer group performed better than those in a noncomputer group (4:1) in general reading skills, general language skills, general writing skills, and revision; effect sizes varied with age of group and length of treatment.

Post-1987 research focused less on isolated skills and was better grounded in research designs in theoretical frameworks; there were not so much experimental versus control groups as comparison of groups all receiving the same treatment to see how subgroups interacted with same treatment. Studies since 1987 have reflected lengthier treatments and much more pedagogically complex treatments or instruction. Research in writing evolved toward writing performance and processes. Now research has merged the Internet or earlier network systems and writing. 
In summary, computer-based writing research shared many of same features: (1) younger writers tended to perform at a less impressive level than older students, (2) lengthier treatments tended to produce more impressive results than briefer treatments, and (3) studies grounded in writing process theory produced desirable results. Despite the design flaws of early studies, they tested minimal design features and helped the evolution of computer-based writing research, and helped later researchers establish new beginning points.

Computer-assisted instruction. A year later, the main focus of Cotton's 1997 report was the most commonly used and most frequently researched kind of educational computer usecomputer-assisted instruction (CAI). Emerging from an analysis of 59 research reports, findings about other educational computer applications were presented as they related to this main focus. Each study or report documented some relationship(s) between computer-based learning and student outcome; 28 were research studies, 22 were reviews, and 9 were meta-analyses of research studies. Most involved American students. The 59 reports were concerned with the effects one or more of the following types of educational computer use has on student outcomes: computer-assisted instruction (CAI) (35), computer-based education (CBE) in general (15), the use of word processors for written composition (5), computer-managed instruction (3). Studies also focused on students' attitudes toward the content of courses in which computers were used (21), toward computers themselves (19), and toward the quality of instruction in courses with computer activities (4).

While both traditional and computer-based delivery systems had valuable roles in supporting instruction, they were of greatest value when complementing one another. As with the Parr (1993/94) and Sadler (1987) studies, positive outcomes included: longer written 
samples, greater variety of word usage, more variety of sentence structure, more accurate mechanics and spelling, more substantial revision, greater responsiveness to teacher and peer feedback, better understanding of the writing process, freedom from the problem of illegible handwriting, and better attitudes toward writing.

Student attitudes and academic background as predictors of achievement in college English. House and Prion (1998) conducted one of the few quantitative studies to research student attitudes to predict achievement in college English by investigating the predictive relationship between student attitudes and their subsequent achievement in a freshmen composition course.

The results of the study indicated that academic background and student attitudes were significantly correlated with subsequent grade performance in a freshman English course. Further, attitude variables were more closely related to overall grade performance than with satisfactory/unsatisfactory grade status. These findings were consistent with results from research on other types of general education courses.

The study used a sample of 257 students who began college during the same fall semester and took an introductory English course (Rhetoric and Composition) during their first year. There were $112(43.6 \%)$ male and 145 (56.4\%) female students. Further, the sample was composed of 17 (6.6\%) Hispanic students, 14 (5.4\%) Asian-American, 36 (14.0\%) AfricanAmerican, and 192 (70.8\%) White students. Ethnic information was not available for 8 (3.1\%) students in this sample.

Students were asked to complete a survey that assessed their attitudes and achievement expectancies (5 items), including writing ability. On these 5 items, students indicated themselves 
to be 1 of 5 ranks from lowest $10 \%$ to highest $10 \%$. Three items measured specific achievement expectancies (e.g., expecting to fail one or more courses, making at least a B average, and graduating with honors). For these items, students estimated their probability of these outcomes with one of four possibilities from no chance to very good chance. Two other predictor variables were included: ACT composite scores and the number of years of high school English taken by each student. Finally, the dependent measure was the grade earned in the Rhetoric and Composition course.

For the entire sample, ACT composite scores were found to be significantly correlated with English course grades. Significant positive correlations were obtained for three attitude variables (self ratings of overall academic ability, drive to achieve, and expectations of graduating with honors), indicating that students who had higher initial self-ratings on these variables subsequently earned higher grades in their freshman English course.

There was a significant negative correlation between expectations of failing one or more courses in college and English course grades. For male students, only one variable (self-ratings of overall academic ability) was significantly correlated with course grades. Two variables (ACT composite scores and self-ratings of overall academic ability) were significantly correlated with gender for females.

The results of this study indicated that academic background and attitude variables were significantly correlated with subsequent grade performance in a freshman English course. When the entire sample was considered, several specific attitude variables were predictive of achievement in freshman English; further, the overall multiple regression model was significant, indicating that the joint set of predictor variables explained a significant proportion of the total 
variance in freshman English grades. However the results of this study also indicated that attitude variables were not significant predictors of whether or not students earned a passing grade in their freshmen English course. Consequently, attitude variables were more closely related to overall grade performance than with satisfactory/unsatisfactory grade status.

There were several limitations of the study. First, only traditional aged students were included in this analysis. Earlier research findings have indicated that adult learners often have different educational objectives and employ different learning strategies than younger students. A second limitation of the study was that students from only one institution were included. Further research with students at other types of colleges and universities would enhance the generalizability of these findings. A third limitation of this study is that insufficient numbers of minority students were in this sample to allow meaningful analyses to be made for each student ethnic group.

Although they acknowledged the study's weaknesses, the authors believed the results of this study indicated that student attitudes were significant predictors of achievement in an English course taken during the first year of college. These results suggested that instructional designers should give consideration to initial attitudes when evaluating factors that predict academic success.

Summary. Overall, the study of computer-assisted composition (CAC) has included meta-analyses or reports, qualitative and quantitative research methods, and sometimes a combination of one or more methods. Whatever the method used, researchers came to several common conclusions. First, because of advancement of the technology, its increasing use in educational settings, and previous mixed results, they saw the need for further research, 
particularly quantitative (Eldred \& Hawisher, 1995; Erickson, 1992; Hawisher, 1989; Herrington \& Moran, 2001; Selfe, 1999; Sullivan \& Porter, 1997).

Several studies showed that, when computers are used to write, students had a more positive attitude toward writing and revising (Cotton, 1997; Hawisher, 1989; Parr, 1994/95; Sadler, 1987). In fact, House and Prion (1998) concluded that student attitudes were significant predictors of achievement in an English course taken during the first year of college. Others revealed that use of computers, specifically word processors, facilitates the writing process. Students tended to write longer and higher quality papers with the aid of computers, although they cautioned that quality depended on many variables (Cotton, 1997; Erickson, 1992; Hawisher, 1989; Parr, 1994/95; Sadler, 1987).

Researchers also urged further study of the use of computers to write, fearing that both teachers and students are not aware or critical enough of how the technological tool may shape their thinking or writing (Duffelmeyer, 2000; Eldred \& Hawisher, 1995; Herrington \& Moran, 2001). Technological literacy depends on access to and practice with the technology, and researchers pointed out that certain students (including ethnic minorities and those of relatively low socio-economic status) might be at academic risk because they lack access to computers (Harrington, 2000; Selfe, 1999).

When the traditional classroom was compared with computer-based or computerenhanced instruction, studies showed that both students and teachers are influenced by the technology (Harrington, 2000). However, there were very few significant differences between the computer-assisted and traditional classes in the students, overall faculty effort, and teaching and learning practices. Harrington pointed out that there are other possible influences of course 
curriculum or class size in addition to or instead of the technology. Cotton (1997) found that computer-based and traditional delivery methods are both valuable, but are of greatest value when they complement each other. These studies involving writing with computers took the research several steps forward, moving from isolated skills to performance and process then merging with research of use of the Internet or earlier network systems and writing (Reed, 1996). Measurement of Students' Attitude Toward Educational Use of the Internet (ATEUI)

Although numerous variations of computer attitude scales were designed, tested, and validated during the mid-to-late 1980 s and into the early 1990 s, these scales did not measure student attitudes toward more sophisticated and complex computer applications and environments, such as the World Wide Web (WWW) or the Internet. Results of the three studies most pertinent here are summarized in Table 5 (below).

Information technology and education: Student perceptions of computer and Web-based environments. Liaw's (2000) study focused on attitudes toward computers and Web-based technology. It also examined the relationship between students' perceptions of computer and Web-based environments. According to Liaw, a Web-based environment is a hypermedia-based environment that may create potential learning advantages, for example, interactive opportunities for learners and teachers. A psychometric questionnaire/survey was administered, using what Liaw called the Computer and Web-based Attitude Scale (CWAS), a combination of two other scales, the Computer Attitude Scale (CAS) and the Web-based Attitude Scale (WAS). Liaw (2000) felt that learners' perceptions of computers, hypermedia, and Web-based technologies were a crucial factor influencing and affecting learning and learning outcomes; thus, he believed that attitude and behavior were related. He also believed that the success of 
Table 5

Research Summary for Measurement of Students' Attitude Toward Educational Use of the Internet

Study

Findings

Liaw

(2000)

Information technology and education: Student perceptions of computer and Web-based environments

Duggan et al.

(2001)

Measuring students' attitude toward educational use of the Internet

Sanders \& Morrison-Shetlar (2001)

Student attitudes toward Web-
Focused on attitudes toward computers and Web-based environments, and examined the relationships between students' perceptions of computer and Web-based environments. Study developed the CWAS, a combination of the Computer Attitude Scale (CAS) and the Computer and Web-based Attitude Scale (WAS). Correlation between the two scales was $.81(\underline{p}=.000)$. Computer experience correlated significantly with both the CAS and the WAS. A t-test revealed significant gender differences on both scales, with male students having more positive attitudes toward computers and the Internet/WWW than females. There was no significant difference in attitude for majors of study.

Developed the Attitude Toward Educational Use of the Internet (ATEUI) scale and the Behavioral Correlates to measure attitudes specific to use of the Internet for Questionnaire educational purposes and to study selected behavioral correlates. Cronbach's alpha measured at .91. Students' attitudes were generally positive. Frequencies, descriptive statistics, and results of a one-way ANOVA showed that favorable attitudes were associated with several corresponding behaviors, such as keeping track of valuable educational Internet sites. The study found that using multiple instructional methods to learn the Internet was associated with more favorable attitudes. No gender differences were found; neither year in school nor selfreported grade point average showed significant differences.

Examined undergraduate students' attitudes toward introduction of a Web component into a general biology course. The Web-based Instruction Attitude Scale was developed 
Table 5 (continued)

Study

Findings

enhanced instruction in an introductory biology course to assess participants' attitude toward Web-enhanced instruction. Student attitudes toward Web-based instruction were generally positive. A one-way ANOVA revealed a significant different in attitudes between the genders; females' attitude was significantly more positive than males'. No significant difference was found for age, race/ethnicity, year in school, learning style, or computer experience.

computer utilization is largely dependent upon the faculty's and students' attitudes toward computers. Most previous studies had focused on computer attitudes analyses or Web-based attitudes analyses. Because these two educational technologies have high correlation, Liaw (2000) believed it was necessary to detect the relationship between these two learning environments by integrating attitudinal surveys for each technology. Thus the study surveyed and evaluated students' computer and Web-based attitudes to enhance the success of computer technology use, especially hypermedia-based environments that integrated the Internet and WWW in educational systems.

The research was designed to find out: (1) the relationship between the CAS and WAS, (2) the relationship between computer experience and the CWAS, (3) any significant gender difference in the CWAS, (4) significant differences between majors of study and years of computer-related experience on the CWAS, and (5) predictor variables of various computer experiences to the CWAS. The study developed the CWAS, consisting of three major components: (1) demographic information and computer and Web-based experiences; (2) the 
CAS, 16 questions representing four components of computer attitudes, confidence, liking, usefulness, and learning; and (3) the WAS, 16 questions presenting the same four components except toward Web-based attitudes.

A 7-point Likert-type instrument with anchors from 1 (strongly disagree) to 7 (strongly agree) was used to survey 809 Seattle Pacific University students who were contacted via their email accounts. Data analysis included three parts: descriptive statistics (means and standard deviations), instrument statistics, and inferential procedures. The CAS and WAS produced Cronbach's alpha reliability coefficients of .91 and .93 , respectively. Calculation of the relationship between the CAS and the WAS resulted in a Pearson correlation coefficient of $\underline{r}=$ $.81, \mathrm{p}=.000$. Various computer experiences correlated significantly with both the CAS and the WAS, $\underline{p}<.01$. Results of a t-test revealed significant gender differences on both scales: on the CAS, $\underline{\mathrm{t}}(258)=2.62, \underline{\mathrm{p}}=.009$, and on the WAS, $\underline{\mathrm{t}}(258)=3.42, \underline{\mathrm{p}}=.001$, with male students having more positive attitudes toward computers and the Internet/WWW than female students. There was no statistically significant difference in attitude for majors of study.

A stepwise regression analysis was performed to check the effect of computer experience on the two scales. The results showed that categorized experience, years of computer-related experience, and experience using word processing programs were three predictors on the CAS $\left(\underline{F}(3,256)=70.50, \underline{p}=.000, \underline{\mathrm{R}}^{2}=.45\right)$. For the WAS, only years of computer-related experience and experience using word processing programs were predictors $\left(\underline{F}(2,257)=89.94, \underline{p}=.000, \underline{R}^{2}\right.$ $=.41)$.

Nearly $97 \%$ of the sample were undergraduate students; of 260 respondents, 109 selected 6 years or more computer-related experience, and only 7 chose 6 months or less. Thus it 
appeared that the more computer-related experience individuals had, the more willing they were to answer the Internet survey. The study supported the assumption that the individuals who had more experiences with computers have more positive attitudes toward hypermedia or Web-based technologies.

Application of the study's findings had certain limitations. Respondents were skewed in distribution by years of computer-related experience, perhaps a crucial limitation of the Internet or WWW survey. It could be supposed that when individuals had more positive feelings toward computers they were more willing to answer the survey. Another limitation was the confidence issue. To maintain respondent confidentiality, identification statuses were not examined by use of passwords or other access keys, so there may have been duplicate responses by a single respondent.

Student attitudes toward Web-enhanced instruction in an introductory biology course. Sanders and Morrison-Shetlar (2001) examined student attitudes toward the introduction of a Web component into a general biology course for undergraduate nonmajors at a midsized rural university. The Web component primarily allowed asynchronous learning outside the classroom and increased student-to-student interaction.

Because student attitudes toward computers were important in influencing the future use of computers in instructional settings, many attempts have been made to assess students' overall attitude toward computers. Gender, race/ethnicity, age, and prior computer experience were some of the factors found to influence computer attitude. Likewise, student attitudes toward the Web and Web-based instruction can influence future use of instructional materials provided on 
the Web and could ultimately affect how educationally beneficial Web-based resources were for students in a learning environment.

Although there have been several studies that focused on the relationship between student attitudes and individual characteristics, most concentrated on attitudes toward computers in general, as opposed to Web-enhanced instruction. This study sought to determine the attitudes of college students in an introductory biology course toward using Web-enhanced instruction through a Web-based instructional program called Web Course Tools. Therefore, the question addressed was, "What is the relationship, if any, of student attitudes toward Web-enhanced instruction and the sex, race/ethnicity, age, year in school, computer experience, and learning style of the students?"

Participants were 110 students enrolled in a general biology course for nonmajors at a midsized rural university. The majority of the students participating in the study were female, White, between the ages of 18 and 19, and in their freshman year of college. Most students reported having a moderate amount of computer experience.

The Web-Based Instruction Attitude Scale was developed by the researchers to assess participants' attitudes toward Web-enhanced instruction. It consisted of 19 questions and was found to have a reliability coefficient of .78. Of the 19 questions, 12 used a Likert-type response scale with anchors from 1 to 4, asking participants for a range of opinion from strongly agree (4) to strongly disagree (1). The lowest possible student attitude score was 12 , and the highest possible score was 48; a higher score signified a more positive attitude toward Web-based instruction. Attitude scores for each question were summed to compute a total attitude score for each student. 
Student attitudes toward Web-based instruction were generally positive. The mean attitude score was 35.04 with a standard deviation of 4.85 . The attitude scores in this study ranged from 24 to 46 , with $57.8 \%$ of the respondents having an attitude score of 35 or higher.

A one-way analysis of variance (ANOVA) was performed to determine if differences in attitudes toward Web-enhanced instruction existed between males and females. At the .05 level of significance, a difference was found when comparing sex and student attitude toward Webenhanced instruction, $\underline{\mathrm{F}}(1,107)=9.91, \underline{\mathrm{p}}=.002$ with females $(\underline{\mathrm{M}}=36.09$, $\underline{\mathrm{SD}}=4.86)$ being significantly more positive toward Web-based instruction than males $(\underline{\mathrm{M}}=33.15, \underline{\mathrm{SD}}=4.28)$.

Initially, a significant difference between age and student attitude toward Web-enhanced instruction based on age categories was detected, but further analysis was needed to determine where the differences lay. When age groups were combined and recategorized as $<20$ and $>20$, no significant difference in attitude was found at the .05 level of significance, $\underline{F}(1,107)=3.46, \underline{p}$ $=.066$. Likewise, student attitude toward Web-enhanced instruction was found to have no significant relationship with race/ethnicity, $\underline{\mathrm{F}}(4,104)=.27, \underline{\mathrm{p}}=.898$; year in school, $\underline{\mathrm{F}}(4,104)=$ $.31, \underline{p}=.871$; learning style, $\underline{F}(6,100)=1.25, \underline{p}=.288$; or computer experience, $\underline{F}(3,105)=2.60$, $\mathrm{p}=.056$.

In this study, females were found to have a more positive attitude toward Web-enhanced instruction than males. These findings contrasted with those of other studies that have examined the relationship between sex and student attitudes toward computers in general. This study found no significant relationship between attitude and the college student's year in school, an anticipated result based on similar findings among year categories. This contradicted one study conducted by Liu and Reed (1992) where students in year 1 were found to have significantly 
more computer anxiety than those in Years 2, 3, or 4. Likewise, in this study, the fact that $98 \%$ of the students taking the biology course reported having at least some degree of computer experience can be most likely attributed to the consistency of attitude among most of the groups analyzed. It further supported the belief that students are increasingly more exposed to computers both before and during their college careers.

Based on the results of the study, the authors felt that today's students, traditional and nontraditional aged, are gaining more computer experience and knowledge through increased computer exposure at school and work. They believed that students, as a whole, are much more computer savvy today than even a few years ago. They also predicted that as the gap between levels of computer experience becomes smaller and smaller among students, improvement in student attitudes toward Web-based instruction will be observed.

Measuring students' attitude toward educational use of the Internet. Where Liaw (2000) and Sanders and Morrison-Shetlar (2001) studied attitude toward Web-enhanced instruction, Duggan, Hess, Morgan, Kim, and Wilson (2001) developed the Attitude Toward Educational Use of the Internet (ATEUI) scale, measuring attitudes specific to use of the Internet for educational purposes. Reiterating Sanders and Morrison-Shetlar's (2001) findings, Duggan et al. (2001) suggested that attitudes toward computers as well as computer-related behaviors have changed drastically over the last decade. Moreover, previous scales did not measure affect for use of the Internet, and, according to the authors, the ATEUI was the first instrument of its kind.

Like Sanders and Morrison-Shetlar (2001), Duggan et al. (2001) pointed out that previous research provides a background for understanding the evolution of Internet use and the inclusion of Internet-related classroom instruction and exercises, but student attitudes toward the Internet 
for education had not been researched. Moreover, student attitudes were expected to vary with regard to experience and Internet-related behaviors, but such behavioral correlates had not yet been described as a result of systematic research. Their study set out to (a) develop an instrument that would measure student attitudes toward educational uses of the Internet, and (b) study some selected behavioral correlates of those attitudes.

Similar to the methods proposed by Thurstone and Chave (1929), Gable (1986), and Gable and Wolf(1993), the development of the ATEUI scale included five steps: (1) generating an initial pool of statements, (2) determining the scalability of statements, (3) operationalizing statements, (4) assessing initial student reactions based on a 5-point scale, and (5) evaluating student attitudes about the affective component of using the Internet for educational purposes. Students enrolled in various communications and health promotion classes at a large Southeastern university were used to construct the scale by completing some form of the questionnaire $(\underline{\mathrm{N}}=395)$, and the final form was administered to 188 participants, including 67 males and 113 females (eight did not respond to the gender item). The 18-item scale contained six each of positive, neutral, and negative items. Internal consistency of the final form, as measured by Cronbach's Alpha, was found to be .91. Students' attitudes were generally positive; means ranged from 2.58 to 4.08 on the 5-point scale. Editing for duplication, redundancy, item phrasing, and development yielded 11 behaviors included with the ATEUI in the final form of the questionnaire.

Frequencies, descriptive statistics, and results of a one-way ANOVA were reported. Eight of the 11 behavioral correlate items yielded statistically significant results. For example, favorable attitudes were associated with: (1) keeping track of valuable educational Internet sites; 
(2) sharing educational information found on the Internet with friends; (3) choosing classes that require Internet use; (4) greater frequency of Internet use, both in general and for educational purposes; (5) greater number of reasons for using the Internet for education; and (6) greater number of Internet features used.

The study found that using multiple instructional methods to learn the Internet was associated with more favorable attitudes, with self-taught, followed by friends/colleagues and class instruction, being the most popular instructional method used by students. Attitudes were more positive when students said they use the Internet for any one specific purpose. Although slightly more than half of the students in the sample reported ownership of a computer, there was no difference in attitude toward using the Internet for education between those who owned a computer and those who did not. Nor was there a difference in attitude between students who were connected to the Internet and those who were not. Unlike the Liaw (2000) and the Sanders and Morrison-Shetlar (2001) studies, Duggan et al. (2001) found no gender differences for any of the behavioral correlate items or for general attitudes toward educational use of the Internet, suggesting to the authors a progression from the expectations of male use of computers in the 1980s, as well as the prevalence of computer use among both male and female college students. Consistent with the previous studies, year in school did not show significant differences.

The authors suggested that future research expand these findings and explore whether more favorable attitudes motivate one to "search out" courses in which instructors have chosen to implement Internet technology. Class year produced no differences in attitude, nor was the attitude related to self-reported grade point average. Since one might expect that attitude becomes more (or less) favorable as one progresses from the freshman to the senior year of 
college, future research may want to examine the developmental and educational point where a student acquires a specific attitude. Finally, the authors felt that future research using the ATEUI should gather more information concerning other potential correlates of the attitude.

Summary. The three studies reviewed here revealed similar results as far as students' attitudes toward Web-based courses or use of the Internet for educational purposes, that is, students' attitudes were generally positive. Demographic variables, such as age, year in school, ethnicity, and major of study were not statistically significant. However, gender was significant for two of the studies, but in different ways. One study found that females had a significantly more positive attitude toward using Web-based instruction (Sanders \& Morrison-Shetlar, 2001), and one found that males' attitude was significantly more positive (Liaw, 2000). The Duggan et al. (2001) study found no significance for gender.

As previous research had found, the Liaw (2000) and Duggan et al. (2001) studies supported the assumption that the individual who had more experience with computers had a more positive attitude toward hypermedia and Web-based technology. In contrast, the Sanders and Morrison-Shetlar study (2001) found that experience was not significantly related to attitude, nor was learning style.

These studies were among the very first to measure attitude toward Web-based instruction and use of the Internet in an educational setting, and how attitude is related to behavior. They form a foundation upon which future research can be built. Non-traditional Aged Students Compared to Traditional Aged Students

In the 1970s, higher education saw an influx of adult students returning to school for various reasons (Bowden \& Merritt, 1995). Adults were the fastest growing segment of all the 
population groups in higher education. That trend continued; now predictions are that, given the smaller number of high school graduates, the pool of traditional aged students will shrink, and institutions will actively recruit adult students.

Studies have examined the dynamic of the non-traditional aged student by identifying traits of the older learner (Bishop-Clark \& Lynch, 1998; Bowden \& Merritt, 1995; Justice, 1997; Wagschal, 1997), their motivation to learn and how they learn (Donaldson, 1999; Justice, 1997; Kasworm, 1990), discussing how their presence changes the classroom environment (BishopClark \& Lynch, 1998; Bowden \& Merritt, 1995; Darkenwald \& Novak, 1997; Wagschal, 1997) and how it affects classroom learning (Darkenwald \& Novak, 1997). Researchers have examined how interactions between non-traditional aged students and instructors affect the students' attitude and course performance (Rosenthal, Folse, Alleman, Boudreaux, Soper, \& Von Bergen, 2000), and have compared them to traditional aged students in academic environments (Bishop-Clark \& Lynch, 1998; Bowden \& Merritt, 1995; Darkenwald \& Novak, 1997; Donaldson, 1999; Graham \& Donaldson, 1999; Justice, 1997; Kasworm, 1990; Rosenthal et al., 2000; Wagschal, 1997). A summary for the research in traditional versus non-traditional students is contained in Table 6 (below).

I became clueless teaching the GenXers: Redefining the profile of the adult learner. As far as non-traditional aged students are concerned, there are at least two distinct generations - the Baby Boomers and Generation Xers (Wagschal, 1997). They have different life experiences, different cultural expectations, ambitions, learning styles, and attitudes.

Wagschal (1997) pointed to the complex profile of adult learners. The descriptive account of the author's experiences teaching adults focused on the difficulties encountered by the 
author in addressing the lifestyles of both generations (Boomers and Xers). Like other researchers and teachers, Wagschal held the view that adult learners are highly motivated but overly concerned with grades, so was particularly interested in methods with which adult learners learn best. The author realized that the previously accurate profile of the adult learner had changed; there were at least two generations of adult students in her class: Boomers (born between 1943 and 1960) and Xers (those born between 1961 and 1981).

Wagschal pointed out that adult learners are typically over-concerned with grades. Often, adult learners will actually say, "Tell me what to do to get an 'A' and I will do it." Despite their enthusiasm for learning, they have a lot of anxiety about returning to school. They willingly meet the challenge of high expectations set by the instructor, but they are concerned and need to be reassured that they are going in the right direction and that they clearly understand what is expected of them.

For the first time in the history of our country, the educational skills of one generation will not surpass, will not equal, will not even approach, those of their parents. Wagschal found that, although the Boomers accepted high expectations and stressed over their grades, the Xers complained about how much work needed to be done.

Adult learners learn best when their wealth of personal experience can be tied to the subject matter, but the experience of the Xers and Boomers is not the same. Adult learners find learning most meaningful when they can make a direct connection between their past experiences and their current concerns.

The adult learner challenge: Institutionally and administratively. Bowden and Merritt (1995) examined the instructional and administrative challenge of adult learners and how 
Table 6

Research Summary for Traditional Versus Non-traditional Students

Study

Bowden \& Merritt

(1995)

The adult learner challenge:

institutionally and

administratively

House \& Keeley

(1996)

Differential prediction of adult student performance from

Miller Analogies Test (MAT)

scores

Darkenwald \& Novak

(1997)

Classroom age composition

and academic achievement

in college

Justice

(1997)

Facilitating adult learning

in a liberal education context

Wagschal

(1997)

I became clueless teaching the

Gen Xers: Redefining the profile

of the adult learner
Findings

Outlined characteristics of adult learners: much life experience, busy, seeks useful information, motivated, goal oriented. Discussed how colleges and universities can make higher education attractive to the adult learner ( 25 or older). Instructionally, a participative style of information sharing is most effective.

Studied how well admissions test scores predict subsequent achievement outcomes for graduate students. Significant differences between age groups. MAT scores over predicted grades of younger (25-34) and oldest (45+) groups, and under predicted middle group (35-44). Thus, MAT scores do not predict subsequent grade performance similarly for all adult graduate students.

Researched how the presence of adult students (over 25) in colleges and universities affects classroom learning. Tentative support for the postulate that, controlling for student age, the greater the proportion of adults in a classroom, the higher the aggregate average performance of the class as measured by class grades.

Profiled older adult student, what the adult brings to learning: habit of learning, motivations, generative capacity.

Discussion of difficulties encountered in addressing the lifestyles/life experiences of both Generation Xers and Baby Boomers. Previous profile of the adult learner has changed. View that adult learners are highly motivated and overly concerned with grades, among other characteristics, including the differences between the two generations of adult students. 
Table 6 (continued)

Study $\quad$ Findings

Bishop-Clark \& Lynch

(1998)

Comparing teacher and

student responses to the mixed age college classroom

Donaldson

(1999)

A model of college outcomes

for adults

Graham \& Donaldson

(1999)

Adult students' academic and intellectual development in college
Investigated similarities and differences in student and faculty attitudes toward age diversity in several areas: student/professor relationships, the mixed age classroom, and attitudes toward younger students. Faculty and both traditional and non-traditional students hold some negative perceptions regarding younger students. The general atmosphere conveyed in focus group discussion was appreciation of older students.

Presented a model of college outcomes for adult undergraduate students to address the key elements that affect their learning to stimulate research and theory building about adults' experience in college. Considered the relationship between 6 major elements related to adults' undergraduate collegiate experiences: (1) prior experiences, (2) orienting frameworks such as motivation, (3) adults' cognition or the declarative, procedural, and self regulating knowledge structures and processes, (4) the connecting classroom as the central avenue for social engagement and for negotiating meaning for learning, (5) the life-world environment and concurrent work, family, and community settings, and (6) the different types and levels of learning outcomes experience by adults. Conclusion: Adults tend to do as well as or better than traditional aged students.

Investigated the effects of college on the intellectual and academic development of adult students and compares their growth to more traditional-aged students who are likely to have different levels of campus involvement. Significant differences in variables in involvement outside the classroom: adults are less involved in college clubs and organizations, less involved in college sponsored events, much higher rates in caring for family. Most significant finding was that even though adults' involvement in on- and off-campus activities was markedly different than younger students, their reported 
Table 6 (continued)

\begin{tabular}{ll}
\hline \multicolumn{1}{c}{ Study } & \multicolumn{1}{c}{ Findings } \\
\hline & $\begin{array}{l}\text { growth was equal to or greater than the younger students } \\
\text { across } 26 \text { areas of academic and intellectual development. }\end{array}$ \\
& $\begin{array}{l}\text { Readministration and revision of a previous survey of } \\
\text { closed-ended and narrative items. Twofold purpose: }\end{array}$ \\
$\begin{array}{l}\text { Rosenthal et al. } \\
\text { The one-to-one survey: }\end{array}$ & $\begin{array}{l}\text { interactions affect their performance in a course and } \\
\text { Traditional versus non- } \\
\text { traditional student satisfaction } \\
\text { with professors during one-to- } \\
\text { one contacts }\end{array}$ \\
$\begin{array}{l}\text { responses of a sample of non-traditional students (26+, } \\
\text { and/or married, and/or with children) to a sample of } \\
\text { traditional students. Results: the two groups did not differ } \\
\text { significantly in their tendencies to initiate one-to-one } \\
\text { interactions, nor was either group more satisfied with their } \\
\text { interactions with faculty. They did not differ to the extent } \\
\text { that they felt a positive interaction affected course } \\
\text { performance. }\end{array}$
\end{tabular}

colleges and universities can make higher education attractive to them. The authors urged those involved in adult learning to consider four things about them—age, needs, desires, and goals. Traditionally, general education, e.g., a core curriculum, was directed at the 18 -year-old college freshman. When the college-age population dropped dramatically in the late 1970s and into the 1980s, many schools turned to adult education as the means to support the college or university. The authors noted that the age of the learners in the classroom is a major adjustment for any college professor; for instance, he or she can no longer command attention by being the oldest in the classroom. Along with the age comes experience, and most of the students in an adult learning program have much practical experience. 
Comparing teacher and student responses to the mixed-aged college classroom. Bishop-

Clark and Lynch (1998) agreed, noting that college educators continue to find an increasing number of students over age 25 in their classrooms. Faculty and students alike have reported that age heterogeneity creates a unique atmosphere for learning. Some research has focused on identifying traits of the older student; whereas, other works described the similarities and differences between the returning non-traditional student and the younger student population.

This paper reported select results of a three-year study of students and faculty at two branch campuses of a medium-sized Midwestern university with a high non-traditional aged (>25) student population. The research investigated similarities and differences in student and faculty attitudes toward age diversity in several areas. Three themes guided the study: studentprofessor relationships, the mixed-age classroom, and attitudes toward younger students.

Faculty and students from two branch campuses were interviewed. The branch campuses were open admission and therefore attracted a diverse student body. Many students were older and had been working for many years; still other students had just completed high school. In short, the students varied tremendously in their motivations, aptitudes, and age.

The study used focus groups and interviews with students to construct a student questionnaire. The researchers subsequently selected a random sample of 320 students from those enrolled in two branch campuses. The survey included 73, 5-point Likert-type questions, 4 open-ended questions, and 20 demographic questions.

This method was used to construct a similar faculty questionnaire of 64, 5-point Likerttype questions and 7 open-ended questions. When appropriate, the questions on the faculty instrument were exactly the same as those on the student instrument. 
Professors reported that older students "make class meaningful," that they were "more interested in learning for the sake of learning," and that they were "willing to challenge the instructor." Professors reflected a frustration with the behavior of the younger student who "misses class," "does not take learning seriously," and "is disruptive."

Characteristics of the younger students included a greater willingness to engage in philosophical discussions and those that do not have an immediate practical impact. These students seemed not as preoccupied by grades. However, the professors felt they were less serious about class work and "demand more patience"; they have been "coddled in high school." According to the survey, younger students were more disrespectful and disruptive in class, indicating a less serious attitude about the classroom.

It appeared that faculty and both traditional and non-traditional aged students hold some negative perceptions regarding younger students. The general atmosphere conveyed in focus group discussions was appreciation of older students, but all groups overwhelmingly agreed that they liked the mixed-age classroom, and almost all agreed that having students of different ages helped students see different perspectives.

The one-to-one survey: Traditional versus non-traditional student satisfaction with professors during one-to-one contacts. As students increasingly use computers for course work or to interact electronically with instructors in addition to the traditional classroom setting, it becomes important to investigate how these and other interactions between students and instructors may affect the students' attitudes and course performance, among other factors. Rosenthal et al. (2000) conducted a survey to study not only student satisfaction with professors during one-to-one contacts, but also to compare/contrast traditional and non-traditional students. 
The study examined "real interactions" rather than "imagined or idealized relationships." It argued that student-faculty "interactions” were more frequent than student-faculty "relationships" and that research should focus on the least positive interaction as well as the most positive a student experienced. Finally, the survey stressed that the interactions be one-to-one (personal), thus minimizing the effects of in-class factors on the survey variables.

The survey instrument utilized both closed-ended and narrative items. Its purpose was twofold. First, to determine if students felt that one-to-one interactions affected their performance in the course and evaluation or the professor. Second, to compare the responses of a sample of non-traditional students (NTS) to a sample of traditional students (TS). Nontraditional students were defined as students over 25 years old, and/or married, and/or with children.

The study used 193 undergraduate students enrolled at a small southern university, including 28\% freshmen, 38\% sophomores, 20\% juniors, and 14\% seniors; their ages ranged from 17 to $70(\underline{\mathrm{M}}=24.7, \underline{\mathrm{SD}}=8.4)$. The non-traditional subsample of 77 students $(14$ males and 63 females) ranged in age from 19 to $70(\underline{\mathrm{M}}=32.7, \underline{\mathrm{SD}}=8.2)$. The traditional subsample included 116 students (46 males, 70 females), ranging in age from 17 to $24(\underline{\mathrm{M}}=19.5, \underline{\mathrm{SD}}=1.5)$.

When the two groups were compared using an independent t-test, NTS and TS did not differ significantly in their tendencies to initiate one-to-one interactions. Nor was either group more satisfied with their one-to-one interactions with all faculty.

NTS and TS did not differ to the extent that they felt a positive or negative interaction affected their course performance, nor to the extent that a positive or negative interaction 
affected their student evaluations of the professor. Hence, the two groups may be more similar than has been assumed at least with regard to faculty interaction variables.

Another study focused on classroom age composition and academic achievement in college; in 1997 Darkenwald and Novak specifically examined how the presence of adult students in colleges and universities affects classroom learning.

The researchers postulated that, controlling for student age, the greater the proportion of adults in a classroom, the higher the aggregate average performance of the class as measured by class grades. The hypothesis was tested in two very different settings: a suburban community college and a nearby large, public research university. Data for 2,794 subjects were obtained from official records. The findings from the community college sample strongly supported the predicted relationship; at the university, a modified hypothesis that excluded performance in math classes was also supported.

Classroom age composition and academic achievement in college. In their work with the community college, Darkenwald and Novak (1997) selected a sample from 44 randomly selected evening and Saturday morning credit classes offered on campus and at five high school sites. The 619 students were taught by 30 instructors; 53\% were women, $74 \%$ employed full-time, $84 \%$ white, $85 \%$ high school graduates or had attended college previously, and $13 \%$ were college graduates. Background data and end-of-course grades were obtained from records.

Factor 1 (age) was a control variable trichotomized into pre-adult (23 or younger), young adult (24-29), and mature adult (30+). Factor 2 was class age composition. Course grade means aggregated by class age composition categories were the dependent measures. 
Data were analyzed using a $3 \times 3$ factorial analysis of variance with the Scheffé test for mean contrasts. As hypothesized, only class age composition predicted class grade, explaining $25 \%$ of the variance. Regardless of student age, those students enrolled in predominantly adult classes earned the highest grade. The reverse was also true. There were no differences in performance as a function of course subject matter.

Results at the university differed greatly from the community college. On average, adults over 25 at this university and at similar institutions performed as well as better prepared young students, and some adult subgroups performed far better (e.g., women over 30). Of a total of 2,175 students, 84 classes had adult enrollment of $39 \%$ over age $24 ; 54 \%$ were female.

To test a modified "except for math" version of the age composition hypothesis, all 22 math courses were dropped from the analysis, which reduced the high adult enrollment courses by nearly a third. To compensate for this problem, an alternative, two-step ANOVA design was substituted for the $3 \times 3$ MANOVA. Test of the hypothesis that chronological age and academic performance were positively associated indicated no relationship; however, there was a significant effect for class age composition on student grades. A linear increase was found in course grades in the direction hypothesized, and a Scheffé test showed significant differences among the three group means. The differences in grades by class age composition were not as large as those observed in the community college setting.

Cross-breaks of grades by class age composition, age category, and gender showed that, except in math, women over 30 outperformed men in every age category, and that traditional age (under 24) students did in fact earn better grades in classes with 50\% or more adult enrollment. Adults also performed better in the high adult enrollment classes, especially those over age 30 . 
The findings provided tentative support of the proposition that academic performance in college is enhanced as the proportion of adults to young people increases in the classroom. In the university environment, mathematics classes proved to be a decided exception. These classes were heavily populated by adult students, mostly women, who were under prepared and encountered greater difficulty, especially in remedial algebra.

Adults over 30 were over represented at the community college compared to the university. One variable that affected the study's results could be that community college students in general have poorer records in high school and lower SAT scores.

The findings indicated that adult students bring some very desirable attributes to college and university campuses that are not always recognized. When present in sufficient numbers, adults seem to affect positively the culture of the classroom by their commitment to active engagement in learning and the sharing of that commitment with their younger peers.

A model of college outcomes for adults. Much of what Darkenwald and Novak (1997) found, Donaldson (1999) echoed in an article that presented a model of college outcomes for adult undergraduate students to address the key elements that affect their learning and to stimulate research and theory building about adults' experience in college.

Donaldson (1999) noted that, at the time of the article, adults comprised $40-45 \%$ of the students enrolled as undergraduates in higher education. They were enrolling part-time, taking courses through the Internet and other distance technologies, and demanding creative ways to complete their education where they spend little or no time on campus. Despite these trends, most of the insights about the undergraduate experience have been drawn from the past two decades of research on young adults and their development and are in many ways limited in 
explaining how adults learn and develop in college. Because most models explaining college outcomes addressed traditional-aged students, they may not fully capture the essence of the experience for adults in higher education.

To help explain the nature of the undergraduate experience for adults, Donaldson (1999) offered a Model of College Outcomes for Adults that pulled together the literature and research on the adults' undergraduate experience in higher education. The model attempted to take into consideration the complex nature of adults' lives and explain the key components affecting their undergraduate experiences. It considered the preexisting conditions and motives, adults' cognition, ways the adult learners engage the classroom to foster learning, adults' learning in context of their current life/world experiences, and the outcomes adults observe as a result of their college experiences.

Adult undergraduates in higher education: A review of past research perspectives. Adults often enroll in college to address work or life transitions, reasons that are different than those of traditional aged students. Frequently, adults report rusty study skills, low selfconfidence, or fears about returning to college. Yet somehow, adults generally compensate for this lack of campus engagement. Kasworm (1990) reviewed more than 300 studies and found that adult students did as well or better than traditional aged students in higher education settings based on grades and aptitude/content test performance measures.

Despite a lack of certain types of campus involvement and recent academic experience, adult students apparently learn and grow as much or more as younger students during their undergraduate collegiate experiences. This implies that adults may be using different skills, techniques, settings, or interactions with faculty, fellow students, and others to achieve their 
desired results. Adults have complex and rich mental schemas that might make learning more personally meaningful for them, and integrate new learning by making connections to existing knowledge schema. Adults make connections to other real-life activities in various adult roles and then apply this learning immediately in real-life contexts.

Adult students' academic and intellectual development in college. Graham and Donaldson (1999) compared non-traditional aged and traditional aged undergraduate students' academic progress. They analyzed data collected from 27,811 undergraduate college students over a 3-year period, two-thirds of which were between the ages of 18-22. The adults comprised the other $37 \%$ of the subjects, and their median age was 35 . The students involved in this study completed the ACT College Outcomes Survey (COS) as part of their institutions' efforts to assess student growth during college and were drawn from private, technical, 2-year, and 4-year colleges and universities from a variety of geographical regions in the U.S.

Subjects were working on undergraduate degrees and had completed more than 24 hours of coursework at the college where they were enrolled. Students aged 23-26 were eliminated to produce two distinct age groups; those 18-22 and those 27 and older, to ensure comparison of a traditional college age group with a group of adults who had been out of school for several years.

Differences were relatively modest between adult/traditional students when examining the reported "importance" of various areas of intellectual and academic growth; half of the differences were less than .05 of a point on a 5-point scale. Variances between the two groups of measures of their "progress" were somewhat greater with differences of approximately .20 or greater in six areas (i.e., knowledge and skills for career, developing problem-solving skills, drawing conclusions after weighing evidence, study skills, writing skills, and applying scientific 
knowledge and skills). Adults had higher mean scores in these six areas as well as in 22 of the 26 comparisons on "progress."

There were statistically significant differences for all five variables in involvement outside the classroom: adults were less involved in college clubs and organizations, and there was less involvement in college-sponsored events, but much higher rates in caring for family. The most significant finding of this study was that even though adults' involvement in on- and off-campus activities was markedly different than younger students, their reported growth was equal to or greater than the younger students across all 26 areas of academic and intellectual development.

This study did not address the issue of part- or full-time enrollment status. Patterns of enrollment were changing for both adult and traditional students. Notwithstanding the weaknesses of the study, findings suggested that despite a lack of certain types of campus involvement and recent academic experience, adult students learn and grow as much or more than younger students during their collegiate experience.

There were several theories that may, in combination, help explain why adults did as well as traditional students despite much lower levels of campus involvement, rusty academic skills, busy lifestyles, and conflicting roles, including their approach to their college experiences. Having a clearer purpose, being more intent on learning, taking the advice of advisors, and hoping to gain something they can apply to their work are among the reasons for adult students' success. Their life experience helps them learn by allowing new learning to build on "old" learning, and adults tend to see the "big picture," ways that learning can be applied to real life. 
Differential prediction of adult student performance from Miller Analogies test scores.

Given this information about adults as undergraduate students, one might ask if adults have equal success as graduate students. And can their academic success be predicted by admissions test scores? At least one study by House and Keeley (1996) points to a positive outcome for the students but also to prediction bias in the relationship between test scores and later academic achievement. Their study, conducted over a 7-year period, consisted of 1,177 students who began master's level study in education at a private university. Three specific groups of students were identified: $25-34$ years old $(\underline{\mathrm{n}}=594), 35-44(\underline{\mathrm{n}}=465)$, and $45+(\underline{\mathrm{n}}=118)$. Data collected for each student included Miller Analogies Test (MAT) score, age, and cumulative graduate GPA. Analysis of variance revealed significant differences between the three age groups for the prediction of graduate GPA from MAT scores were obtained, $\underline{\mathrm{F}}(3,1174)=4.22, \mathrm{p}<.05$.

Follow-up analyses indicated that MAT scores over predicted the grades of the younger adult students and of the oldest students in the sample. Conversely, MAT scores under predicted the grade performance of the students in the middle age group. The results of the study suggested that MAT scores do not predict subsequent grade performance similarly for all adult graduate students.

Facilitating adult learning in a liberal education context. As with the studies above and others, Justice (1997) studied the differences between adult and traditional age students, but in a liberal education context. Justice noted that adults differ in significant and definable ways from recent high school graduates who have, in the past, defined "the college student." Most of them return to higher education in their early or mid-thirties, although significant numbers are now 
returning later. Indeed, the most salient characteristic of the new adult learner is the wide range of ages at which they seek higher education and degrees.

Justice offered a profile of older adult students. First, they are older. They come to their education with more experiences and with a greater sense of themselves. They have established, even if only tentatively, a sense of identity, defined by family, place and obligation, career or work, and membership in religious or community organizations. Their return to education may be to make changes in that identity— to change jobs, recover from a marriage that has ended, or establish a new life in a new location, but they bring to their new involvement in formal learning an established base, a deeper and more defined context.

Adults come to education in their mid-thirties with a more firmly established habit of learning. Consciously or not, they have used a cognitive style in figuring out what to do and how to do it in the myriad of daily, weekly, monthly, and annual tasks that often involved learning new knowledge or skills or simply acquiring the information. Increasingly, adults come back to school because education and formal learning are now more often prized at the workplace, and there is recognition that learning can be a strategic advantage to the employer.

In addition to their developed sense of identity, adult students also come with a more focused sense of purpose and direction, usually associated with the need to contribute to their profession, to their families, or simply to society. Most common for adults in their thirties, the need to produce and contribute is a major motivation for returning to education. This generative time manifests itself most commonly in the adult learner's view that education is closely linked to vocational advancement and development. Working adults believe they must have additional credentials to be successful in their careers; students in their late twenties and thirties come back 
to school because they feel the need to have more expert knowledge to reach both their personal and professional goals. For them, academic achievement is both a public declaration of qualification and a personal validation of generative capacity.

Summary. Research involving the comparison of traditional and non-traditional aged students repeatedly reveals certain characteristics of each group, how they differ and how they are similar. The two age groups may differ in motivation, life experience, and life style. Research showed that if they differ academically, the non-traditional aged student performs as well as or better than the traditional aged student. Specifically, non-traditional aged students are highly motivated to learn and to apply that learning to real-life situations (Bowden \& Merritt, 1995). The consistently perform as well as or better than the younger students (Darkenwald \& Novak, 1997; Graham \& Donaldson, 1999; Kasworm, 1990). They bring a wealth of knowledge and practical experience to the classroom that enhances the educational experience for their age cohort as well as for younger (traditional aged) students (Bowden \& Merritt, 1995; Wagschal, 1997). In fact, regardless of student age, those students enrolled in predominantly adult classes earned the highest grades, and the reverse also was true (Darkenwald \& Novak, 1997).

A summary of the literature. The literature for six areas of research was examined here: (1) attitude as a component of the affective domain; (2) measurement of students' attitudes toward computers, including the variety of attitude scales developed and tested during the 1980s; (3) attitude toward use of computers, (4) using computers for English composition (computerassisted composition), including the World Wide Web and the Internet; (5) measurement of students' attitudes toward educational use of the Internet; and (6) non-traditional aged students compared to traditional aged students. The categories of literature themselves represent 
progression of the research — from attitude as a viable component of human learning to attitude toward computers, then to attitude toward increasingly complex computer applications in general, and finally to measurement of attitude toward computer applications used in educational settings for specific disciplines, such as English composition, and comparison of age groups within those classes.

\section{Research Questions}

What all of the studies and their descriptions, analyses, recommendations, caveats, and techniques share is an interest in learning. Student attitude, motivation, behavior, and other factors may contribute to or detract from that learning. If there is a relationship between a student's attitude toward use of the Internet and his/her Internet and composition behaviors, what is that relationship? Is there a difference in attitude or behaviors between traditional and nontraditional aged groups? The purpose of this study was to measure English composition students' attitudes toward educational use of the Internet (ATEUI) along with determining what selected Internet and composition behaviors are reported and whether there is a relationship between students' ATEUI score and their subsequent behaviors.

Although variations of computer attitude scales were designed, tested, and validated during the mid-to-late 1980s and into the early 1990s, these scales did not measure student affect nor subsequent behavior for more sophisticated and complex computer applications, such as the Internet. Scales to measure students' attitudes toward these applications were needed. Only recently, researchers (Duggan et al., 2001) published the Attitude Toward Educational Use of the Internet (ATEUI) scale, a Likert scale accompanied by a questionnaire eliciting selected 
behavioral correlates to use of the Internet for educational purposes. According to the authors, it was the first of its kind.

The present study used the ATEUI scale to measure undergraduate students' attitudes toward the Internet in a specific discipline, one differing from those in the original studyEnglish composition. This study then broadens the application of the ATEUI scale as well as adds to the body of research for composition, a discipline for which use of the Internet is increasingly important to a student's success, but for which relatively little quantitative research has been conducted (Eldred \& Hawisher, 1995). Most composition studies and articles that discussed students' attitudes toward using computers include software; programs, such as word processing and text editors; and even hypertext/hypermedia, but these studies have been primarily qualitative and anecdotal in nature. Moreover, when groups of students have been compared, the comparison was made for gender differences; thus, the comparison of traditional aged and non-traditional aged students in the present study further adds to the application and use of the ATEUI scale.

The questions for the present study using the ATEUI scale included the following: 1. As measured by the ATEUI scale, what are English composition students' attitudes toward educational use of the Internet?

2. Is there a difference in the ATEUI scores of traditional aged and non-traditional aged students?

3. What is the relationship between English composition students' ATEUI scores and reported Internet and composition behaviors? 
4. Is there a difference in the frequencies of traditional aged and non-traditional aged English composition students' reported Internet and composition behaviors?

5. Is there a relationship between English composition students' sex and their ATEUI scores?

6. Is there a relationship between English composition students' academic rank and their ATEUI scores?

7. Is there a relationship between English composition students' sex and their reported Internet and composition behaviors?

8. Is there a relationship between English composition students' academic rank and their reported Internet and composition behaviors?

To answer these questions, the following hypotheses were tested:

H1. When measured by the ATEUI scale, English composition students' mean ATEUI scores are positive, i.e., 3.0 or higher on a 5.0 scale.

H2. There is a statistically significant difference in the ATEUI scores between traditional aged and their non-traditional aged students.

H3. There is a relationship between English composition students' ATEUI scores and reported Internet and composition behaviors.

H4. There is a difference in the frequencies of traditional aged and non-traditional aged English composition students' reported Internet and composition behaviors.

H5. There is a relationship between English composition students' sex and their ATEUI total scores.

H6. There is a relationship between English composition students' academic rank and their ATEUI total scores. 
H7. There is a relationship between English composition students' sex and their reported Internet and composition behaviors.

H8. There is a relationship between English composition students' academic rank and their reported Internet and composition behaviors. 


\section{Chapter 3}

Method

\section{Objectives}

The purpose of the study was to measure English composition students' attitudes toward educational use of the Internet and to study selected behavioral correlates to those attitudes using the Attitude Toward Educational Use of the Internet (ATEUI) scale developed by Duggan, Hess, Morgan, Kim, and Wilson (2001). Relationships between attitude, behavior, age, sex, and academic rank were also examined. Further, students were categorized by age to determine any differences between those who were traditional aged $(<25)$ and those who were non-traditional aged ( $\geq 25)$ (WVU Extended Learning, 2002).

The computer attitude scales emerging during the mid-to-late 1980s and into the early 1990s did not measure student affect or subsequent behavior for computer applications such as the Internet. Scales to measure students' attitudes toward these applications were needed. Recently Duggan et al. (2001) published the Attitude Toward Educational Use of the Internet (ATEUI) scale along with a questionnaire eliciting selected behavioral correlates to use of the Internet for educational purposes.

The present study used the ATEUI scale to measure undergraduate students' attitudes toward Internet use in English composition. By doing so, this study broadens the application of the ATEUI scale as well as adds to the body of research for composition, a discipline for which use of the Internet is increasingly important to student success, but for which relatively little quantitative research has been conducted (Eldred \& Hawisher, 1995). Moreover, this study 
further adds to the application and use of the ATEUI scale by comparing traditional aged and non-traditional aged students.

The questions for the present study using the ATEUI scale included the following:

1. As measured by the ATEUI scale, what are English composition students' attitudes toward educational use of the Internet?

2. Is there a difference in the ATEUI scores of traditional aged and non-traditional aged students?

3. What is the relationship between English composition students' ATEUI scores and reported Internet and composition behaviors?

4. Is there a difference in the frequencies of traditional and non-traditional aged English composition students' reported Internet and composition behaviors?

5. Is there a relationship between English composition students' sex and their ATEUI scores?

6. Is there a relationship between English composition students' academic rank and their ATEUI scores?

7. Is there a relationship between English composition students' sex and their reported Internet and composition behaviors?

8. Is there a relationship between English composition students' academic rank and their reported Internet and composition behaviors?

To answer these questions, the following hypotheses were tested:

H1. When measured by the ATEUI scale, English composition students' ATEUI mean scores are positive, i.e., 3.0 or higher on a 5.0 scale. 
H2. There is a statistically significant difference in the ATEUI mean scores between traditional aged and non-traditional aged students.

H3. There is a relationship between English composition students' ATEUI total scores and reported Internet and composition behaviors.

H4. There is a difference in the frequencies of traditional and non-traditional aged English composition students' reported Internet and composition behaviors.

H5. There is a relationship between English composition students' sex and their ATEUI total scores.

H6. There is a relationship between English composition students' academic rank and their ATEUI total scores.

H7. There is a relationship between English composition students' sex and their reported Internet and composition behaviors.

H8. There is a relationship between English composition students' academic rank and their reported Internet and composition behaviors.

\section{Pilot Study}

A pilot study (Duran, 2001) measured English composition students' ATEUI score and behavioral correlates. The study also compared non-traditional aged and traditional aged students. It was expected that the findings from the pilot study and the present study would be similar.

In the pilot study, it was expected that, as a group, English composition students' ATEUI scores would be positive, that is, greater than 3.0 on a 5.0 scale. It also was expected that, when tested against the ATEUI, certain behavioral correlate items would yield statistically significant 
results; that is, certain behaviors would indicate a more positive ATEUI score. When students were categorized by age, it was expected that there would be no statistically significant difference between the two age groups' ATEUI score or behavioral correlates to the ATEUI.

Participants. Participants for the study were 25 students enrolled in one of two Summer 2001 sections of English 108, Written English II, at Fairmont State College (FSC), a four-year college in Fairmont, West Virginia, with an enrollment of approximately 6,500 students for the Fall 2000 semester, according to FSC Registrar Richard McCray (personal communication, August 20, 2001). Non-traditional aged students ( $>25$ years of age) comprise about $25 \%$ of the enrollment at FSC, and the sample demographics were comparable, with $8(32 \%)$ of the 25 students older than 25 . Their ages spanned 30 years, ranging from 18 to 48 . Of the students, 17 $(68 \%)$ were female; $8(32 \%)$ were male; however, only one of the eight non-traditional aged students was male. Academic rank categorization showed 5 (20\%) freshmen, 10 (40\%) sophomores, 4 (16\%) juniors, and 5 (20\%) seniors (one student left this question blank). Academic rank was relatively evenly distributed between males and females, and between age groups.

Treatment of participants was in accordance with the ethical standards of the American Psychological Association. The data were collected during a regular class meeting of the students' English composition class. The students had no prior knowledge that they would be surveyed, but their participation was entirely voluntary.

Design. The purpose of this study was to measure students' attitudes toward educational use of the Internet and to study selected behavioral correlates to those attitudes using the Attitude Toward Educational Use of the Internet (ATEUI) scale developed by Duggan et al. (2001). The 
18-item Likert format uses a 5-point response scale ranging from 1 "strongly disagree" to 5 "strongly agree"; thus, a higher score reflected a more positive attitude, with 3.0 on a 5.0 scale considered neutral. The 18 items include six each of negative items $(4,5,8,10,15$ and 18), neutral items $(2,7,11,14,16$, and 17), and positive items $(1,3,6,9,12$, and 13). Nine items were reverse scored (six negative items - 4, 5, 8, 10, 15, and 18 - and three neutral items-11, 14, and 17).

In addition to the ATEUI scale, a Behavioral Correlates Questionnaire was administered. The questionnaire had 11 items relating to computer ownership, selecting courses, frequency of use of the Internet for browsing and searching, interaction on the Internet with friends and classmates, how they learned to use the Internet, educational purposes for which they use the Internet, and which features for using the Internet applied to them. Answer formats included dichotomous (yes/no), selection of one answer from a list of three or more choices, and multiple answers selected from lists of three or more choices. Three items asked for demographic information: age, sex, and year rank in school. Finally, one open-ended question asked participants for anything else they wanted to say about using the Internet for educational purposes. So that students had opportunity to use the Internet for the course prior to responding in this study, the ATEUI and the Behavioral Correlates Questionnaire were administered at the beginning of a regular class meeting after mid-point in the course's length, i.e., the latter part of the third of five weeks during the summer 2001 session.

Age group was the independent variable for the study, and there were two levels: nontraditional aged (those students older than 25) and traditional aged (those students 25 and younger). Dependent variables included the ATEUI score for each student and the behavioral 
correlates questionnaire responses. (However, for the analyses where the behavioral correlates were tested for age-related differences, the independent variable was the item response (yes/no, etc.), and age was the dependent variable.) Statistical tests also were computed on independent variables sex and academic rank in school.

According to the literature, the present study was the first to administer the original ATEUI to measure attitudes toward educational use of the Internet after it was designed and tested in an initial study by Duggan et al. (2001). As a control measure to compare results, thus reliability, the present study organized the data and used the same statistical analyses that Duggan et al. (2001) did.

Results. The ATEUI score for each participant was the mean of the 18 items, with items $4,5,8,10,11,14,15,17$, and 18 reverse scored. The ATEUI sample grand mean was 3.79 on a 5.0 scale $(\underline{\mathrm{SD}}=.53)$, with a traditional aged students' group mean score of $3.87(\underline{\mathrm{SD}}=.47)$ and a non-traditional students' group mean score of $3.60(\underline{\mathrm{SD}}=.63)$. The range in participants' ATEUI scores varied from a low of 2.44 to a high of 4.67. Scores for non-traditional aged students ranged from 2.44 to 4.22 (a 1.78-point range), and 3.0 to 4.67 (a 1.67-point range) for traditional aged students. Because the ATEUI mean score for this sample was $>3.0$ on a 5.0 scale, the hypothesis that freshman English composition students would have a positive ATEUI was accepted.

A one-way analysis of variance $($ ANOVA) yielded an $\underline{F}$ statistic $(1,23)$ of $1.546(\underline{p}=$ .226), indicating no statistically significant difference between the mean scores of the two age groups $(\alpha=.05)$. A Levene test yielded a 1.61 statistic $(\mathrm{p}=.217)$, suggesting that the two groups' scores had equality of variance, or homogeneity. An inter-item reliability analysis of the 
attitude scale gave an internal consistency of .85, as measured by Cronbach's Alpha, indicating a high reliability of the measure, comparable to that in the original study (Duggan et al., 2001).

To determine whether there was a relationship between the participants' age and their ATEUI, a Pearson Product-Moment Correlation was computed. The test showed no significant relationship between the two variables. There was also no statistically significant correlation for sex, year rank, and ATEUI score.

One-way analysis of variance (ANOVA) was computed on the ATEUI scores by each of the 33 response choices (e.g., yes or no) in the 11 behavioral correlates questionnaire items to determine whether certain behaviors indicate a more (or less) positive ATEUI score. Therefore, there were 33 tests total, the number of which, together with the rather unequal frequencies for some responses (e.g., Item 6 with yes/no responses in a ratio of $\sim 7: 1$, respectively, and Item 7 with frequencies of 1, 5, and 19), could have increased the possibility for Type I error (Reed, 1990). Response items on the Behavioral Correlates Questionnaire were converted to numeric values, e.g., Yes $=1$, No $=2$, which were used as the independent variable; the 18 ATEUI item score totals were the dependent variables. The tests yielded statistically significant results on five of the 33 behavioral correlate items.

Participants who reported discussing or sharing class-related information found on the Internet showed stronger attitudes toward educational use of the Internet than those who did not, $\underline{F}(1,22)=16.17, \underline{p}<.01$. Given a choice, those who would take a course that required Internet use showed significantly more favorable attitudes toward educational use of the Internet than those who would not, $\underline{\mathrm{F}}(1,23)=14.05, \underline{\mathrm{p}}<.01$. As far as purposes for which participants used the Internet and its features, those students who reported browsing the Internet more often also 
showed a more favorable attitude toward educational use of the Internet than those who did not, $\underline{F}(2,22)=3.33, \underline{p}=.05$. Participants who use the Internet to consult with a classmate(s) showed a significantly more favorable attitude than those who do not, $\underline{\mathrm{F}}(1,23)=10.88, \underline{\mathrm{p}}<.01$. Finally, those students who reported using the Internet to upload information showed a significantly more favorable attitude toward educational use of the Internet than those who did not, $\underline{F}(1,23)=8.13$, $\mathrm{p}<.01$. Given these results, the hypothesis that certain behaviors would be significant for positive ATEUI scores was accepted.

Next, the Chi-square test was computed to determine any significant differences in the behavioral correlates for the two age groups ( $\underline{n}=17$ traditional aged students versus 8 nontraditional aged students). Each response choice was assigned a number value (e.g., yes $=1$, no $=2$ ) for the 33 items. The resulting sets of data were frequencies, thus non-continuous in nature. Response choice was the dependent variable for each test; age group was the independent variable. Alpha was set at .05 . Only two of the behavioral correlates indicated significant differences between the age groups: consulting with classmates, $\chi^{2}(1, \underline{\mathrm{N}}=25)-6.62, \underline{\mathrm{p}}<.05$, and use of chat rooms, $\chi^{2}(1, \underline{\mathrm{N}}=25)-4.74, \underline{\mathrm{p}}<.05$. Interestingly, none of the non-traditional students said that they consulted with classmates, but $47 \%$ ( 8 of 17) of the traditional aged students did. Likewise, only one non-traditional aged student said that he or she used chat rooms; however, $59 \%$ ( 10 of 17$)$ of the traditional aged students used chat rooms. Thus, it was concluded that there were significant differences between the two age groups' behavioral correlates to their ATEUI score for consulting with classmates and use of chat rooms. Only one other behavior approached significance: keeping track of valuable educational Internet sites, $\chi^{2}(1, \underline{N}=25)$ $-3.44, \mathrm{p}=.06$, for which $85 \%$ (6 of 8$)$ non-traditional aged students said they keep track of 
valuable educational sites; whereas, only $35 \%$ (6 of 17 ) traditional aged students do. Because there were frequencies fewer than five in some cells, resulting in a possible distortion of the chisquare statistic, these results should be interpreted cautiously.

Finally, participants' written responses to Item 15, the open-ended question on the Behavioral Correlates Questionnaire, mirrored their ATEUI scores and behavioral correlates. In general, the 10 students ( 8 females, 2 males) who responded said that the Internet is a beneficial research tool with which students can easily find good information, although they offered such caveats as "sometimes it takes a while to find a site that is credible with all the personal sites people have out there" and that "there is also a lot of trash on the Internet." They felt it is important for instructors to require use of the Internet to help students "keep up with the times." However, all comments were not positive. One student, a traditional aged female in her junior year, wrote that (sic) "sometime the Internet provide good information than teachers do, but some Internet have false info, which it will misled people." Another woman, a non-traditional aged sophomore, said, "I feel confused and somewhat overwhelmed by using the Internet. I prefer books. I do not feel nearly as knowledgeable as the younger students in the class. I think my lack of knowledge and uneasiness with the Internet puts me at a disadvantage."

The findings in the pilot study suggested that the two age groups were more similar than they were different as far as ATEUI scores were concerned. The lack of correlation between sex, year in school, and ATEUI score also was not surprising given the proliferation and widespread use of personal computers at home and at work, and the fact that $100 \%$ of these students said they owned a personal computer and were connected to the Internet. As Sanders and MorrisonShetlar (2001) noted, today's undergraduates seem knowledgeable of and comfortable with 
computers in general and with the Internet specifically. The most salient finding in this study was that previous contrasts in confidence/anxiety toward computers between males and females, and between traditional aged and non-traditional aged students seems to have diminished, perhaps to the point of nonexistence.

\section{The Present Study}

Participants. Participants in the present study were students enrolled in sections of English 102, Composition and Rhetoric, an English composition course at West Virginia University (WVU) in which students write college-level research papers based on argumentative models. It is required of all bachelor's degree candidates unless the requirement is waived. For the present study, the students were first analyzed as a group, then categorized as either traditional aged $(<25)$ or non-traditional aged $(\geq 25)$. Categorization of students by age differs somewhat in studies comparing the two age groups, with most using 25 years, plus or minus a year, as the division between them (Bishop-Clark \& Lynch, 1998; Darkenwald \& Novak; House \& Keeley, 1996; Rosenthal et al., 2000). Because the present study used WVU English composition students, participants were categorized by age in accordance with WVU Extended Learning's definition of the non-traditional aged student (2002). Non-traditional aged students were categorized as being equal to or older than 25 years and traditional aged students as 24 years or younger.

According to the WVU Office of Institutional Analysis and Planning, 7 percent of all undergraduate students enrolled during the Fall 2002 semester were 25 years or older (D. Wilson, Data Technician II, personal correspondence, December 13, 2002). Because English composition is required of all undergraduate students at WVU, it was expected that enrollment in 
the English composition classes surveyed in the study would reflect the age demographic of the university as a whole.

Unless the requirement is waived, all undergraduate students must enroll in English composition at some point in their undergraduate academic career; thus, it was expected that students who participated in the proposed study would reflect a varied undergraduate academic rank; that is, any given section would contain a mixture of freshman, sophomore, junior, and senior level students (although technically, freshmen are not allowed to enroll in English 102). Treatment of participants was in accordance with the ethical standards of the American Psychological Association and the WVU Institutional Review Board.

Participant Recruitment Procedure. Recruitment of participants began with the English Department Chair's sending an email message to instructors who were teaching English 102 during the Fall 2002 semester. The message briefly explained the study and included an attached flyer describing the study in more detail. (See Appendix C for a copy of the recruitment flyer.) A printout of the flyer also was placed in all English 102 instructors' mailboxes. A few days later, the researcher followed up with a second email to potential instructors.

The flyer asked interested faculty to help with the research. The " $5 \mathrm{~W}$ 's" were then identified with brief descriptions of "what" (the dissertation title and descriptions of the attitude scale and the behavioral correlates questionnaire), "who" (the researcher), "when" (Fall 2002 semester), "where" (E102 classroom), and "why" (data gathering and statistical analysis). Finally, contact information was given, and instructors were asked to contact the researcher by a given date. 
In addition to administering the surveys in class meetings, the researcher asked each instructor a set of eight (8) questions to determine how use of the Internet was required in the class, how use of the Internet was taught, and how it was used by the class, among other questions. Each interview took about 30 minutes. The instructor interview questions were:

1. In what ways did the syllabus require use of the Internet?

2. Were there ways the student used the Internet for the class that weren't required?

3. Did you instruct students in how to use the Internet, e.g., exercises, homework, workshop? Did students seem familiar with how to access the Internet for research?

4. Describe how you approached teaching the course to incorporate use of the Internet.

5. What would you say is the average length of students' papers?

6. Could you describe the students as writers (in general terms), and their progress in the class (skill building), etc.?

7. Do you think use of the Internet has improved the quantity or quality of what they write?

8. What research do you think needs to be done, or you want to be done?

A copy of each instructor's course syllabus was collected to determine how it required the students to use the Internet, and for use in cross-validation (triangulation) of the qualitative data.

\section{Research Design}

This study measured students' ATEUI and the behavioral correlates in the $13^{\text {th }}$ and $14^{\text {th }}$ weeks of the semester so that students had several weeks of using the Internet for research and other purposes in their English composition course. Thus, the study can be considered an ex post facto design (Tuckman, 1999). Age group was the independent or predictor variable for the study, and there were two levels: non-traditional aged (those participants age 25 or older) and 
traditional aged (those participants younger than 25). Because the study sought to determine any relationship between ATEUI score, Internet behaviors, age, sex, and academic rank, it can be considered a correlational study.

\section{Instruments}

This study used two instruments to answer eight (8) research questions: (1) the ATEUI scale, and (2) the Behavioral Correlates Questionnaire (the instruments are contained in Appendices A and B, respectively). The ATEUI is a Likert scale containing 18 statements relevant to students' attitude toward educational use of the Internet for an English composition course, for example, Item 16, "Using the Internet is as convenient as using the library." Participants ranked their disagreement or agreement with each statement on a scale with anchors from 1 (strongly disagree) to 5 (strongly agree). The ATEUI scale's content duplicated the original Duggan et al. (2001) study.

The 18-item Likert format used a 5-point response scale ranging from 1 "strongly disagree" to 5 "strongly agree"; thus, a higher score reflected a more positive attitude, with 3.0 on a 5.0 scale considered neutral. The 18 items included 6 each of negative items $(4,5,8,10,15$ and 18), neutral items $(2,7,11,14,16$, and 17), and positive items $(1,3,6,9,12$, and 13). Nine items were reverse scored (six negative items and three neutral items- $4,5,8,10,11,14,15,17$, and 18).

In addition to the ATEUI scale, a 20-item Behavioral Correlates Questionnaire was administered. In contrast to the ATEUI scale, this questionnaire was modified from the one used in the Duggan et al. (2001) study to elicit behaviors specific to English composition as well as general Internet behaviors. Of the Behavioral Correlates Questionnaire's 20 items, 10 related to 
computer ownership, selecting courses, frequency of use of the Internet for browsing and searching, interaction on the Internet with friends and classmates, how participants learned to use the Internet, educational purposes for which they use the Internet, and which features for using the Internet apply to them (Items $1,2,3,4,5,6,7,9,10$, and 15).

There were six (6) items relevant to composition and/or writing behaviors, including frequency of use of the Internet for research, quantity and quality of writing, attitude toward writing, writing ease or difficulty, use of the library for research, and use/purpose specific to English composition (Items 8, 11, 12, 13, 14, and 16). Answer formats for these 16 items included: (1) dichotomous (yes/no), (2) selection of one answer from a list of three or more choices, or (3) multiple answers selected from lists of three or more choices. Three of these questions $(9,10$, and 16$)$ provided a space for participants to write in "Other" responses, and one question (12) asked participants to give specific ways in which using the Internet had affected their writing.

Items 17, 18, and 19 asked for demographic information: age, sex, and academic rank, respectively. Finally, one open-ended question (Item 20) asked participants for anything else they wanted to say about using the Internet for educational purposes in their English composition course.

Procedure

Data collection procedure. The data collection consisted of a five-step process: recruitment of students through instructors via email distribution of a flyer explaining the study, distribution of the flyer to instructors' department mailboxes, follow-up email to non-responding instructors, administration of the Attitude Toward Educational Use of the Internet survey and the 
Behavioral Correlates Questionnaire to English 102 classes, and instructor interviews (see Figure 1 below).

Setting. The data were collected at the beginning of a regularly scheduled meeting of the participants' English composition classes (English 102). Visits were scheduled to survey individual sections of the class during the 13th and 14th weeks of the semester (all data were collected within a nine-day period). The students had no prior knowledge that they were to be surveyed, and their participation was voluntary. Treatment of participants was in accordance

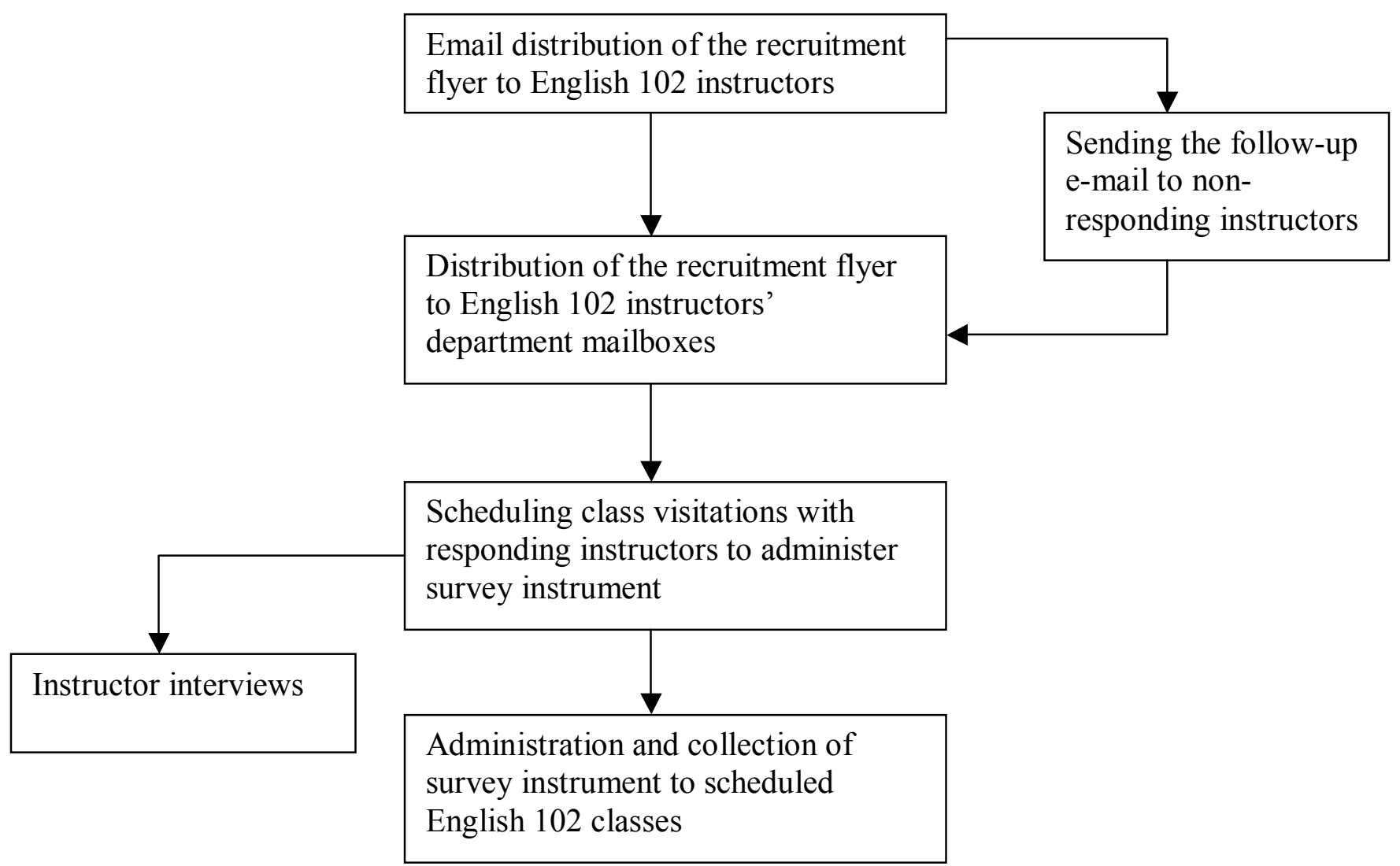

Figure 1. The data collection procedure. 
with the ethical standards of the American Psychological Association and the WVU Institutional Review Board. The briefing script, read to the participants prior to distribution of the survey instrument, can be found in Appendix D.

Measurement. The purpose of this study was to measure English composition students' attitudes toward educational use of the Internet (ATEUI) along with determining what selected Internet and composition behaviors were reported and whether there was a relationship between students' ATEUI score and their subsequent Internet and writing behaviors. ATEUI scores also were categorized by age (traditional aged versus non-traditional aged) to determine any difference between the two age groups. Behavioral frequencies were calculated and compared by age group. Additionally, age, sex, and academic rank were examined for relationship to students' ATEUI scores and behaviors.

Qualitative data were gathered from three sources: (1) Item 12 on the Behavioral Correlates Questionnaire; (2) Item 20, an open-ended question on the Behavioral Correlates Questionnaire; and (3) instructor interviews. These data were recorded and analyzed in accordance with guidelines suggested by Patton (1990) and Denzin and Lincoln (1998); that is, field notes (raw data) were reviewed and analyzed, then categorized to discern patterns, themes, and clusters. These patterns were used to discern both similarities and differences between students and their instructors, and were tabulated to determine frequencies. The instructors were interviewed using the standardized open-ended interview method, in which each respondent was asked the same sequence of questions with essentially the same words. Further, fieldwork was cross-validated (triangulated) by gathering different kinds of data, specifically, information from 
the students, their instructors, and copies of the instructors' syllabi. Finally, the qualitative data were incorporated into the study as a complement to and further explication of statistical data.

This study used a psychometric questionnaire developed by Duggan et al. (2001), consisting of two major components. The first component was an Attitude Toward Educational Use of the Internet (ATEUI) scale containing 18 statements using a 5-point Likert response format (see Appendix A for the ATEUI scale). The scale ranged from 1 "strongly disagree" to 5 "strongly agree" so that a higher score reflected a more positive attitude, with 3.0 on a 5.0 scale considered neutral. The 18 items included 6 each of negative items $(4,5,8,10,15$ and 18$)$, neutral items $(2,7,11,14,16$, and 17$)$, and positive items $(1,3,6,9,12$, and 13). Nine items were reverse scored (the six negative items and three neutral items- $4,5,8,10,11,14,15,17$, and 18).

In addition to the ATEUI scale, a 20-item Behavioral Correlates Questionnaire was administered (see Appendix B for the Behavioral Correlates Questionnaire). This questionnaire was designed to elicit behaviors specific to English composition as well as general Internet behaviors. The Behavioral Correlates Questionnaire contained 10 items relating to computer ownership, selecting courses, frequency of use of the Internet for browsing and searching, interaction on the Internet with friends and classmates, how participants learned to use the Internet, educational purposes for which they use the Internet, and which features for using the Internet apply to them. There were six (6) items relevant to composition and/or writing behaviors including frequency of use of the Internet for research, quantity and quality of writing, attitude toward writing, writing ease or difficulty, use of the library for research, and use/purpose specific to English composition. Answer formats for these 16 items included: (1) dichotomous 
(yes/no), (2) selection of one answer from a list of three or more choices, or (3) multiple answers selected from lists of three or more choices.

Three (3) items asked for demographic information: age, sex, and academic rank. Finally, one open-ended question asked participants for anything else they wanted to say about using the Internet for educational purposes in their English composition course.

Hypotheses. H1. The purpose of H1 was to measure English composition students' attitudes toward educational use of the Internet (ATEUI) along a scale from 1 (strongly disagree) to 5 (strongly agree), with a higher score reflecting a more positive attitude, and 3.0 considered neutral. Therefore, an overall mean for the sample, means for each of the 18 items across the sample, and individual student means (representing that student's ATEUI mean score across the 18 items) were calculated.

H2. H2 sought to determine whether there was significant difference in the ATEUI mean scores of traditional aged $(<25)$ and non-traditional aged $(\geq 25)$ students. For comparison by age group, an ATEUI mean score was calculated for each student, derived from the mean of the 18 ATEUI scale items. Analysis of variance was used for this purpose $(\alpha=.05)$.

H3. The purpose of H3 was to examine a possible relationship between the students' ATEUI total score and their Internet and composition behaviors. Pearson Product-Moment Correlation was used for this calculation. There were a total of 16 correlations. Because questions 9, 10, and 16 accepted multiple answers from participants, frequencies were instead calculated for those questions, leaving a total of 16 correlations from the questionnaire (the remaining 13 questions in addition to age, sex, and academic rank). (See Table 11.) For calculation of correlations, the total ATEUI score was used. The ATEUI total score consisted of 
the sum of each student's responses across the 18 scale items, with each response ranging from 1 to 5; thus, any student's ATEUI total score could range from a minimum of 18 to a maximum of 90.

H4. H4 sought to determine any difference in the frequencies in the reported Internet and composition behaviors between the two age groups (traditional and non-traditional).

H5. The purpose of H5 was to examine a possible relationship between English composition students' sex and their ATEUI total scores.

H6. H6 aimed to examine a possible relationship between English composition students' academic rank and their ATEUI total scores.

H7. H7 aimed to examine a possible relationship between English composition students' gender and their reported Internet and composition behaviors.

H8. The purpose of H8 was to examine a possible relationship between English composition students' academic rank and their reported Internet and composition behaviors.

Data analysis procedure. The data analysis procedure included four (4) components: descriptive statistics, instrument statistical procedure, inferential procedure, and qualitative procedure (see Table 7 below). Descriptive statistics were calculated for the ATEUI scale, including an overall sample mean, along with means for each of the 18 scale items and the corresponding standard deviations, as well as individual student means.

Descriptive statistics (frequencies) also were calculated for the Behavioral Correlates Questionnaire items relating to computer ownership, selecting courses, frequency of use of the 
Table 7

Data Analysis Procedure

\begin{tabular}{lll} 
Analysis Component & \multicolumn{1}{c}{ Data } & \multicolumn{1}{c}{ Calculation } \\
\hline Descriptive Statistics & $\begin{array}{l}\text { ATEUI Scores } \\
\text { Behavioral Correlates }\end{array}$ & $\begin{array}{l}\text { Frequencies, Means, Standard } \\
\text { Deviation }\end{array}$ \\
Instrument Statistics & ATEUI Scores & $\begin{array}{l}\text { Cronbach's Alpha Reliability } \\
\text { Coefficient }\end{array}$ \\
Inferential Procedure & $\begin{array}{l}\text { ATEUI Scores } \\
\text { Behavioral Correlates }\end{array}$ & $\begin{array}{l}\text { ANOVA, Pearson Product-Moment } \\
\text { Correlation (two-tailed test of } \text { r) }\end{array}$ \\
& Behavioral Correlates & Descriptive Analysis
\end{tabular}

Internet for browsing and searching, interaction on the Internet with friends and classmates, how participants learned to use the Internet, educational purposes for which they use the Internet, and which features for using the Internet apply to them. Frequencies also were calculated for six (6) items relevant to composition and/or writing behaviors including frequency of use of the Internet for research, quantity and quality of writing, attitude toward writing, writing ease or difficulty, use of the library for research, and use/purpose specific to English composition. Finally, frequencies were calculated for the demographics of age, sex, and academic rank.

Instrument statistics included procedures used to establish psychometric qualities, including validity and reliability, of a measurement tool, test, and/or questionnaire (Liaw, 2000). One of the main purposes of this study was to understand students' attitude toward using the 
Internet for educational purposes. Cronbach's alpha coefficient was calculated to test the reliability of the ATEUI scale.

Third, inferential statistics were run to test $\mathrm{H} 2, \mathrm{H} 3, \mathrm{H} 5, \mathrm{H} 6, \mathrm{H} 7$, and $\mathrm{H} 8$. The purpose of H2 was to test for significant difference between the ATEUI scores of traditional aged and nontraditional aged students in the sample. Analysis of variance ( $\underline{F}$ test) was used for this calculation. H3 sought to examine the relationship between English composition students' ATEUI total scores and their reported Internet and composition behaviors. The purpose of H5 was to examine the relationship between English composition students' sex and their ATEUI total scores. H6 examined a possible relationship between English composition students' academic rank and their ATEUI total scores. H7 examined a possible relationship between English composition students' sex and their reported Internet and composition behaviors, and H8 sought to examine a possible relationship between English composition students' academic rank and their reported Internet and composition behaviors. Pearson Product-Moment correlation, followed by a two-tailed test of $\underline{\mathrm{r}}$, was used for these calculations (H3, H5, H6, H7, and H8).

Finally, qualitative data were gathered from three sources: (1) Item 12 on the Behavioral Correlates Questionnaire; (2) Item 20, an open-ended question on the Behavioral Correlates Questionnaire; and (3) instructor interviews. These data were recorded and analyzed in accordance with guidelines suggested by Patton (1990) and Denzin and Lincoln (1998); that is, field notes (raw data) were reviewed and analyzed, then categorized to discern patterns, themes, and clusters. These patterns were used to discern both similarities and differences between students and their instructors, and were tabulated to determine frequencies. Further, fieldwork was cross-validated (triangulated) by gathering different kinds of data, specifically, information 
from the students, their instructors, and copies of the instructors' syllabi. Finally, the qualitative data were incorporated into the study as a complement to and further explication of statistical data. Types of comments from the students who responded to Behavioral Correlates Questionnaire Items 12 and 20 were noted and counted, then categorized as basically positive or negative. Qualitative data were analyzed for the participants who responded as a group, but data were not categorized and analyzed by demographic characteristics, such as age, sex, and academic rank.

The instructors were interviewed using the standardized open-ended interview method, in which each respondent was asked the same sequence of questions with essentially the same words. Instructors were asked a set of eight (8) questions to determine how use of the Internet was required in the class, how use of the Internet was taught, and how it was used by the class, among other questions (see page 141 for the instructor interview questions). Qualitative data gathered from the instructor interviews were also categorized as either positive or negative, then compared to the students' responses for differences and similarities. 


\section{Chapter 4}

Results

The research results presented here were the outcome of four data analyses, including descriptive statistics, instrument statistics, inferential statistics, and qualitative data. Descriptive statistics were used for $\mathrm{H} 1$ and $\mathrm{H} 4$; instrument statistics were used for $\mathrm{H} 2$, and inferential statistics were used for H2, H3, H5, H6, H7, and H8. Qualitative data from the instructor interviews, responses from Item 12 on the Attitude Toward Educational Use of the Internet (ATEUI), and the open-ended question from the Behavioral Correlates Questionnaire (Item 20) were further used to understand and analyze the statistical data.

\section{Participants}

Participants were 167 students enrolled in sections of English 102, Composition and Rhetoric, an English composition course at West Virginia University (WVU) in which students write college-level research papers based on argumentative models. The survey instrument was administered at the beginning of a regularly scheduled class meeting of the participants' English composition classes (English 102). Visits were scheduled during the $13^{\text {th }}$ and $14^{\text {th }}$ weeks of the semester, and all data were gathered within a nine-day period. A briefing script (Appendix D) was read to the participants prior to distribution of the survey instruments (Appendices A and B). The data collection took about 15 minutes. Participation was entirely voluntary, and treatment of participants was in accordance with the ethical standards of the American Psychological Association and the WVU Institutional Review Board. 
Participant descriptive statistics. Three types of descriptive statistics were collected for the sample: age, sex, and academic rank (see Table 8 below, for a summary of participant descriptive statistics). English 102 (or the equivalent) is required of all bachelor's degree candidates unless the requirement is waived; thus, it was expected that students who participated in the proposed study would reflect a varied undergraduate academic rank; that is, any given section would contain a mixture of freshman, sophomore, junior, and senior level students (although technically, freshmen are not allowed to enroll in English 102). Of the 165 participants responding to the age demographic, $156(94.5 \%)$ were traditional aged, and $9(5.5 \%)$ non-traditional aged (in accordance with WVU Extended Learning (2002), traditional aged students were categorized as those whose age was $<25$; non-traditional aged students were categorized as those whose age was $\geq 25$ ). The youngest respondent was 18 and the oldest 37 , a range of 19 years. The mean age was 20.4 years.

According to the WVU Office of Institutional Planning and Analysis, 7\% (1,175 of 16,692) of undergraduate students at WVU are non-traditional aged (B. Wilson, Data Technician II, personal communication, December 13, 2002); thus, the sample underrepresented the university demographic for non-traditional aged undergraduate students. The percent of nontraditional aged students may have been lower because the classes surveyed were morning and early afternoon classes except for one evening class. These class times may not have been convenient for non-traditional aged students, who typically work full-time. Moreover, nontraditional aged students who enroll in the WVU Regents Bachelors Program are not necessarily required to enroll in English 102; they may instead enroll in two writing ("W") courses at the university, which may have reduced the number of non-traditional aged students enrolled in 
Table 8

Demographic Frequencies and Percentages for Sex, Age Group, and Academic Rank

\begin{tabular}{|c|c|c|}
\hline & Frequency & Percentage \\
\hline \multicolumn{3}{|l|}{$\operatorname{Sex}^{\mathrm{a}}$} \\
\hline Male & 86 & 51.8 \\
\hline Female & 80 & 48.2 \\
\hline \multicolumn{3}{|l|}{ Age Group ${ }^{b}$} \\
\hline Traditional Aged & 156 & 94.5 \\
\hline Non-traditional Aged & 9 & 5.5 \\
\hline \multicolumn{3}{|l|}{ Academic Rank ${ }^{\mathrm{c}}$} \\
\hline Sophomore & 115 & 69.3 \\
\hline Junior & 34 & 20.5 \\
\hline Senior & 17 & 10.2 \\
\hline
\end{tabular}

${ }^{\mathrm{a} O n e}$ student did not respond to Item 17 (Sex); thus, here $\mathrm{N}=166$.

${ }^{\mathrm{b}}$ Two students did not respond to Item 18 (Age); thus, here $\mathrm{N}=165$.

'One student did not respond to Item 19 (Year in School); thus, here $\mathrm{N}=166$.

English 102. Thus, it was thought that a comparison of the percent of non-traditional aged students in the sample and the percent enrolled in English 102 during the Fall 2002 semester would be amore meaningful comparison. According to the WVU Office of Admissions and Records, non-traditional aged students $(\geq 25)$ comprised $4 \%$ of all students enrolled in English 102 during the Fall 2002 semester (J. Tennant, Applications Programmer, personal communication, March 7, 2003). This percentage more closely matched that of the nontraditional aged subsample $(5.5 \%)$. 
Participants also were asked to indicate their sex, and 166 students responded to this question. Respondents consisted of 86 males and 80 females, $51.8 \%$ and $48.2 \%$, respectively; thus, the number of males and females was roughly equal.

Relevant to academic rank, none of the 166 respondents were freshmen (one student did not give an academic rank). Sophomores comprised the majority of the sample, with 115 participants $(69.3 \%)$ in this category. Juniors numbered $34(20.5 \%)$, and 17 Seniors $(10.2 \%)$ responded. Females (57) comprised $49.6 \%$ of the sophomores, $52.9 \%$ (18) of the juniors, and $29.4 \%$ (5) of the seniors. The vast majority of females $(71.3 \%)$ were sophomores, with $22.5 \%$ juniors, and $6.3 \%$ seniors. In contrast, males comprised $50.4 \%(58)$ of the sophomores, $50 \%$ of the juniors, and $70.6 \%$ of the seniors. Compared to females, a smaller percentage of the males were sophomores $(67.4 \%)$ or juniors $(19.8 \%)$, but a higher percentage $(14 \%)$ were seniors.

\section{Hypotheses}

Quantitative data analysis. H1. The purpose of H1 was to measure English composition students' attitude toward educational use of the Internet. The Attitude Toward Educational Use of the Internet (ATEUI) scale developed by Duggan et al. (2001) was used for this purpose. The 18-item Likert format used a 5-point response scale with anchors ranging from 1 "strongly disagree" to 5 "strongly agree"; thus, a higher score reflected a more positive attitude, with 3.0 on a 5.0 scale considered neutral. Frequencies (means and standard deviations for each of the 18 items) across the sample were calculated to determine participants' ATEUI scores (see Table 9 below). It was expected that English composition students' attitude toward educational use of the Internet would be positive. 
The overall ATEUI mean score for the sample across the 18 scale items was 3.95 , reflecting that participants' ATEUI mean score was positive ( $>3.00$ on the 5.00 scale); thus, H1 was accepted. These findings contrasted somewhat with the Duggan et al. (2001) study and the pilot study (Duran, 2001), which found overall mean ATEUI scores of 3.44 and 3.79, respectively, in that the overall mean was more positive. The highest item mean in the present study was 4.59 , and the lowest was 2.76 , a range of 1.83 . The highest individual ATEUI score was 4.89 and the lowest 1.78 , a range of 3.11 points. Table 9 (below) gives a summary of the ATEUI scale item means and standard deviations.

Qualitative data tended to reinforce the statistical measure of ATEUI as positive. Although there were both positive and negative comments from the participants, positive comments considerably outnumbered negative ones. In response to Behavioral Correlates Questionnaire Item 12, which asked students for specific ways in which using the Internet had affected their writing, positive comments outnumbered negative ones by almost 17:1. The most frequent positive response was related to being able to find "lots of information," "a wider variety of sources," and "more information that is more accessible." Students also wrote that information is "easier/quicker to find," "the research process is easier," or that "research using the Internet is easier than going to the library." Students felt their writing was more in-depth or longer, gave more viewpoints, or gave a broader view on a topic, and that their language was more "proper" since online tools, such as style manuals, are readily available on the Internet. Negative comments were related to the ease with which students could plagiarize papers and the questionable quality or trustworthiness of some Internet sources. 
Table 9

Item Means and Standard Deviations for the Attitude Toward Educational Use of the Internet (ATEUI) Based on Likert Format $(\mathrm{N}=167)$

Item

Mean SD

1. Knowledge of the Internet is essential for surviving college.

$4.25 \quad .85$

2. The Internet is as important as other research tools.

$4.35 \quad .84$

3. I prefer to use the Internet to do research.

$4.34 \quad .95$

4. I feel that the Internet contains mostly useless information. $(\mathrm{R})^{\mathrm{a}} \quad \begin{array}{lll}3.88 & .90\end{array}$

5. The Internet is too difficult to use for school. $(\mathrm{R})^{\mathrm{a}}$

$4.59 \quad .71$

6. I feel the Internet is easier to use than the library.

4.001 .03

7. Generally, I feel the Internet is as informative as the teacher.

2.761 .06

8. I hate using the Internet for important educational projects. $(\mathrm{R})^{\mathrm{a}} \quad \begin{array}{lll}\mathrm{a} & 4.31 & .88\end{array}$

9. I enjoy getting information from books and the Internet equally. $\quad 2.86 \quad 1.12$

10. I feel overwhelmed when I try to use the Internet for my classes. $(\mathrm{R})^{\mathrm{a}} \quad \begin{array}{lll}4.23 & .98\end{array}$

11. The Internet does not particularly excite me. $(\mathrm{R})^{\mathrm{a}} \quad 3.88 \quad 1.06$

12. Using the Internet makes learning fun. $\quad 3.38 \quad .95$

$\begin{array}{lll}\text { 13. I feel the Internet is an integral part of the educational process. } & 3.91 & .89\end{array}$

14. I am indifferent about using the Internet for education. $(\mathrm{R})^{\mathrm{a}} \quad 3.87 \quad .90$

15. I wish I did not have to use the Internet for educational purposes. $(\mathrm{R})^{\mathrm{a}} \quad \begin{array}{lll}4.42 & .82\end{array}$

16. Using the Internet is as convenient as using the library. $\quad 3.74 \quad 1.18$

17. Access to the Internet for educational purposes is not important

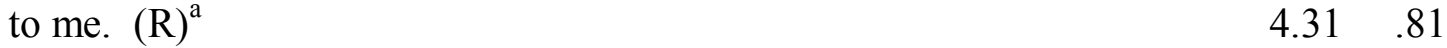

18. Browsing the Internet confuses me. $(\mathrm{R})^{\mathrm{a}} \quad 4.41 \quad .96$

${ }^{\mathrm{a}}(\mathrm{R})=$ reversed scored item

Note: Response is on a 5-point scale $(5=$ strongly agree; 1 = strongly disagree.)

A smaller ratio of positive to negative comments was found in responses to Behavioral

Correlates Questionnaire Item 20, which asked participants if there was anything else they would

like to say about using the Internet for English composition. After categorization, the total

positive comments outnumbered negative ones by nearly $3: 1$. Reiterating responses from Item 
12 , students wrote that the Internet makes it "easier to find specific information/research," and that Internet sources are "easy to cite." Students liked the convenience of research from their home or dorm rather than having to go to the library building. In contrast, students advised that they "need guidance and instruction before using the Internet as a research tool," and that the Internet "can be confusing." Students wrote that using the Internet for research encourages plagiarism, that it is "making students lazy," and one student wrote that it is "completely worthless."

H2. H2 aimed to determine any statistically significant difference in the ATEUI scores between traditional aged participants $(<25)$ and non-traditional aged participants $(\geq 25)$. A oneway analysis of variance (ANOVA) was used for this calculation $(\alpha=.05)$. For comparison by age group, an ATEUI score was calculated for each student, derived from the mean of the 18 ATEUI scale items. Results of the ANOVA showed a mean ATEUI score of $3.96(\mathrm{SD}=.55)$ for traditional aged participants, compared to $3.78(\mathrm{SD}=.75)$ for non-traditional aged participants, a mean difference of .18 .

The ANOVA yielded an $\underline{F}$ statistic $(1,164)$ of $.90(\underline{p}=.35)$, indicating no statistically significant difference in the mean scores of the two age groups. Thus, $\mathrm{H} 2$ was rejected. Because the number of students in each of the two age groups was greatly unequal, the mathematical assumption for equality was not met. However, assumptions for homogeneity and independence were met. A Levene test gave a 3.70 statistic $(\mathrm{p}=.06)$, indicating homogeneity of variance between the age groups. Additionally, an inter-item reliability analysis of the attitude scale, as measured by Cronbach's Alpha, gave a 
Table 10

Results of ANOVA of ATEUI Mean Scores by Age Group for ATEUI Items 4, 5, and 8

\begin{tabular}{|c|c|c|c|c|c|c|}
\hline Item & $\begin{array}{l}\text { Question } \\
\text { Content }\end{array}$ & $\begin{array}{c}\text { Age } \\
\text { Group }^{a}\end{array}$ & Mean(SD) & $\underline{F}$ & $\mathrm{df}$ & $\underline{p}$ \\
\hline \multirow[t]{2}{*}{4.} & I feel that the Internet contains & 1 & $3.91(.89)$ & 5.09 & 1,164 & $.025 *$ \\
\hline & mostly useless information. $(\mathrm{R})^{\mathrm{b}}$ & 2 & $3.22(1.10)$ & & & \\
\hline \multirow[t]{2}{*}{5.} & The Internet is too difficult to use & 1 & $4.61(.68)$ & 4.19 & 1,164 & $.042 *$ \\
\hline & for school. $(\mathrm{R})^{\mathrm{b}}$ & 2 & $4.11(1.17)$ & & & \\
\hline \multirow[t]{2}{*}{8.} & I hate using the Internet for & 1 & $4.34(.83)$ & 5.11 & 1,164 & $.025 *$ \\
\hline & important educational projects. $(\mathrm{R})^{\mathrm{b}}$ & 2 & $3.67(1.41)$ & & & \\
\hline
\end{tabular}

${ }^{\mathrm{a}} 1=$ Traditional aged participants, $2=$ Non-traditional aged participants.

${ }^{\mathrm{b}}(\mathrm{R})=$ Reversed scored item.

*Significant at the .05 level.

reliability coefficient of .85 (standardized item alpha), indicating a high reliability of the measure comparable to the original study by Duggan et al. (2001) and the pilot study (Duran, 2001), where the coefficients were .91 and .85 , respectively. Reliability is an indication of the proportion of variation in test scores, which could be considered true variance as opposed to error variance (Gable, 1986). 
Interestingly, when the ATEUI mean scores were compared by age group item-by-item, there was statistical significance for three of the 18 scale items: 4, 5, and 8 . All three items were negatively worded, thus reverse scored. Item 4 yielded an $\underline{F}$ statistic $(1,164)$ of $5.09(\underline{p}=.025)$.

Item 5 yielded an $\underline{F}$ statistic $(1,164)$ of $4.19(\mathrm{p}=.042)$, and Item 8 yielded an $\underline{F}$ statistic $(1,164)$ of $5.11(\mathrm{p}=.025)$. Thus, it may be concluded that, for these three ATEUI scale items, there was a statistically significant difference in the mean scores of the two age groups. Table 10 (above) contains the complete results of the one-way ANOVA for these three items. One-way ANOVAs of the difference in participants' mean ATEUI scores by sex and academic rank yielded no statistically significant results, $\underline{\mathrm{F}}(1,164)=.099, \underline{\mathrm{p}}=.75$ and $\underline{\mathrm{F}}(2,163)=.738, \underline{\mathrm{p}}=.48$, respectively.

H3. The purpose of $\mathrm{H} 3$ was to determine whether there is a statistically significant relationship between the participants' mean ATEUI total scores and their reported composition and Internet behaviors, as measured by the Behavioral Correlates Questionnaire. The Pearson Product-Moment correlation was used to determine relationship, and a two-tailed test was used to compute significance of $\underline{r}$. Because questions 9,10 , and 16 accepted multiple answers from participants, frequencies were instead calculated for those questions, leaving a total of 16 correlations from the questionnaire (the remaining 13 questions in addition to age, sex, and academic rank). (See Table 11 below.)

A test of the Pearson correlation yielded significant relationships between ATEUI total scores and several of the composition and Internet behaviors from the Behavioral Correlates Questionnaire $(\alpha=.05)$. Items $2,3,5,6,7,8,11,12,13,14$, and 15 all showed statistically 
Table 11

Correlations for ATEUI Total Scores with Selected Behavioral Correlates Questions

\begin{tabular}{|c|c|c|}
\hline Behavioral Correlates Question & $\begin{array}{l}\text { Pearson } \\
\text { Correlation }\end{array}$ & $\begin{array}{l}\text { Significance } \\
\text { (p) }\end{array}$ \\
\hline 1. Do you own a personal computer? & -.144 & .063 \\
\hline 2. Are you connected to the Internet? ${ }^{\mathrm{a}}$ & -.208 & $.007 *$ \\
\hline 3. Do you keep track of valuable educational sites? ${ }^{a}$ & -.321 & $.001 *$ \\
\hline $\begin{array}{l}\text { 4. If you could get all lecture and course information } \\
\text { from the Internet, would you go to class? }\end{array}$ & .001 & .993 \\
\hline $\begin{array}{l}\text { 5. Do you and your friends discuss/share class-related } \\
\text { information found on the Internet? }\end{array}$ & -.354 & $.001 *$ \\
\hline $\begin{array}{l}\text { 6. Given a choice, would you take a course that required } \\
\text { Internet use? }\end{array}$ & -.355 & $.001 *$ \\
\hline 7. On average, how often do you browse the Internet? ${ }^{\text {b }}$ & .289 & $.001 *$ \\
\hline $\begin{array}{l}\text { 8. On average, how often do you search the Internet for } \\
\text { English composition coursework? }\end{array}$ & .344 & $.001 *$ \\
\hline $\begin{array}{l}\text { 11. How has using the Internet affected the length of your } \\
\text { papers? }^{\mathrm{c}}\end{array}$ & -.299 & $.001 *$ \\
\hline $\begin{array}{l}\text { 12. How has using the Internet affected the quality of your } \\
\text { papers? }^{\text {c }}\end{array}$ & -.299 & $.001 *$ \\
\hline $\begin{array}{l}\text { 13. How has using the Internet for research in English } \\
\text { composition changed your attitude toward writing? }^{\mathrm{c}}\end{array}$ & -.299 & $.001 *$ \\
\hline
\end{tabular}


Table 11 (continued)

$\begin{array}{ccc} & \text { Pearson } & \text { Significance } \\ \text { Behavioral Correlates Question } & \text { Correlation } & \text { (p) }\end{array}$

14. How has using the Internet for research in English composition affected the ease or difficulty with which you write papers? ${ }^{\mathrm{c}}$

$-.463 \quad .001 *$

15. On average, how often do you visit the library (building) to find research material? $-.190 \quad .014^{*}$

*Correlation is significant at the .01 level (two-tailed).

${ }^{\mathrm{a}}$ Yes $=1$, No $=2$, for example, Item 1, Do you own a personal computer?

${ }^{b}$ Never $=1$, Daily $=5$, for example, Item 7 , On average, how often do you browse the Internet? ${ }^{c}$ Much $=1$, Little $=5$, for example, Item 11, How has using the Internet affected the length of your papers? 
Table 12

Number (Percent) of Response Frequencies for Behavioral Correlates Questionnaire $(\mathrm{N}=165)^{*}$

\begin{tabular}{|c|c|c|c|c|}
\hline Item & $\begin{array}{l}\text { Response } \\
\text { Option }\end{array}$ & $\begin{array}{l}\text { Response } \\
\text { Frequency } \\
\text { (Total) }\end{array}$ & $\begin{array}{l}\text { Response } \\
\text { Frequency } \\
\text { (Non-Trad.) }\end{array}$ & $\begin{array}{l}\text { Response } \\
\text { Frequency } \\
\text { (Traditional) }\end{array}$ \\
\hline $\begin{array}{l}\text { 1. Do you own a personal } \\
\text { computer? }\end{array}$ & $\begin{array}{l}\text { Yes } \\
\text { No }\end{array}$ & $\begin{array}{l}158(95.8) \\
7(4.2)\end{array}$ & $\begin{array}{c}9(100) \\
--\end{array}$ & $\begin{array}{l}149(95.5) \\
7(4.5)\end{array}$ \\
\hline $\begin{array}{l}\text { 2. Are you connected to the } \\
\text { Internet? }\end{array}$ & $\begin{array}{l}\text { Yes } \\
\text { No }\end{array}$ & $\begin{array}{l}156(93.4) \\
11(6.6)\end{array}$ & $\begin{array}{l}9(100) \\
--\end{array}$ & $\begin{array}{c}145(92.9) \\
11(7.1)\end{array}$ \\
\hline $\begin{array}{l}\text { 3. Do you keep track of } \\
\text { valuable educational sites? }\end{array}$ & $\begin{array}{l}\text { Yes } \\
\text { No }\end{array}$ & $\begin{array}{l}96(58.1) \\
69(41.9)\end{array}$ & $\begin{array}{l}3(33.3) \\
6(66.7)\end{array}$ & $\begin{array}{l}93(59.6) \\
63(40.4)\end{array}$ \\
\hline $\begin{array}{l}\text { 4. If you could get all lecture } \\
\text { and course information } \\
\text { from the Internet, would } \\
\text { you go to class? }\end{array}$ & $\begin{array}{l}\text { Yes } \\
\text { No }\end{array}$ & $\begin{array}{l}99(60.0)^{\mathrm{a}} \\
63(38.2)\end{array}$ & $\begin{array}{l}5(55.6) \\
4(44.4)\end{array}$ & $\begin{array}{l}94(60.3) \\
59(37.8)\end{array}$ \\
\hline $\begin{array}{l}\text { 5. Do you and your friends } \\
\text { discuss/share class-related } \\
\text { information found on the } \\
\text { Internet? }\end{array}$ & $\begin{array}{l}\text { Yes } \\
\text { No }\end{array}$ & $\begin{array}{r}106(64.2) \\
59(35.8)\end{array}$ & $\begin{array}{l}3(33.3) \\
6(66.7)\end{array}$ & $\begin{array}{r}103(66.0) \\
53(34.0)\end{array}$ \\
\hline $\begin{array}{l}\text { 6. Given a choice, would you } \\
\text { take a course that required } \\
\text { Internet use? }\end{array}$ & $\begin{array}{l}\text { Yes } \\
\text { No }\end{array}$ & $\begin{array}{r}137(83.0)^{b} \\
23(13.9)\end{array}$ & $\begin{array}{l}6(66.7) \\
3(33.3)\end{array}$ & $\begin{array}{r}131(84.0) \\
20(12.8)\end{array}$ \\
\hline $\begin{array}{l}\text { 7. On average, how often do } \\
\text { you browse the Internet? }\end{array}$ & $\begin{array}{l}\text { Never } \\
\text { Once/semester } \\
\text { Once/Month } \\
\text { Once/Week } \\
\text { Daily }\end{array}$ & $\begin{array}{c}1(.6) \\
1(.6) \\
2(1.2) \\
23(13.8) \\
138(83.7)\end{array}$ & $\begin{array}{l}-- \\
-- \\
-- \\
3(33.3) \\
6(66.7)\end{array}$ & $\begin{array}{c}1(.6) \\
1(.6) \\
2(1.3) \\
20(12.8) \\
132(84.6)\end{array}$ \\
\hline
\end{tabular}


Table 12 (continued)

\begin{tabular}{|c|c|c|c|c|}
\hline Item & $\begin{array}{l}\text { Response } \\
\text { Option }\end{array}$ & $\begin{array}{l}\text { Response } \\
\text { Frequency } \\
\text { (Total) }\end{array}$ & $\begin{array}{l}\text { Response } \\
\text { Frequency } \\
\text { (Non-Trad.) }\end{array}$ & $\begin{array}{l}\text { Response } \\
\text { Frequency } \\
\text { (Traditional) }\end{array}$ \\
\hline $\begin{array}{l}\text { 8. On average, how often do } \\
\text { you search the Internet for } \\
\text { English composition course- } \\
\text { work, (for example, to find } \\
\text { research material, consult } \\
\text { with classmates or instructor } \\
\text { download class lessons/note }\end{array}$ & $\begin{array}{l}\text { Never } \\
\text { Once/Semester } \\
\text { Once/Month } \\
\text { Once/Week } \\
\text { Daily } \\
\text { r, } \\
\text { es)? }\end{array}$ & $\begin{array}{c}3(1.8)^{\mathrm{c}} \\
12(7.2) \\
28(16.8) \\
102(61.8) \\
19(11.4)\end{array}$ & $\begin{array}{l}-- \\
-- \\
-- \\
8(88.9) \\
1(11.1)\end{array}$ & $\begin{array}{l}3(2.0) \\
12(7.7) \\
28(17.9) \\
94(60.3) \\
18(11.5)\end{array}$ \\
\hline $\begin{array}{l}\text { 9. How did you initially learn } \\
\text { to use the Internet? } \\
\text { (Please check all that apply.) }\end{array}$ & $\begin{array}{l}\text { Class } \\
\text { Journal/Book } \\
\text { Conf./Present. } \\
\text { Friends/Colleagues } \\
\text { Library/Instruction } \\
\text { Self-taught } \\
\text { Other }\end{array}$ & $\begin{array}{c}40(24.2)^{\mathrm{d}} \\
1(.6) \\
6(3.6) \\
76(46.1) \\
22(13.3) \\
140(83.8) \\
7(4.2)\end{array}$ & $\begin{array}{c}2(22.2) \\
-- \\
-- \\
3(33.3) \\
-- \\
7(77.8) \\
2(22.2)\end{array}$ & $\begin{array}{c}38(24.4) \\
1(.6) \\
6(3.8) \\
73(46.8) \\
22(14.1) \\
133(85.3) \\
5(3.2)\end{array}$ \\
\hline $\begin{array}{l}\text { 10. Which of the following } \\
\text { features for using the } \\
\text { Internet apply to you? } \\
\text { (Please check all } \\
\text { that apply.) }\end{array}$ & $\begin{array}{l}\text { Electronic Mail } \\
\text { World Wide Web } \\
\text { Newsgroups } \\
\text { FTP } \\
\text { LISTSERVs } \\
\text { Chat Rooms } \\
\text { Telnet } \\
\text { Forwarding } \\
\text { Downloading } \\
\text { Uploading } \\
\text { Other }\end{array}$ & $\begin{array}{c}164(99.4)^{\mathrm{d}} \\
158(95.8) \\
27(16.2) \\
18(10.8) \\
15(9.0) \\
63(38.2) \\
11(6.6) \\
83(50.3) \\
155(94.0) \\
83(50.3) \\
21(12.6)\end{array}$ & $\begin{array}{l}9(100) \\
8(88.9) \\
2(22.2) \\
2(22.2) \\
1(11.1) \\
2(22.2) \\
1(11.1) \\
3(33.3) \\
7(77.8) \\
2(22.2) \\
1(11.1)\end{array}$ & $\begin{array}{c}155(99.4) \\
150(96.2) \\
25(16.0) \\
16(10.3) \\
14(9.0) \\
61(39.0) \\
10(6.4) \\
80(51.3) \\
148(94.9) \\
81(51.9) \\
20(12.8)\end{array}$ \\
\hline $\begin{array}{l}\text { 11. How has using the } \\
\text { Internet affected the } \\
\text { length of your papers? }\end{array}$ & $\begin{array}{l}\text { Much longer } \\
\text { Somewhat longer } \\
\text { No effect } \\
\text { Somewhat shorter } \\
\text { Much shorter }\end{array}$ & $\begin{array}{c}16(9.6)^{\mathrm{c}} \\
72(43.1) \\
73(44.2) \\
2(1.2) \\
1(.6)\end{array}$ & $\begin{array}{c}1(11.1) \\
-- \\
8(88.9) \\
-- \\
--\end{array}$ & $\begin{array}{l}15(9.6) \\
72(46.2) \\
65(41.7) \\
2(1.3) \\
1(.6)\end{array}$ \\
\hline
\end{tabular}


Table 12 (continued)

\begin{tabular}{|c|c|c|c|c|}
\hline Item & $\begin{array}{l}\text { Response } \\
\text { Option }\end{array}$ & $\begin{array}{l}\text { Response } \\
\text { Frequency } \\
\text { (Total) }\end{array}$ & $\begin{array}{l}\text { Response } \\
\text { Frequency } \\
\text { (Non-Trad.) }\end{array}$ & $\begin{array}{l}\text { Response } \\
\text { Frequency } \\
\text { (Traditional) }\end{array}$ \\
\hline $\begin{array}{l}\text { 12. How has using the } \\
\text { Internet affected the } \\
\text { quality of your writing? }\end{array}$ & $\begin{array}{l}\text { Much better } \\
\text { Somewhat better } \\
\text { No effect } \\
\text { Somewhat worse } \\
\text { Much worse }\end{array}$ & $\begin{array}{c}11(6.6)^{\mathrm{c}} \\
71(42.5) \\
80(48.5) \\
1(.6) \\
1(.6)\end{array}$ & $\begin{array}{c}1(11.1) \\
-- \\
8(88.9) \\
-- \\
--\end{array}$ & $\begin{array}{l}10(6.4) \\
71(45.5) \\
72(46.2) \\
1(.6) \\
1(.6)\end{array}$ \\
\hline $\begin{array}{l}\text { 13. How has using the } \\
\text { Internet for research in } \\
\text { English composition } \\
\text { changed your attitude } \\
\text { toward writing? }\end{array}$ & $\begin{array}{l}\text { Enjoy much more } \\
\text { Enjoy somewhat more } \\
\text { No change } \\
\text { Enjoy somewhat less } \\
\text { Enjoy much less }\end{array}$ & $\begin{array}{c}11(6.6) \\
22(13.2) \\
131(79.4) \\
-- \\
1(.6)\end{array}$ & $\begin{array}{l}1(11.1) \\
1(11.1) \\
7(77.8) \\
-- \\
--\end{array}$ & $\begin{array}{c}10(6.4) \\
21(13.5) \\
124(79.5) \\
-- \\
1(.6)\end{array}$ \\
\hline $\begin{array}{l}\text { 14. How has using the } \\
\text { Internet for research in } \\
\text { English composition } \\
\text { affected the ease or } \\
\text { difficulty with which } \\
\text { you write papers? }\end{array}$ & $\begin{array}{l}\text { Much easier } \\
\text { Somewhat easier } \\
\text { No difference } \\
\text { Somewhat difficult } \\
\text { Much more difficult }\end{array}$ & $\begin{array}{l}47(28.1)^{\mathrm{c}} \\
88(52.7) \\
26(15.8) \\
3(1.8) \\
1(.6)\end{array}$ & $\begin{array}{l}2(22.2) \\
4(44.4) \\
2(22.2) \\
1(11.1) \\
--\end{array}$ & $\begin{array}{l}45(28.8) \\
84(53.9) \\
24(15.4) \\
2(1.3) \\
1(.6)\end{array}$ \\
\hline $\begin{array}{l}\text { 15. On average, how often } \\
\text { do you visit the library } \\
\text { (building) to find } \\
\text { research material? }\end{array}$ & $\begin{array}{l}\text { Never } \\
\text { Once/Semester } \\
\text { Once/Month } \\
\text { Once/Week } \\
\text { Daily }\end{array}$ & $\begin{array}{l}20(12.0)^{\mathrm{e}} \\
37(22.4) \\
62(37.1) \\
39(23.4) \\
6(3.6)\end{array}$ & $\begin{array}{l}2(22.2) \\
3(33.3) \\
2(22.2) \\
2(22.2) \\
--\end{array}$ & $\begin{array}{c}18(11.5) \\
34(21.8) \\
60(38.5) \\
37(23.7) \\
6(3.8)\end{array}$ \\
\hline $\begin{array}{l}\text { 16. For which of the } \\
\text { following purposes do } \\
\text { you use the Internet } \\
\text { specific to English } \\
\text { composition? } \\
\text { (Please check all that } \\
\text { apply.) }\end{array}$ & $\begin{array}{l}\text { Consult/instructor } \\
\text { Consult/classmates } \\
\text { Homework } \\
\text { Research/paper } \\
\text { Search library online } \\
\text { Retrieve lessons } \\
\text { Peer review/paper } \\
\text { Other }\end{array}$ & $\begin{array}{c}104(63.0)^{\mathrm{d}} \\
37(22.4) \\
61(37.0) \\
152(92.1) \\
145(86.8) \\
37(22.2) \\
17(10.2) \\
4(2.4)\end{array}$ & $\begin{array}{l}8(88.9) \\
4(44.4) \\
5(55.6) \\
9(100) \\
8(88.9) \\
2(22.2) \\
3(33.3) \\
1(11.1)\end{array}$ & $\begin{array}{c}96(61.5) \\
33(21.2) \\
56(35.9) \\
143(91.7) \\
137(87.8) \\
35(22.4) \\
14(9.0) \\
3(2.0)\end{array}$ \\
\hline
\end{tabular}


Table 12 (continued)

*Two students did not respond to Item 17 (Age); thus, their responses were not calculated for age group comparison, making $\mathrm{N}=165$.

${ }^{a}$ Four (4) students did not respond to this question, but one was a student who did not give an age demographic and was not included in the calculation $(\mathrm{N}=162)$.

${ }^{b}$ Five (5) students did not respond to this question $(\mathrm{N}=160)$.

${ }^{\mathrm{c}}$ One (1) student did not respond to this question $(\mathrm{N}=164)$.

${ }^{\mathrm{d}}$ Because students could select multiple answers, the totals will be greater than 165 , and percentages will add to more than $100 \%$.

${ }^{\mathrm{e}}$ Two (2) students did not respond to this question $(\mathrm{N}=163)$.students did (33.3\%).

significant correlation to the ATEUI total scores; thus H3 was accepted. (Only items 1 and 4 yielded no statistically significant correlation.) Items $2,3,5,6,7$, and 8 elicited Internet behaviors, and Items $11,12,13,14$, and 15 pertained to composition (writing) behaviors. Complete results of the correlations are shown in Table 11 (above).

H4. H4 sought to determine any differences in the frequencies in the reported Internet and composition behaviors between the two age groups (traditional and non-traditional, $\mathrm{T}$ and NT, respectively). Descriptive statistics were used for this calculation. A summary of Behavioral Correlates Questionnaire response frequencies for the sample as a whole and by age group are shown in Table 12 (above). When the response frequencies were compared by age group, several questions reflected different response frequencies; however, the two age groups tended to be more similar than different. Thus, H4 was rejected. Among those questions relating to computer or Internet use, for example, nearly $96 \%$ of the students sampled owned a personal computer $(100 \%$ NT, $95.5 \%$ T), with $93.4 \%$ of them connected to the Internet $(100 \%$ 
NT, $92.9 \% \mathrm{~T}$ ). The majority of both age groups would still go to class even if all lecture/class information were available on the Internet $(55.6 \% \mathrm{NT}, 60.3 \% \mathrm{~T})$, but traditional aged students kept track of valuable educational sites almost twice as often (59.6\%) as non-traditional aged Traditional aged students also discussed/shared class-related information found on the Internet with their friends twice as much as non-traditional aged students (66\% versus 33.3\%), and they were more likely to take a course that required Internet use ( $84 \%$ versus $66.7 \%)$.

The two age groups browsed the Internet at similar frequencies, with $100 \%$ of NT aged students browsing once/week or daily, and $95.4 \%$ of their traditional aged counterparts browsing at the same frequency. In contrast, when asked how frequently they searched the Internet for English composition coursework, only $71.8 \%$ of traditional aged students searched once/week or daily; whereas, $100 \%$ of non-traditional aged students did.

The two age groups learned how to use the Internet in similar ways, and used the various features of the Internet at similar rates. In response to questions relating to their writing behaviors, almost half (46.2\%) of the traditional aged students said that, as a result of using the Internet, their papers were much or somewhat longer; only 1 (11.1\%) NT aged student responded that use of the Internet had affected paper length. Similarly, $45.5 \%$ of traditional aged students said that using the Internet made the quality of their writing much or somewhat better; again, only $11.1 \%$ of the NT aged students said use of the Internet had improved paper quality. Interestingly, $46.2 \%$ (T) and $88.9 \%$ (NT) of students said that use of the Internet has had no effect on the quality of their writing.

As far as using the Internet for English composition, students reported that there had been no change in their attitude toward writing ( $77.8 \%$ and $79.5 \%$ for T and NT, respectively). The 
majority of students reported that using the Internet for research in English composition has made writing either somewhat or much easier $(82.7 \%$ and $66.6 \%$ for $\mathrm{T}$ and $\mathrm{NT}$, respectively). The two age groups tended to visit the library at the same rate, with less than a third visiting the library once/week or daily (27.5\% and $22.2 \%$ for T and NT, respectively).

One of the most striking differences in the two age groups was the purpose(s) for which they use the Internet for English composition. Non-traditional aged students tended to consult with their instructor more frequently $(88.9 \%)$ than did traditional aged students $(61.5 \%)$. Likewise, non-traditional aged students consulted with their classmates more frequently (44.4\%) than their traditional aged counterparts did $(21.2 \%)$. The older students reported using the Internet for homework more frequently $(55.6 \%)$ than the younger students did $(35.9 \%)$. Almost four times the percentage of the non-traditional aged students $(33.3 \%)$ used the Internet for peer review compared to the traditional aged students $(9.0 \%)$. However, both age groups used the Internet for research at similar rates (100\% and $91.7 \%$ for NT and T, respectively).

Three questions on the Behavioral Correlates Questionnaire-9, 10, and 16 - contained the response choice "Other," where students could write in an answer in addition to or instead of listed options. These written responses were categorized and tabulated. Question 9 asked, "How did you initially learn to use the Internet?' A total of seven (7) students wrote in answers. Three (3) students said they learned from a relative (one said husband, one parent, and the third from family in general). Three (3) said they learned in middle school (1) or high school (2), and one (1) student wrote "job."

Question 10 asked, "Which of the following features for using the Internet apply to you?" This question elicited 22 responses to "Other." Ten (10) students said they use instant 
Table 13

Correlation Matrix of ATEUI Total Score, Age Group, Academic Rank, and Sex

\begin{tabular}{|c|c|c|c|c|c|}
\hline \multirow{3}{*}{ ATEUI Score } & \multirow{3}{*}{$\begin{array}{l}\text { Pearson Correlation } \\
\text { Probability }\end{array}$} & \multirow{3}{*}{$\begin{array}{c}\text { ATEUI } \\
\text { Score } \\
1.000 \\
.\end{array}$} & \multirow{3}{*}{$\begin{array}{l}\text { Age } \\
\text { Group } \\
-.089 \\
.257\end{array}$} & \multirow{3}{*}{$\begin{array}{l}\text { Academic } \\
\text { Rank } \\
-.002 \\
.975\end{array}$} & \multirow{3}{*}{$\begin{array}{l}\operatorname{Sex}^{\mathrm{a}} \\
.009 \\
.910\end{array}$} \\
\hline & & & & & \\
\hline & & & & & \\
\hline \multirow[t]{2}{*}{ Age Group } & Pearson Correlation & & 1.000 & .051 & -.073 \\
\hline & Probability & & $\cdot$ & .512 & .353 \\
\hline \multirow[t]{2}{*}{ Academic Rank } & Pearson Correlation & & & 1.000 & -.086 \\
\hline & Probability & & & - & .270 \\
\hline $\operatorname{Sex}^{\mathrm{a}}$ & Pearson Correlation & & & & 1.000 \\
\hline
\end{tabular}

${ }^{\mathrm{a}}$ Male $=1$, Female $=2$.

messaging, and three (3) wrote they use the Internet for playing games. Research and entertainment/songs each got responses from two (2) students, and the use of search engines, file sharing, shopping and music, Web forums, and Web Master elicited one response each.

Question 16 asked students, "For which of the following purposes do you use the Internet specific to English composition?" Two students said they use the Internet for class purposes, writing in "grades" and "to take online quizzes." One student wrote that he/she uses instant messaging "to ask classmates about class." Another student said that "all of these are required," and one student wrote, "I do not."

The Pearson Product-Moment correlation was tested for significance for H5, H6, H7, and H8. Because questions 9, 10, and 16 accepted multiple answers from participants, frequencies were instead calculated for those questions, leaving a total of 16 correlations from the 
questionnaire (the remaining 13 questions in addition to age group, sex, and academic rank). Table 13 (above) contains the correlation test results for ATEUI Total Scores, Age Group, Academic Rank and Sex.

H5. The purpose of H5 was to determine any significant relationship between English composition students' sex and their ATEUI total scores. A test of the Pearson Product-Moment correlation yielded no statistically significant relationship between sex and ATEUI total scores ( $\mathfrak{p}$ $=.754)$; thus, $\mathrm{H} 5$ was rejected.

H6. The purpose of H6 was to determine any significant relationship between English composition students' academic rank and their ATEUI total scores. A test of the Pearson Product-Moment correlation was used to test $\mathrm{H} 6$ and showed no statistically significant relationship between these two variables $(\mathrm{p}=.975)$; thus, H6 was rejected. See Table 13 (above) for the correlation matrix of ATEUI Total Scores, Age Group, Academic Rank, and Sex. H7. H7 sought to determine any significant relationship between English composition students' sex and their reported Internet and composition behaviors. The test yielded significant correlation to sex on two items of the Behavioral Correlates Questionnaire (8 and 15); therefore, H7 was accepted for these items. Item 8 asked how often students search the Internet for English composition coursework; this item was significant at the .01 level $(\mathrm{p}=.007)$, and Item 15 asked for frequency of visitation to a WVU library building (as opposed to using the library resources online). For this item, significance was at the .05 level $(\mathrm{p}=.03$ ). See Table 14 (below) for the results of the correlation between the Behavioral Correlate Questionnaire Items, Age Group, Sex, and Academic Rank. 
H8. H8 sought to determine any significant relationship between English composition students' academic rank and their reported Internet and composition behaviors. The Pearson correlation yielded significant relationship between two of the behavioral correlate items (5 and 11) and academic rank. Item 5 asked whether students shared class-related information found on the Internet, and was significant at the .01 level $(\mathrm{p}=.011)$. Item 11 asked how using the Internet had affected the length of students' papers and was significant at the .05 level $(\mathrm{p}=.029)$. Therefore, $\mathrm{H} 8$ was accepted for these items. Table 14 (below) illustrates the complete results of these correlations.

\section{Qualitative Data Analysis}

Qualitative data were gathered from three sources: (1) Item 12 on the Behavioral Correlates Questionnaire; (2) Item 20, an open-ended question on the Behavioral Correlates Questionnaire; and (3) instructor interviews. These data were recorded and analyzed in accordance with guidelines suggested by Patton (1990) and Denzin and Lincoln (1998); that is, field notes (raw data) were reviewed and analyzed, then categorized to discern patterns, themes, and clusters. These patterns were used to discern both similarities and differences between students and their instructors, and were tabulated to determine frequencies. The instructors were interviewed using the standardized open-ended interview method, in which each respondent was asked the same sequence of questions with essentially the same words. Further, fieldwork was cross-validated (triangulated) by gathering different kinds of data, specifically, information from the students, their instructors, and copies of the instructors' syllabi. Finally, the qualitative data were incorporated into the study as a complement to and further explication of statistical data. 
Table 14

Correlations for Behavioral Correlate Questions with Age Group, Sex, and Academic Rank

\begin{tabular}{|c|c|c|c|}
\hline Behavioral Correlate Question & $\begin{array}{l}\text { Age } \\
\text { Group }\end{array}$ & Sex & $\begin{array}{l}\text { Academic } \\
\text { Rank }\end{array}$ \\
\hline 1. Do you own a personal computer? ${ }^{b}$ & $\begin{array}{r}-.051^{\mathrm{a}} \\
.519\end{array}$ & $\begin{array}{r}-.022 \\
.774\end{array}$ & $\begin{array}{l}.006 \\
.939\end{array}$ \\
\hline 2. Are you connected to the Internet? ${ }^{b}$ & $\begin{array}{r}-.064 \\
.413\end{array}$ & $\begin{array}{l}.034 \\
.665\end{array}$ & $\begin{array}{r}-.018 \\
.815\end{array}$ \\
\hline $\begin{array}{l}\text { 3. Do you keep track of valuable educational } \\
\text { sites? }^{b}\end{array}$ & $\begin{array}{l}.121 \\
.122\end{array}$ & $\begin{array}{l}.129 \\
.099\end{array}$ & $\begin{array}{l}.042 \\
.587\end{array}$ \\
\hline $\begin{array}{l}\text { 4. If you could get all lecture and course } \\
\text { information from the Internet, would you } \\
\text { go to class? }\end{array}$ & $\begin{array}{l}.028 \\
.727\end{array}$ & $\begin{array}{l}.000 \\
.995\end{array}$ & $\begin{array}{l}.116 \\
.142\end{array}$ \\
\hline $\begin{array}{l}\text { 5. Do you and your friends discuss/share } \\
\text { class-related information found on the } \\
\text { Internet? }^{b}\end{array}$ & $\begin{array}{l}.013 \\
.872\end{array}$ & $\begin{array}{r}-.112 \\
.153\end{array}$ & $\begin{array}{l}.198^{* *} \\
.011\end{array}$ \\
\hline $\begin{array}{l}\text { 6. Given a choice, would you take a course that } \\
\text { required Internet use? }{ }^{\text {b }}\end{array}$ & $\begin{array}{l}.088 \\
.264\end{array}$ & $\begin{array}{r}-.053 \\
.498\end{array}$ & $\begin{array}{l}.019 \\
.807\end{array}$ \\
\hline $\begin{array}{l}\text { 7. On average, how often do you browse the } \\
\text { Internet? }^{c}\end{array}$ & $\begin{array}{r}-.056 \\
.474\end{array}$ & $\begin{array}{r}-.058 \\
.458\end{array}$ & $\begin{array}{l}.131 \\
.091\end{array}$ \\
\hline $\begin{array}{l}\text { 8. On average, how often do you search the } \\
\text { Internet for English composition course- } \\
\text { work? }^{\mathrm{c}}\end{array}$ & $\begin{array}{l}.107 \\
.171\end{array}$ & $\begin{array}{l}.209^{* *} \\
.007\end{array}$ & $\begin{array}{r}-.053 \\
.500\end{array}$ \\
\hline $\begin{array}{l}\text { 11. How has using the Internet affected the } \\
\text { length of your papers? }{ }^{\mathrm{d}}\end{array}$ & $\begin{array}{l}.133 \\
.090\end{array}$ & $\begin{array}{l}.102 \\
.194\end{array}$ & $\begin{array}{l}.170^{*} \\
.029\end{array}$ \\
\hline $\begin{array}{l}\text { 12. How has using the Internet affected the } \\
\text { quality of your writing? }\end{array}$ & $\begin{array}{l}.120 \\
.126\end{array}$ & $\begin{array}{l}.131 \\
.093\end{array}$ & $\begin{array}{l}.070 \\
.370\end{array}$ \\
\hline
\end{tabular}


Table 14 (continued)

\begin{tabular}{|c|c|c|c|}
\hline Behavioral Correlate Question & $\begin{array}{l}\text { Age } \\
\text { Group }\end{array}$ & Sex & $\begin{array}{l}\text { Academic } \\
\text { Rank }\end{array}$ \\
\hline $\begin{array}{l}\text { 13. How has using the Internet for research } \\
\text { in English composition changed your } \\
\text { attitude toward writing? }{ }^{\text {dc }}\end{array}$ & $\begin{array}{r}-.032 \\
.687\end{array}$ & $\begin{array}{l}.005 \\
.950\end{array}$ & $\begin{array}{l}.063 \\
.417\end{array}$ \\
\hline $\begin{array}{l}\text { 14. How has using the Internet for research in } \\
\text { English composition affected the ease or } \\
\text { difficulty with which you write papers? }\end{array}$ & $\begin{array}{l}.094 \\
.228\end{array}$ & $\begin{array}{l}.005 \\
.951\end{array}$ & $\begin{array}{l}.054 \\
.490\end{array}$ \\
\hline $\begin{array}{l}\text { 15. On average, how often do you visit the } \\
\text { library (building) to find research material? }\end{array}$ & $\begin{array}{r}-.092 \\
.239\end{array}$ & $\begin{array}{l}.165^{*} \\
.034\end{array}$ & $\begin{array}{r}-.069 \\
.379\end{array}$ \\
\hline
\end{tabular}

*Correlation is significant at the .05 level (two-tailed).

** Correlation is significant at the .01 level (two-tailed).

${ }^{\mathrm{a}}$ In the columns, the top number represents the Pearson Product-Moment correlation ( $\underline{\mathrm{r}}$ ); the bottom number represents probability.

${ }^{\mathrm{b}} \mathrm{Yes}=1, \mathrm{No}=2$.

${ }^{\mathrm{c}}$ Never $=1$, Daily $=5$.

${ }^{\mathrm{d}}$ Little $=1$, Much $=5$.

Behavioral Correlates Item 12. Item 12 on the Behavioral Correlates Questionnaire asked students, "How has using the Internet affected the quality of your writing?" Students could check one of five choices ranging from "My writing is much better" to "My writing is much worse," but they were also asked an open-ended question, "Can you give specific ways in which using the Internet has affected your writing?" Of the 167 students responding to the survey, $91(54.5 \%)$ responded to this question. Their responses varied from a few words to short paragraphs that often contained more than one way use of the Internet had affected their writing; 
therefore, the number of incidences reported exceed the number of students responding to the question.

Both positive and negative responses appeared in the survey. The most frequent positive response was related to being able to find "lots of information," "a wider variety of sources," and "more information that is more accessible." A total of 30 students wrote these or very similar responses. Related to accessibility of information, 30 students wrote that information, such as online journals, is "easier/quicker to find," "the research process is easier," or that "research using the Internet is easier than going to the library." Similarly, three students said that because they spend less time researching, they spend more time writing the paper, and five students wrote that they get more "up-to-date information" from the Internet. And one student, a male, nontraditional aged sophomore, cast a vote for tradition by saying, "No matter how much info is on the Internet, it cannot replace a teacher."

Students (14 total) felt that their papers were now more in-depth or longer, gave more viewpoints, or gave a broader view on a topic; thus, as more than one student wrote, "more research equals a better paper." The students (7) also said that use of the Internet has improved their wording, grammar, and typing skills, that they use "proper" language for college-level writing because the Internet has easy-to-use tools, such as online style manuals, and that their writing is more concise. Although it is something of a mixed metaphor, one student proved the point by saying, “. . . writing is the paintbrush of the mind; to write you must open your mind and allow yourself to be the world around you." Six students said they also use the Internet as a heuristic to help them get ideas on what to write, support for certain topics, information on how to write, and that they get additional ideas while they are typing. Three said that they read a lot 
more and think that the reading has improved their writing and that their arguments are better supported. Other comments included getting resume information, using translation services for foreign language assignments, and simply, "I learn better."

Negative comments were fewer and illustrated students' misuse of the tool or their mistrust of use of the Internet for English composition. One student wrote, "I search Yahoo! for a topic or a quote, and just interject it into my paper." Others said that "it is hard to know whether to trust Internet sources; they may or may not be reliable," and “. . . the Internet is not generally a trustworthy source. Being required to use the Internet causes more work because I must research what I have researched." Two students warned that "it has made it easier to cheat. It encourages plagiarism; the Internet is good only for email or recreation.” In all, nine students said that using the Internet for English composition has had no effect on their writing. One student, a female, traditional aged sophomore, wrote that "I have been taught to never resort to use Internet sources for my papers; therefore, the Internet hasn't affected my writing."

Behavioral Correlates Item 20. The Behavioral Correlates Questionnaire contained one open-ended question (Item 20) that asked, "Is there anything else you would like to say about using the Internet for English composition?" Only 28 (16.8\%) of the surveyed students responded to this question. Answers here were much more varied than those recorded for Item 12, which one might expect given the open-ended nature of Item 20. Nevertheless, some responses duplicated or were very similar to those given for Item 12. And again, students offered both positive and negative comments.

Positive comments were most frequent. For example, and very similar to comments in Item 12, five students wrote that use of the Internet makes it "easier to find specific 
information/research, and that Internet sources are "easy to cite." One student expanded this comment by saying, "I think the Internet is a great research tool, but as for teacher replacement, it isn't even close." As they did in response to Item 12, students gave convenience as a plus, with four students writing, "It allows you to do it on your time, not library hours. I don't feel as rushed," or similar comments. Four students wrote that the Internet is a useful research tool, that it makes research papers possible, that it is beneficial because it makes the research process more adaptable. Other comments included one from a student who would "prefer everything come from the Internet," and one who felt that the Internet is a "positive and productive influence." One appreciated the fact that he/she could "go to Japanese Web sites, Chinese, UK, all over the world," and one used it to communicate with instructors. One student noted that use of the Internet "uses less paper," and another pointed out that it is "really useful for gaming." One simply stated, "It's a good idea."

Along with their appreciation of the Internet as a writing and research tool, students offered advice and caveats for instructors. One student advised that "students need guidance and instruction before using the Internet as a research tool," that the Internet "can be confusing but gives alternatives to the library." One thought that the university should "give everybody who is a student free Internet access at their home," and one wrote, "This course could be given online and visits to the instructor's office." One wished for "more English Internet courses and not just Extended Learning."

Some negative comments echoed those gathered from Item 12. Three students warned that one drawback to using the Internet is that they know students who plagiarize their papers and that use of the Internet encourages plagiarism. Another student believed it is "making 
students lazy." One said that the Internet is "not as useful educationally as traditional lecture and research"; another gave the most drastic opinion, considering use of the Internet for English composition "completely worthless; it has no academic value whatsoever. I would rather have all my teeth pulled out than to have to use the Internet for scholarly research."

Instructor interviews. Five English 102 instructors responded to the recruitment flyer and agreed to participate in the study, yielding 9 sections and 167 students. See Appendix $\mathrm{C}$ for a copy of the flyer. In addition to administering the ATEUI and the Behavioral Correlates Questionnaire in class meetings, the researcher asked each instructor a set of eight (8) questions to determine how use of the Internet was required in the class, how use of the Internet was taught, and how it was used by the class, among other questions. Each interview took about 30 minutes. The instructor interview questions were:

1. In what ways did the syllabus require use of the Internet?

2. Were there ways the student used the Internet for the class that weren't required?

3. Did you instruct students in how to use the Internet, e.g., exercises, homework, workshop? Did students seem familiar with how to access the Internet for research?

4. Describe how you approached teaching the course to incorporate use of the Internet.

5. What would you say is the average length of students' papers?

6. Could you describe the students as writers (in general terms), and their progress in the class (skill building), etc.?

7. Do you think use of the Internet has improved the quantity or quality of what they write?

8. What research do you think needs to be done, or you want to be done? 
A copy of each instructor's course syllabus was collected to determine how it required the students to use the Internet and for use as cross-validation (triangulation) of qualitative data.

Question 1. In what ways did the syllabus require use of the Internet? One instructor explicitly stated in the course syllabus that, "You will learn how to use technology for research and text production." Because English 102 is a research-based course, the other instructors believed that use of the Internet was inherent to the course requirements and activities listed in the syllabus. One instructor required activities such as "an introduction to the library assignment," and an annotated bibliography of six sources, one of which had to be an Internet Web site. "They had to search via Google to find three sources and rank them most credible to least credible." These requirements, in addition to use of email, were typical of four instructors. One section was held in a computer lab. These students "had to use chat rooms and WEBCT. Each student had a Web page. For one assignment, they had to find song lyrics on the Internet and analyze them, then use email to submit their analyses. Their papers were submitted via email, and evaluations, in the form of both written and audio comments, were returned via Internet."

Question 2. Were there ways the students used the Internet for the class that weren't required? Only one instructor answered this question "No." Two responded with "I suppose," and "Probably." The instructor who responded "probably," added that "I gave them an assignment to find some details, e.g., my dissertation title; they approached the task in different ways. (As part of another assignment) one found a song lyric server; they used search engines I didn’t know about (e.g., Dog Pile)." Students' use of e-mail was not required by one instructor, and another found that students "sought out full text databases on their own." 
Question 3. Did you instruct them in how to use the Internet (did they seem familiar with how to access the Internet for research)? All the instructors instructed students in use of the Internet for research. One instructor required students "to complete directed exercises of finding reliable sources. Also, if a draft wasn't submitted on time (for a workshop), the student was required to email it to classmates for peer review in lieu of the in-class workshop."

Two instructors took their classes to the library for a tour and instruction at computers from a reference librarian who also showed them how to evaluate Web sites. One class "sat down at computers. They had an assignment to look for particular kinds of sites, e.g., .edu versus non-.edu.” One instructor who previously set up mandatory library tours now sets up a day for an optional tour. During the first class, the computer lab instructor "demonstrated hardware, Apple Lab, and assigned some exercises on research; they then had to show on-screen how they found the information."

Question 4. Describe how you approached teaching the course to incorporate use of the Internet. English 102 lends itself to the assignment of specific, incremental tasks that contribute to research and writing skills that build during the semester, a form of scaffolding. As one instructor said, "The way the course is structured, there is a culminating research paper due at the end of the semester. During the semester, they have contributing assignments such as submitting an annotated bibliography." Another instructor responded, "Several days were spent discussing documentation assignments they had to bring to class. Gathering, evaluating, and annotating evidence were also allotted class time; students had specific assignments and had to bring them to class." A third instructor agreed, "The criteria for the final essay requires research on the Internet and use of the Internet." 
Two instructors commented on students' technological skills. "They are pretty savvy with the technology," said one instructor. "But I try to give them a basis to become more information literate, to be skeptical of types of Web sites, for example, .com, .org, or .gov, and to beware of pac's. They are more willing to use other sources using the Internet, e.g., newspapers, because they're easier to find, but I make them look through the Card Catalog to find a book to use, not just Internet sources. For their last paper, I'm more hands off and let them use the skills they've learned." Another instructor said, "My approach is computer-based, including submission of essays, my evaluation/feedback, peer review, modeling, songs, ads they analyze as an assignment."

Question 5. What would you say is the average length of students' papers? Responses here varied depending on the assignment and at what time during the semester the assignment was made, with earlier papers shorter (2-3 pages) than the final paper (5-9+). One instructor commented, "They seem/tend to write only what is required."

Question 6. Could you describe the students as writers (in general terms)? All of the instructors saw progress in the form of skill building during the semester, not only students' writing and research skills, but also what one instructor termed "information literacy," the ability to evaluate the credibility of Internet sources. One instructor said, "There is usually a big increase in skill level during the fall semester. They haven't written during the summer, and they've gotten out of the habit of drafting, but you'll see a big jump in quality about mid-term." But another instructor disagreed, "I saw some progress, mainly that they seem to know more about researching. They're a little more aware of themselves as writers, but not as much as I'd like. There was some improvement, but it wasn't a quantum leap. Those that struggled at the 
beginning of the semester still were at the end. I do think, however, that the practice they get in the course helps their writing skill."

There are differences in skills and abilities among the students. As one instructor observed, "There are several skill levels among the class and among different disciplines, for example, those in the sciences seem more pragmatic, but those in the humanities seem more confident with the essays. They seem to enjoy writing more when they can choose their topic. They have difficulty evaluating the quality of sources; they're sort of indiscriminate in choosing sources. They have difficulty distinguishing between databases and Web sites, and they think using the Internet obviates use of the Library (building). They don't understand that it's more than a collection of books, or realize the human resources available there, or perhaps don't want to take the time to go."

However, one instructor believed students were "very serious about their work; the classes this semester are not so social and are serious about learning. Their writing skills are very strong this semester with only one or two weak students per class. They came into the class strong, but saw improvement; they used what I taught them." Similarly, another instructor said, "They apply the skills they learn to different situations; some eliminate errors (make corrections). They are more receptive to criticism, especially peer review."

Question 7. Do you think use of the Internet has improved the quantity or quality of what they write? Instructors' answers to this question varied considerably. One said simply, "No." Others were divided, saying that either quantity or quality increased or decreased, a variable that may depend on how the course is taught, how the Internet is incorporated into it, and how students use the Internet. As one instructor put it, "I don't think it helps the quality of their 
writing mainly because we work with the Internet toward the latter part of the course. There isn't enough time to see an improvement. As for quantity, I think so because it makes them feel more comfortable; it enables them to write more although I have a suspicion that when they work on the Internet, they tend to 'bulk import' source material, a kind of plagiarism." Similarly, another instructor believed that "quality will decrease because they want to rely on the Internet too much."

Quantity (length) may be affected, as one instructor said, "Because of the sources they use; they use a bigger variety of documentation and different types, for example, government documents. Email also makes it possible for them to interview experts more easily, e.g., faculty. They seem very willing to use email." Another instructor summarized his thoughts and his approach to the course thus: "I've been teaching this way for 10 years (computer-based); I would return to the traditional way if I thought it was better. The way I teach the course, it is a blend of the traditional and the technological."

Question 8. What research do you think needs to be done or you want to be done? Answers to this question were perhaps as individual as the instructors themselves. Those responding to the question would like to see different kinds of research and for different purposes, including "hard data about the benefits of a 'reading' composition course versus one without reading that concentrates solely on writing practice-empirical data that would indicate pragmatic results." This same instructor would also like to see "a study of comparable benefits of a course with required continuing revision of a single manuscript versus multiple, new, smaller writing projects." 
A second instructor "has concerns about information literacy and how to train composition instructors to teach information literacy to the students. And how to teach them to use the information effectively, how to narrow down their search for sources. Perhaps a Research 101 — they need help narrowing down the topic." A third wants to know "how to combat this wanting to over incorporate, overuse the Internet-how to get them to use a variety of research methods, not just the Internet. Plagiarism is a problem with Internet use." Finally, one instructor would like to see research on "different learning strategies, based on ethnic or cultural background/origin. How does this affect how they learn, perceive? The thinking processes people follow when they write. How writing and personality are tied.”

In summary, the present study surveyed students enrolled in English 102 during the Fall 2002 semester at WVU. Of the 167 students responding to the survey, $156(94.5 \%)$ were traditional aged $(<25)$, and $9(5.5 \%)$ were non-traditional aged $(\geq 25)$. Males comprised 51.8\% of the sample, and females made up 48.2\%. There were 115 (69.3\%) sophomores, 34 (20.5\%) juniors, and 17 (10.2\%) seniors. It was found that English composition students' attitudes toward educational use of the Internet in their course were highly positive, having a sample mean of 3.95 of a possible 5.00 across the 18 items of the ATEUI scale. When the ATEUI mean scores of traditional aged and non-traditional aged students were compared, a one-way analysis of variance yielded no significant difference between the two age groups. Although the number of students in each group contrasted greatly, a Levene test indicated homogeneity of variance between the two age groups. Additionally, a reliability analysis of the ATEUI scale, as measured by Cronbach's Alpha, gave a reliability coefficient of .85 (standardized item alpha), indicating high reliability of the measure. 
When correlations of ATEUI total scores and behavioral correlate items were tested, several items yielded significant results, indicating that as certain behaviors increased, students' attitudes became more positive. Specifically, those behaviors showing significant relationships to attitude toward the Internet included connection to the Internet on their personal computer, keeping track of valuable educational sites, discussing/sharing class-related information found on the Internet with friends, choosing to take a course that required Internet use, frequency of browsing the Internet, frequency of searching the Internet for English composition coursework, length of papers, quality of papers, attitude toward writing, and ease or difficulty of writing papers. Only one item - frequency of visits to the library (building) to find research materialindicated a negative relationship between behavior and attitude, specifically that, as visits to the library increased, attitude toward the Internet became less positive.

When the reported Internet and composition behavior frequencies were compared for the two age groups, the calculation showed similar results. Nearly all of the students own a personal computer and are connected to the Internet, and they browse the Internet for coursework and research at comparable frequencies. However, when asked about writing behaviors, the age groups differ, with traditional aged students reporting that using the Internet has improved both the length and quality of their papers, but the majority reported that using the Internet had no effect on the quality of their writing. They also reported that using the Internet for English composition has had no effect on their attitude toward writing, with the two age groups almost identical.

How the two age groups use the Internet differed somewhat in that NT aged students reported that they consult with the instructor and classmates, for homework, and peer review 
more frequently than traditional aged students did. However, both groups use the Internet for research at similar rates.

There was no significant relationship between composition students' ATEUI total scores and sex or academic rank. Nor was there an overall significance in the relationship between age group, sex, academic rank, and reported composition and Internet behaviors although individual items yielded significance.

Composition students reported that use of the Internet for English composition made the research process more convenient, that it was easier because more information and more types of information were easier and quicker to find. Some students believed that, because the research process was less time consuming, they spent more time writing papers and that their papers were of higher quality. Likewise, students reported that their papers were longer with use of the Internet and that their language was more "proper." The primary negative comment from students seemed to be that using the Internet fostered plagiarism because it is so easy to "copy and paste" material. Some students said that it was hard to trust Internet sources' reliability, an opinion that the instructors shared.

For English composition instructors, students' use of the Internet seemed to make little difference in either length or quality of papers. Like their students, they are concerned about plagiarism, but also believed that students needed instruction in what one called "information literacy," the ability to judge the value and credibility of Internet sources. In general, instructors reported that their students made steady improvement in students' writing skills during the semester, but did not attribute that improvement strictly to use of the Internet. 
As far as future research, instructors varied on their opinions of the types of research they believed needs to be conducted. They wanted to know how to teach information literacy so that students use the Internet effectively, and how to prevent plagiarism. Instructors wanted "hard data" comparing composition methodologies and their benefits to students, learning strategies, and the connection between thinking and writing processes. 


\section{Chapter 5}

\section{Discussion and Conclusion}

The present study posed several questions regarding English composition students' attitudes toward educational use of the Internet as well as corresponding behaviors and demographics. What are English composition students' attitudes toward educational use of the Internet (ATEUI)? What Internet and composition behaviors correlate to their attitudes? Is there a difference in attitude or behaviors between traditional (T) aged and non-traditional (NT) aged students in the same English composition course? Is there a relationship between students' ATEUI and their sex or academic rank? Is there a relationship between students' Internet and composition behaviors and their sex or academic rank?

Overall, this study found that the students' attitudes toward using the Internet for their English composition course were positive. When tested, there was no significant difference between traditional aged and non-traditional aged students in the sample. Neither were striking differences in frequencies of the students' Internet and composition behaviors found. Some, but not all, of their Internet and composition behaviors were significantly related to their ATEUI scores. In contrast, there was no significant relationship between ATEUI scores and students' age, sex, and academic rank. However, relationships between individual Internet and composition behaviors correlated significantly with age, sex, and academic rank. Finally, the qualitative data collected from the students and their instructors indicated that they were aware of and agreed on strengths and weaknesses of using the Internet for English composition. 


\section{Measurement of ATEUI Scores}

Analysis of the data collected from the 167 English composition students who constituted the sample indicated that, as a group, English composition students' ATEUI mean score was positive ( 3.95 on the 5.00 scale) as measured by the ATEUI scale (see Appendix A). It could be assumed that the ATEUI scale was a reliable instrument since the reliability coefficient was .85 (as measured by Cronbach's alpha).

The finding that English composition students' attitude was positive ( 3.95 on a 5.00 point scale) agreed with those of other studies of students' attitude toward use of computers in general, the Internet, or Web-enhanced instruction (Duffelmeyer, 2000; Duggan et al., 2001; Duran, 2001; Harrington, 2000; Liaw, 2000; Massoud, 1990; Mitra \& Steffensmeier, 2000; Parr, 1994/1995; Sadler, 1987; Sanders \& Morrison-Shetlar, 2001; Sankaran et al., 2000).

Item means on the ATEUI scale yielded a range of 1.83 , with a high of 4.59 on Item 5 and a low of 2.76 on Item 7. Students scored 4.00 or greater on 10 of the scale items $(1,2,3,5$, $6,8,10,15,17$, and 18 ), indicating that students believed knowledge of the Internet is essential to college (4.25), that it is as important as other research tools (4.35), that they prefer to use the Internet to do research (4.34), and that they feel the Internet is easier to use than the library (4.00), among others. Students' written responses to Items 12 and 20 on the Behavioral Correlates Questionnaire (see Appendix B) supported the positive measurement of ATEUI. Students said that they were able to find "lots of information," "a wider variety of sources," and "more information that is more accessible." They also said that information, such as online journals, was "easier/quicker to find," and that "research using the Internet is easier than going to the library." 
Students scored only two items below 3.0-Items 7 and 9, both of which were considered neutrally worded questions. Item 7 was rated 2.76 and asked, "Generally, I feel the Internet is as informative as the teacher." The 2.76 item mean indicated that students disagreed with the statement more than they agreed with it; whether they feel that the Internet is more informative than the teacher or vice versa, one has to speculate. However, their written responses to Behavioral Correlates Items 12 and 20 indicated divided opinions. For example, a male, nontraditional aged sophomore said, "No matter how much info is on the Internet, it cannot replace a teacher." Another student echoed this sentiment, writing, "I think the Internet is a great research tool, but as for teacher replacement, it isn't even close." One student, responding to Behavioral Correlates Item 20, said that the Internet is "not as useful educationally as traditional lecture and research," and another gave perhaps the most drastic opinion, considering use of the Internet for English composition "completely worthless; it has no academic value whatsoever. I would rather have all my teeth pulled out than to have to use the Internet for scholarly research." (Not surprisingly, at 1.78 of 5.00 this student's ATEUI mean score was the lowest score for the sample. On the other hand, it may be surprising to note that the student was a traditional aged male senior.) However, most students who responded to the open-ended question on the Behavioral Correlates Questionnaire (Item 20), wrote statements similar to the student who would "prefer everything come from the Internet," and one who wrote that the Internet is a "positive and productive influence."

ATEUI Scale Item 9 was rated slightly higher than Item 7, but at 2.86, still negatively. It stated, "I enjoy getting information from books and the Internet equally." The students disagreed with this statement, indicating that they enjoy getting information more from books than the 
Internet, or vice versa. Considering the comments students wrote in response to Behavioral Correlates Items 12 and 20, one could conclude that students preferred getting information from the Internet. Their comments about the inconvenience of using the library also indicated this preference. Most students who responded in writing were positive about using the Internet, saying that it is easier to find specific information or research, and that Internet sources are easy to cite. Many students felt that the convenience of the Internet was a big plus. However, the negative item score (2.86) parallels other (negative) comments, such as "It is hard to know whether to trust Internet sources; they may or may not be reliable," and "The Internet is not generally a trustworthy source. Being required to use the Internet causes more work because I must research what I have researched." At least some students seemed to realize that there are plusses and minuses to Internet use.

Although the present study measured students' attitudes toward use of the Internet in English composition, two changes might enhance this research: (1) Modification of the ATEUI scale items (or creation of a new scale) so that statements are worded more specifically toward English composition and more precisely measure attitude as it relates to the discipline, and (2) Longitudinal study of attitude toward using the Internet in English composition. Previous studies advised that results favored, among other variables, lengthy treatments that were well grounded in appropriate theoretical frameworks (Reed, 1996). Hawisher and Selfe (1989) called for a longitudinal approach that might suggest emerging patterns of composing over time. One longitudinal study found that attitude toward computers and their use changed (or decayed) over time (McKinnon et al., 2000), with the attitude becoming less positive over time. 
Writing is a skill that improves with practice, so it would seem that the skill of using the Internet as a writing tool also might improve. Perhaps one of the English 102 instructors who were interviewed put it most succinctly by saying, "I don't think it (the Internet) helps the quality of their writing mainly because we work with the Internet toward the latter part of the course. There isn't enough time to see an improvement." Future research might go beyond a one-time survey of composition students to examine how using the Internet for English composition may affect writing skill, including length and quality of papers, over a period of time, such as a year or throughout the academic career.

Analysis of variance by age group. When the sample was categorized into traditional aged and non-traditional aged students, both sub-groups' ATEUI mean scores remained positive $(\mathrm{T}=3.96, \mathrm{NT}=3.78)$, a difference that was not statistically significant, $\underline{\mathrm{F}}(1,164)=.90, \mathrm{p}=$ .345). This finding agreed with previous studies that found no difference between the age groups (Duggan et al., 2001; Duran, 2001), or found older students to be equal or superior to their traditional aged cohort on an array of academic variables, including motivation, willingness to work, responsibility, self-directedness, and competence (Bishop-Clark \& Lynch, 1998); mean grades (Darkenwald \& Novak, 1997; Kasworm, 1990); and academic progress (Graham \& Donaldson, 1999). It must be noted that the age group numbers were greatly unequal, and this inequality may have affected the soundness of the statistical analysis (there were only 9 NT aged students in the sample).

Although there was not a significant difference between the age groups overall on the ATEUI scale, certain individual scale items did yield statistical significance. Items 4,5 , and 8 showed significance at the .05 level, $\underline{F}(1,164)=5.09, \underline{p}=.025 ; \underline{F}(1,164)=4.19, \underline{p}=.042$; and 
$\underline{F}(1,164)=5.11, \underline{p}=.025$, respectively. Item 4 stated that, "I feel that the Internet contains mostly useless information." Traditional aged students disagreed with this statement, rating it 3.92; however, non-traditional aged students were closer to neutral at 3.22. Item 4 was reverse scored; therefore, it may be assumed that traditional aged students believe the Internet contains information that is mostly useful, in slight contrast to their non-traditional aged counterparts. Both age groups rated Item 5 positively $(\mathrm{T}=4.61, \mathrm{NT}=4.11)$, but $\mathrm{NT}$ aged students agreed less strongly that "the Internet is too difficult to use for school." Item 8 reflected a greater difference in the two age groups, with traditional aged students rating it at 4.34 and non-traditional aged students at 3.67. Since the statement was "I hate using the Internet for important educational projects," and was reverse scored, it could be deducted that traditional aged students have a more positive attitude about using the Internet for important educational projects than non-traditional aged students do.

\section{Correlation of ATEUI total scores with selected behavioral correlates questionnaire}

items. All but two of the 13 composition and Internet behaviors (Behavioral Correlates Questionnaire Items 1 and 4) correlated significantly with students' ATEUI total scores (see Table 11 for the test results). Items 9,10 , and 16 were not included in the correlation analysis because their response options accepted multiple answers. Items 17, 18, and 19 were not included in this analysis because they asked for demographic information, and Item 20 was open-ended. (Correlations for demographic variables and ATEUI total scores can be found in Table 13, and qualitative data from Item 20 appears in the Results section.)

Behavioral Correlates Items 1 through 6 offered students a "Yes or No" response choice $($ Yes $=1$ and No $=2)$. Four of these items $(2,3,5$, and 6$)$ showed statistical significance $(\mathrm{p}=$ 
$\leq .01$ ), and the correlation was negative, indicating that when behavior was positive (Yes), the ATEUI total score tended to be more positive.

Behavioral Correlates Items 7, 8, and 15 also showed significant correlation between behaviors and ATEUI total scores. These three items asked students to report frequency of browsing or searching the Internet and visiting the library. Item 7 asked about browsing in general, but Items 8 and 15 asked about searching specific to English composition coursework. Here, a response of "Never" was counted as "1," and the opposite response "Daily" was counted as "5." The correlations were positive for items 7 and 8 and significant at the .001 level, indicating that as frequency of browsing/searching increased, so did the ATEUI total score. Item 15 asked how often students visited the library building to find research material. The correlation was negative and significant at the .01 level $(\mathrm{p}=.014)$, indicating that as frequency of library visitation increased, the ATEUI total score was lower. That this correlation was negative may seem surprising; however, it may be that those students who visit the library building more often do not rely as heavily on the Internet as those students who do not visit the library as frequently (even though they can access the Internet from within the library building). For example, one student whose ATEUI mean score was 1.78 of 5.00 (reflecting a relatively negative attitude toward use of the Internet) wrote in response to Behavioral Correlates Item 12 that using the Internet for English composition was "completely worthless; it has no academic value whatsoever." Other students wrote that they were not confident that Internet sources were reliable and that one felt it necessary to "research the research."

Behavioral Correlates Items 11 through 14 asked questions pertinent to the students' writing behavior in relation to use of the Internet. These questions gave a value of " 1 " to any 
response choice of "much longer," "much better," "much more," or "much easier," as opposed to the opposite answer, which was recorded as a "5." All of these items yielded significance at the .001 level, and correlations were all negative, indicating again that, as behavior(s) became more positive, so did the ATEUI total scores.

Response frequencies for the Behavioral Correlates Questionnaire items. In addition to correlation analysis, the behavioral correlates items were also examined for differences in frequencies for the two age groups ( $\mathrm{T}$ and NT). (Table 12 contains complete frequency information for the sample and for each age group.) Many of the response frequencies were similar ( $\leq 20 \%$ difference) for the two age groups (Items 1, 2, 4, 9, 13, 14, and 15); however, other items $(3,5,6,7,8,10,11,12$, and 16) showed noteworthy differences. It should be observed that the two groups were greatly unequal in number; these comparisons would perhaps be more meaningful if the two groups had been more equal in number.

First, the vast majority of students in both age groups reported that they owned a personal computer $(\mathrm{T}=95.5 \%, \mathrm{NT}=100 \%)$ and were connected to the Internet $(\mathrm{T}=92.9 \%, \mathrm{NT}=100 \%)$, not surprising considering that these students' ATEUI sample mean score was 3.95 and that they were enrolled in a course that required use of the Internet. These results indicated that previous concerns about accessibility to computers (Selfe, 1999) were not applicable to this group of English composition students. More than three-fourths of the students in the sample reported that using the Internet for research in English composition had not changed their attitude toward writing, perhaps because they routinely used the Internet for many reasons, including other courses and work. 
Here, it also would be interesting to know what their attitude toward writing was on a positive-negative scale, especially considering that $80 \%$ of the sample reported that using the Internet for research in English composition had made writing papers somewhat or much easier. It would be useful to know more precisely how the students defined "easier"; for example, did they mean that writing is easier because they could readily copy and paste material from Internet sources? Their comments indicated that the writing process could be facilitated by their using the Internet as a kind of heuristic device, a way to get ideas about what to write, that online style manuals aided the use of "proper" language, and that, because the information is relatively easy to find, they spend more time writing than they would if research were done without the aid of the Internet, to cite a few examples.

However much they used the Internet to find English composition research material, fully $64 \%$ of the students visited the library once a month or more frequently to find research material, with $12 \%$ reporting that they never visited the library building. It is, of course, possible that students are searching WVU libraries online from the library building, from home, or from their residence halls. Finding research material for an assigned paper was the number one reason (92.1\%) students gave for using the Internet specific to English composition, with searching the WVU libraries online a close second (86.8\%). Future research might seek to learn more about students' behavior at the library versus outside it.

Participants were almost three times more likely to use the Internet to consult with their instructor than with classmates ( $66.0 \%$ versus $22.4 \%)$, and six times more likely than for peer review of a paper (10.2\%), the least frequent use of the Internet specific to English composition. These numbers likely reflect the students' realization that grading stemmed from the instructor, 
not a classmate or peer, and that any peer review of a paper resulted from course requirements rather than a student's voluntary effort.

Although there were similar response frequencies for behavioral items between the two age groups, several reflected interesting if not drastic differences. (Again, these reported differences should be interpreted with caution since there were only 9 students in the nontraditional aged group.) Nearly twice as many traditional aged students (59.6\%) said they track valuable educational sites compared to non-traditional aged students (33.3\%), and fully two times as many in the traditional aged group (66\%) discussed/shared class-related information found on the Internet with their friends. This difference may be explained by the fact that many non-traditional aged students work full-time and have family and other responsibilities, thus do not interact with their classmates (or age cohort) outside of class as much as traditional aged students do. On the other hand, the non-traditional aged students reported consulting with their instructor at a greater rate than traditional aged students did (88.9\% versus $61.5 \%)$.

All of the non-traditional aged students reported searching the Internet once a week or daily for English composition coursework, compared to $71.8 \%$ of the traditional aged students, a difference that could occur if the older students are geographically removed from the campus or Morgantown locale; therefore, it is more convenient for them to search the Internet than to phone or visit the instructor. As far as Internet feature use, the two groups were similar except for uploading of information, where the traditional aged students reported uploading at more than twice the rate of the non-traditional aged students (51.9\% versus $22.2 \%)$. Research might look more specifically at Internet use to determine what kinds of information they are uploading, that is, whether it is class-related or not. 
Greater differences between the two age groups were reported relevant to how Internet use had affected certain writing behaviors. For example, Behavioral Correlates Item 11 asked students how using the Internet had affected the length of their papers. Although the percentages of students reporting that using the Internet had increased paper length "very much" were similar $(\mathrm{T}=9.6 \%, \mathrm{NT}=11.1 \%)$, nearly $50 \%$ of the traditional aged students $(46.2 \%)$ but none of the non-traditional aged students reported that it had made their papers "somewhat longer." Instead, the non-traditional aged students reported at more than twice the rate that Internet use had no effect on the length of their papers (88.9\% versus $41.7 \%)$. Perhaps non-traditional aged students relied on Internet research material more to support their own ideas rather than for the bulk of the paper than the traditional aged students did, summarizing or otherwise using the material more judiciously. Only three students (all traditional aged) reported that Internet use had made their papers somewhat or much shorter.

When asked, the instructors said that students' paper length depended somewhat on the assignment and at what time during the semester the assignment was made, with earlier papers shorter (2-3 pages) than the final paper (5-9+ pages). One instructor commented, "They seem/tend to write only what is required." It should be noted that English 102 is structured so that instruction moves from easier to more difficult writing and research activities, and from shorter to longer assignments as the semester progresses and as students gain writing and research skills; thus, it might be expected that papers' length would increase whether the Internet was a factor or not. Research that isolates these co-variants to determine the effect of each on paper length would be interesting. 
Whether they are wholesale "dumping" research material from the Internet into their papers or not, $51.9 \%$ of the traditional aged students responded to Behavioral Correlates Item 12 that using the Internet increased the quality of their writing compared to $11.1 \%$ of the nontraditional aged students. Often, younger students (novice writers) may believe that resource material "sounds" better than their own words, or they may believe that the more research material included in the paper, the better the paper. Further research might seek to learn how English composition students define "quality" or "better" to gain insight into how they use research material acquired via the Internet.

Students had the opportunity to respond in writing to Behavioral Correlates Item 12, and some of their comments may help to clarify ways in which they believed use of the Internet improved the quality of their papers. They also offered negative comments.

Students seemed to appreciate the convenience and ease of finding research material via the Internet, and they seemed to make clear connections between use of the Internet and specific writing skills and strengths. Three (3) students said that because they spend less time researching, they spend more time writing the paper, and five (5) students wrote that they get more "up-to-date information" from the Internet. Students (14 total) felt that their papers were now more in-depth or longer, gave more viewpoints, or gave a broader view on a topic; thus, as more than one student wrote, "more research equals a better paper." Seven (7) students also said that use of the Internet had improved their wording, grammar, and typing skills; that they used "proper" language for college-level writing because the Internet has easy-to-use tools, such as online style manuals; and that their writing was more concise. 
Six (6) students said they use the Internet as a heuristic device to help them get ideas on what to write, support for certain topics, information on how to write, and that they get additional ideas while they are typing. Three (3) said that they read a lot more and think that the reading has improved their writing and that their arguments are better supported. One simply said, "I learn better." However, students advised that they "need guidance and instruction before using the Internet as a research tool," and that the Internet "can be confusing but gives alternatives to the library."

The instructors apparently agreed with their students and tried to build such instruction into their syllabi. Although only one instructor explicitly stated in the course syllabus that, "You will learn how to use technology for research and text production," all of the instructors instructed students in use of the Internet for research, including "directed exercises of finding reliable sources," and one instructor assigned exercises on research, which students then had to show on-screen how they found the information. Instructors required progressive activities that made use of the Internet inherent to the course requirements, for example, an annotated bibliography of six sources, one of which had to be an Internet Web site.

Although instructors considered students to be "pretty savvy with the technology," one admitted that they need "to become more information literate, to be skeptical of types of Web sites, for example the .com's," and believed the students made progress, not only with writing skill, but with what was termed "information literacy," the ability to evaluate the credibility of Internet sources. Another instructor agreed, adding that "the students are rather indiscriminate in choosing sources. They have difficulty distinguishing between databases and Web sites, and they think using the Internet obviates use of the library (building)." 
In addition to positive comments, students offered opinions on what they considered negative aspects of using the Internet for English composition. Their comments illustrated misuse of the tool or mistrust of use of the Internet for English composition. One student wrote, "I search Yahoo! for a topic or a quote, and just interject it into my paper." Three students warned that they know students who plagiarize their papers and that use of the Internet encourages plagiarism, that it is "making students lazy."

Further research could clarify what students meant by "quality" and reveal specific ways in which they believed Internet use improved their writing. Interestingly, $88.9 \%$ of the nontraditional aged students and $46.2 \%$ of the traditional aged students believed Internet use had no effect on the quality of their writing, and only two students (both traditional aged) reported that Internet use made their writing somewhat or much worse. Again, the students' definition of "worse" could help clarify why they believed the quality of their writing suffered.

When instructors were asked if they thought use of the Internet alone had improved the quantity or quality of their students' writing, they reiterated some of their students' comments. As one instructor put it, "... I have a suspicion that when they work on the Internet, they tend to 'bulk import' source material, a kind of plagiarism." Similarly, another instructor believed that "quality will decrease because they want to rely on the Internet too much." In contrast to their students, none of the instructors thought use of the Internet had improved the quality of their students' papers. It would be helpful in interpreting these data to compare and contrast students' and instructors" criteria for "good" and "bad" writing.

Correlations for ATEUI total scores with age group, academic rank, and sex. No test of correlation of ATEUI total scores with demographic variables yielded significant results (see 
Table 13 for the complete correlation matrix). Although not significant, age group and academic rank correlated negatively with ATEUI total score. Age group correlated negatively with ATEUI total score $(\underline{\mathrm{r}}=-.089, \underline{\mathrm{p}}=.257)$ indicating that ATEUI total scores for traditional aged students were slightly higher than for non-traditional aged students. The correlation between academic rank and ATEUI total score was negligible $(\underline{r}=-.002 ; \underline{p}=.975)$. Correlation between ATEUI total scores and sex was weak but positive $(\underline{\mathrm{r}}=.009, \mathrm{p}=.910)$, indicating that females' ATEUI total scores were slightly more positive than males'.

\section{Correlations for Behavioral Correlate Questionnaire items with age group, sex, and} academic rank. After testing for significant correlation between ATEUI total scores and demographic variables, the next step was to test for significance between these variables and behavioral correlate responses. (Table 14 contains the complete correlation information for these variables). Behavioral Correlates Items 5, 8, 11, and 15 yielded significant correlation for sex or academic rank. Age group was the only demographic variable that yielded no statistically significant correlation with reported behaviors, which might be expected since the analysis of variance showed no statistically significant difference between the age groups' ATEUI mean scores. In contrast, sex correlated significantly with two behavioral items: 8 and 15 . Item 8 (frequency of searching the Internet for English composition coursework) correlated positively at the .01 level $(\underline{\mathrm{r}}=.165, \underline{\mathrm{p}}=.007)$, and Item 15 (frequency of visiting the library building) correlated positively at the .05 level $(\underline{\mathrm{r}}=.165, \underline{\mathrm{p}}=.034)$. These results may be interpreted to mean that females searched the Internet and visited the library more frequently than did males.

Academic rank also correlated positively and significantly with two behavioral items -5 and 11 -indicating that as academic rank increased, so did the behavioral frequency. Item 5 
asked if students discuss/share class-related information found on the Internet and correlated at the .05 level $(\underline{r}=.198, \underline{p}=.011)$. Item 11 asked how Internet use had affected paper length, and correlated with academic rank at the $.05 \operatorname{level}(\underline{\mathrm{r}}=.170, \mathrm{p}=.029)$.

\section{Conclusion}

This study of English composition students offered several insights into their attitudes and behaviors when using the Internet for educational purposes in the course. First, it was noted that their attitude toward using the Internet as part of the course was positive regardless of their age group (traditional aged or non-traditional aged). In fact, results here indicated that these two age groups were more similar than they were different, and the same can be said of male and female students. Although the two age groups may differ in the components of their personal and professional lives outside of the classroom and in their motivation for being in school (Justice, 1997), statistical tests here indicated that these participants were more similar than different on the variables measured, a finding that agreed with recent studies (Bishop-Clark \& Lynch, 1998; Duran, 2001; Graham \& Donaldson, 1999; House \& Keeley, 1996).

Age did not correlate significantly with ATEUI total score, nor did sex, a finding that contradicted earlier studies' findings of a higher level of anxiety or more negative attitudes among females (Dambrot et al., 1985; Darkenwald \& Novak, 1997; Liaw, 2000; Liu \& Reed, 1992; Popovich et al., 1987; Sensales \& Greenfield, 1995; Young, 2000) and with one study that found females held a more positive attitude than did males (Sanders \& Morrison-Shetlar, 2001), but which agreed with others who found no gender difference (Behar \& Hackett, 1991; Duggan et al., 2001; Duran, 2001; Heinssen et al., 1987; Jones, 1994; Kay, 1992; Loyd \& Gressard, 1984b; Loyd \& Loyd, 1985; Walters \& Necessary, 1996). 
The lack of correlation between sex, academic rank, and ATEUI score also was not surprising given the proliferation and widespread use of personal computers at home and at work, and the fact that $95.8 \%$ of the sample ( $100 \%$ of the non-traditional aged students) said they owned a personal computer and were connected to the Internet. As Sanders and MorrisonShetlar (2001) noted, today's undergraduates seem knowledgeable of and comfortable with computers in general and with the Internet specifically. The most salient finding in this study was that previous contrasts in confidence/anxiety toward computers between males and females, and between traditional aged and non-traditional aged students seems to have diminished, perhaps to the point of nonexistence. This stands to reason since some of the students said they received instruction on how to use the Internet as early as middle school (the mean age of the sample was 20.4 years). It may be that, if there were a greater range in the two age groups, statistical analyses would yield significant differences, for example, participants in their 40s, $50 \mathrm{~s}$, or 60s compared to traditional aged undergraduates. (The oldest participant in the present study was 37 years old and the youngest 18 , for a range of 19 years.)

Results from this research were very similar to those found by Duggan et al. (2001) and Duran (2001), but the study's weaknesses should be mentioned here along with its strengths. Perhaps the greatest weakness was the small number of non-traditional aged students in the sample, coupled with the vast inequality in the number of participants in the two age groups. To compensate for this inequality, the Levene test was computed on the data and showed that the assumption for homogeneity of variance was met. Although participants were not chosen at random, the assumption for independence was met. The sample was an intact sample, but because classes of students were surveyed, it also could be considered a cluster sample. 
Moreover, the number of students in the sample (167) was great enough to provide confidence in the results of statistical analyses of these English 102 students' attitudes toward using the Internet for educational purposes and their correlating behaviors. Thus, it is reasonable to conclude that the sample was representative of students enrolled in English 102 at WVU at the time of the study. However, because of variations in course requirements and curriculum, it may not be concluded that these findings could be generalized to composition students at other institutions of higher learning.

This research brought new data to the study of computer attitude measurement, English composition, and the comparison of non-traditional aged and traditional aged students. Although several studies of computer attitude scale design and subsequent measure of students' attitudes toward computers occurred during the 1980s and 1990s, no research measuring students' attitudes toward educational use of the Internet had been published prior to Duggan et al. (2001). The present study broadened the use of the ATEUI to measure undergraduate students' attitude toward the Internet in a discipline differing from those in the original study when the scale was designed. As a discipline, English composition uses qualitative, or descriptive, research methods more frequently than quantitative (Eldred \& Hawisher, 1995). Moreover, this study’s comparison of traditional aged and non-traditional aged students added to the application and use of the scale. The present study could be considered something of a baseline or foundation upon which future research can be built.

When asked what research they believe needs to be done, or what research they would like to see done, the instructors whose students were surveyed in this study responded with answers perhaps as varied and individual as they are. Their questions were valid and centered on 
composition; some pertained to use of the Internet, and some did not. The instructors would like to see different kinds of research and for different purposes, including "hard data about the benefits of a 'reading' composition course versus one without reading that concentrates solely on writing practice-empirical data that would indicate pragmatic results."

Another study might look at the "comparable benefits of a course with required continuing revision of a single manuscript versus multiple new, smaller writing projects." One instructor would like to see research on "different learning strategies, based on ethnic or cultural background/origin, and how ethnic or cultural background or origin affects how students learn, how they perceive?" Since plagiarism is a continuing problem that use of the Internet has perhaps exacerbated, one instructor would like to know how to get students to use a variety of research methods, not just the Internet. Other requests included research on the thinking processes people follow when they write, and how writing and personality are tied. One instructor wanted to know how to train composition instructors to teach information literacy to the students, how to teach students to use the information effectively, and how to narrow down their search for sources as well as their topics.

Further studies might use the scale in yet more academic settings, disciplines, and age groups. Additional research might compare groups of English composition (or other) students, for example, those who own computers versus those who do not, or those who enroll in composition courses for which the Internet is required versus those for which it is not, with the expectation that students who own computers and those choosing Internet-based courses would have more positive attitudes toward the use of it. It would also be interesting to compare ATEUI scores and the behavioral correlates across disciplines or within a discipline, for example, 
business versus biology, or English composition versus technical or creative writing. The behavioral correlates questionnaire might also be expanded to measure more specific or detailed behaviors between both groups of students studied here, for example, their attitude toward writing, or to compare age groups, e.g., Boomers versus Xers, within the non-traditional aged student cohort.

Forward from the present study, research in English composition could examine more specifically what students' attitude toward writing is, what they mean when they say their papers are "better" or "worse," especially compared to their instructors' definitions of those terms. Longitudinal studies might help determine how using the Internet affects writing skill, including length and quality of papers, over a period of time. It would also be interesting to learn more about students' specific research behaviors; for instance, how does the research process differ when the Internet is used than when it is not? When students visit the library building, how are they using the resources there; for example, are they searching online for resources, or finding them on shelves?

As far as the progressive structure of a college English composition course, it would be helpful to know what particular variables affect both length and quality of papers, including use of the Internet, classroom instruction, assigned activities other than use of the Internet, and practice with both writing and research. The findings of the present study, including these instructors' questions, make two things very clear: both the teaching and research of English composition have been complicated by use of the Internet, and continuing study is still very much needed. 


\section{References}

Baker, E. L. \& O’Neil, H. R., Jr. (1987). Assessing instructional outcomes. In R. M. Gagné (Ed.), Instructional Technology: Foundations (pp. 343-377). Hillsdale, New Jersey: Lawrence Erlbaum Associates.

Bandolas, D. \& Benson, J. (1990). Testing the factor structure invariance of a computer attitude scale over two grouping conditions. Educational and Psychological Measurement. $50: 1,49-60$.

Bannon, S. H., Marshall, J. C., \& Fluegal, S. (1985). Cognitive and affective computer attitude scales: A validity study. Educational and Psychological Measurement. 45, 679-681.

Behar, J. E. \& Hackett, M. S. (1991). Challenges of the new information age curriculum: Computers and the liberal arts. Journal of Research on Computing in Education. $23: 4,568-584$.

Bishop-Clark, C. \& Lynch, J. (1998). Comparing teacher and student responses to the mixed-aged college classroom. Community College Review. 25:4, 21-34.

Bloom, B. S., Engelhart, M. D., Furst, E. J., Hill, W. H., \& Krathwohl, D. R. (1956). Taxonomy of Educational Objectives, Handbook I: Cognitive Domain. New York: McKay.

Bowden, R. \& Merritt, R. (1995). The adult learner challenge: Institutionally and administratively. Education. 115:3, 426-432.

Collins, J. L. (1989). Computerized text analysis and the teaching of writing. In G. E. Hawisher \& C. L. Selfe (Eds.), Critical Perspectives on Computers and Composition Instruction (pp. 30-43). New York: Teachers College Press. 
Cotton, K. (1997, September 7). Computer-assisted instruction. Northwest Regional Educational Laboratory, School Improvement Research Series (SIRS), Close-Up \#10. http://www.nwrel.org/scpd/sirs/5/cu10.html

Dambrot, F. H., Watkins-Malek, M. A., Silling, S. M., Marshall, R. S., \& Garver, J. A. (1985). Correlates of sex differences in attitudes toward and involvement with computers. Journal of Vocational Behavior. 27, 71-86.

Darkenwald, G. G. \& Novak, R. J. (1997). Classroom age composition and academic achievement in college. Adult Education Quarterly. 47:2, 108-116.

Denzin, N. K. \& Lincoln, Y. S. (1998). (Eds.). Collecting and Interpreting Qualitative Materials. Thousand Oaks: Sage Publications, Inc.

Divine, R. L. \& Wilson, J. H. (1997). Antecedents of student attitudes toward computers. Journal of Marketing Education. 19:2, 54-65.

Donaldson, J. F. (1999). A model of college outcomes for adults. Adult Education Quarterly. 50:1, 24-40.

Duffelmeyer, B. B. (2000). Critical computer literacy: Computers in first-year composition as topic and environment. Computers and Composition. 17:3, 289-307.

Duggan, A., Hess, B., Morgan, D., Kim, S., \& Wilson, K. (2001). Measuring students' attitude toward educational use of the Internet. Journal of Educational Computing Research. $25: 3,267-281$.

Duran, D. G. (2001). Traditional-aged and non-traditional aged students: Measurement and comparison of attitude toward educational use of the Internet in a freshman English composition class. Unpublished manuscript. West Virginia University. 
Eldred, J. C. \& Hawisher, G. E. (1995). Researching electronic networks. Written Communication. 12:3, 330-369.

Erickson, B. J. (1992). A synthesis of studies on computer-supported composition, revision, and quality. Journal of Research on Computing in Education. 25:2, 172-188.

Francis, L. J. (1993). Measuring attitude toward computers among undergraduate college students: The affective domain. Computers in Education. 20:3, 251-255.

Fuchs, G. E. (1980). Evaluating Educational Research. Lanham, Maryland: University Press of America.

Gable, R. K. (1986). Instrument Development in the Affective Domain.

Boston/Dordrecht/Lancaster: Kluwer-Nijhoff Publishing.

Gable, R. K. \& Wolf, M. B. (1993). Instrument Development in the Affective Domain: Measuring Attitudes and Values in Corporate and School Settings. $2^{\text {nd }}$ ed. Boston/Dordrecht/London: Kluwer Academic Publishers.

Gagné, R. M. (1974). Essentials of Learning for Instruction. $2^{\text {nd }}$ ed. Hinsdale, Illinois: The Dryden Press.

Gagné, R. M. (1985). The Conditions of Learning. ( $4^{\text {th }}$ ed.). New York: Holt, Rinehart \& Winston.

Gagné, R. M. (1987). (Ed.). Instructional Technology: Foundations. Hillsdale, New Jersey: Lawrence Erlbaum Associates.

Graham, S. \& Donaldson, J. F. (1999). Adult students' academic and intellectual development in college. Adult Education Quarterly. 49:3, 147-161. 
Gressard, C. \& Loyd, B. (1985). Validation studies of a new computer attitude scale. AEDS Journal. 18:3, 295-301.

Harrington, S. (2000, September 28). The flashlight project and an introductory writing course sequence: Investigation as a basis for change. Indiana University-Purdue University, Indianapolis. http://www.iupui.edu/ sharrin/flash.htm

Harrison, A. W. \& Rainer, Jr., R. K. (Fall 1992). An examination of the factor structures and concurrent validities for the computer attitude scale, the computer anxiety rating scale, and the computer self-efficacy scale. Educational \& Psychological Measurement. 52, 735-745.

Hawisher, G. E. (1989). Research and recommendations for computers and composition. In G. E. Hawisher \& C. L. Selfe (Eds.), Critical perspectives on Computers and Composition Instruction (pp. 44-69). New York: Teachers College Press.

Hawisher, G. E. \& LeBlanc, P. (1992). (Eds.). Re-imagining Computers and Composition: Teaching and Research in the Virtual Age. Portsmouth, NH: Boynton/Cook Publishers, Inc.

Hawisher, G. E. \& Selfe, C. L. (1989). (Eds.). Critical Perspectives on Computers and Composition Instruction. New York: Teachers College Press.

Heinssen, R. K., Glass, C. R., \& Knight, L. A. (1987). Assessing computer anxiety: Development and validation of the Computer Anxiety Rating Scale. Computers in Human Behavior. 3, 49-59.

Herrington, A. \& Moran, C. (2001). What happens when machines read our students' writing? College English. 63:4, 480-499. 
House, J. D. \& Keeley, E. J. (1996). Differential prediction of adult student performance from Miller Analogies test scores. Journal of Genetic Psychology. 157:4, 501-503.

House, J. D. \& Prion, S. K. (1998). Student attitudes and academic background as predictors of achievement in college English. International Journal of Instructional Media. $25: 1,29-42$.

Jones, W. P. (1994). Computer use and cognitive style. Journal of Research on Computing in Education. 26:4, 514-517.

Justice, D. O. (1997). Facilitating adult learning in a liberal education context. Liberal Education. 83:1, 28-33.

Kasworm, C. (1990). Adult undergraduates in higher education: A review of past research perspectives. Review of Educational Research, 60:3, 345-372.

Kay, R. H. (1989). A practical and theoretical approach to assessing computer attitudes: The computer attitude measure. Journal of Research on Computing in Education. 21:4, 457463.

Kay, R. H. (1992). Understanding gender differences in computer attitudes, aptitude, and use: An invitation to build theory. Journal of Research on Computing in Education. 25:2, 159-161.

Koohang, A. A. (1989, Winter). A study of attitudes toward computers: Anxiety, confidence, liking, and perception of usefulness. Journal of Research on Computing in Education. 137-150.

Krathwohl, D. R., Bloom, B. S., \& Masia, B. B. (1964). Taxonomy of Educational Objectives, Handbook II: Affective Domain. New York: McKay. 
Liaw, S. (2000). Information technology and education: Student perceptions of computer and Web-based environments. (Doctoral dissertation, Seattle Pacific University, 2000). Dissertation Abstracts International, 61(05A, 1808). (UMI No. 9975254).

Liu, M. \& Reed, W. M. (1992). Teacher education students and computers: Gender, major prior computer experience, occurrence, and anxiety. Journal of Educational Computing Research. 24:4, 457-467.

Loyd, B. \& Gressard, C. (1984a). Reliability and factorial validity of computer attitude scales. Educational and Psychological Measurement. 44, 501-505.

Loyd, B. \& Gressard, C. (1984b). The effects of sex, age, and computer experience on computer attitudes. AEDS Journal. 40, 67-77.

Loyd, B. H. \& Loyd, D. E. (1985). The reliability and validity of an instrument for the assessment of computer attitudes. Educational and Psychological Measurement. 45, 903-908.

Massoud, S. L. (1990). Factorial validity of a computer attitude scale. Journal of Research on Computing in Education. 22:1, 290-299.

McKinnon, D. H., Nolan, C. J. P., \& Sinclair, K. E. (2000). A longitudinal study of student attitudes toward computers: Resolving an attitude decay paradox. Journal of Research on Computing in Education. 32:3, 325-335.

Mitra, A. \& Steffensmeier, T. (2000). Changes in student attitudes and student computer use in a computer-enriched environment. Journal of Research on Computing in Education. $32: 3,417-433$.

Montgomery, E. B. (1982, March). Bringing manual input into the $20^{\text {th }}$ century: New keyboard concepts. IEEE. 11-18. 
Murphy, C. A., Coover, D., \& Owen, S. V. (1989). Development and validation of the computer self-efficacy scale. Educational and Psychological Measurement. 49, 893-899.

Nickell, G. S. \& Pinto, J. N. (1986). The computer attitude scale. Computers in Human Behavior. 2, 301-306.

Parr, J. M. (1994/1995). When pens are passé: Students reflect on written composition. Journal of Research on Computing in Education. 27:2, 221-230.

Patton, M. Q. (1990). Qualitative Evaluation and Research Methods. $2^{\text {nd }}$ ed. Newbury Park: Sage Publications, Inc.

Popovich, P. M., Hyde, K. R., Zakrajsek, T., \& Blumer, C. (1987). The development of the attitudes toward computer usage scale. Educational and Psychological Measurement. 47, 261-269.

Reed, W. M. (1990). The effect of computer-and-writing instruction on prospective English teachers' attitudes toward and perceived uses of computers in writing instruction. Journal of Research on Computing in Education. 23:1, 3-27.

Reed, W. M. (1996). Assessing the impact of computer-based writing instruction. Journal of Research on Computing in Education. 28:4, 418-437.

Rosenthal, G. T., Folse, E. J., Alleman, N. W., Boudreaux, D., Soper, B., \& Von Bergen, C. (2000). The one-to-one survey: Traditional versus non-traditional student satisfaction with professors during one-to-one contacts. College Student Journal. 34:2, 315-320.

Sadler, L.V. (1987, Fall). The computers-and-effective-writing movement: Computerassisted composition. ADE Bulletin. 087, 28-33. 
Sanders, D. W. \& Morrison-Shetlar, A. L. (2001). Student attitudes toward Webenhanced instruction in an introductory biology course. Journal of Research on Computing in Education. 33:3, 251-262.

Sankaran, S. R., Sankaran, D., \& Bui, T. X. (2000). Effect of student attitude to course format on learning performance: An empirical study in Web vs. lecture instruction. Journal of Instructional Psychology. 27:1, 66-73.

Selfe, C. L. (1992). Preparing English teachers for the Virtual Age: The case for technology critics. In G. E. Hawisher \& P. LeBlanc (Eds.), Re-imagining Computers and Composition: Teaching and Research in the Virtual Age (pp. 24-42). Portsmouth, NH: Boynton/Cook Publishers, Inc.

Selfe, C. L. (1999). Technology and Literacy in the Twenty-First Century: The Importance of Paying Attention. Carbondale, Illinois: Southern Illinois University Press.

Selfe, C. L. \& Hilligoss, S. (Eds.). (1994). Literacy and Computers: The Complications of Teaching and Learning with Technology. New York: Modern Language Association of America.

Sensales, G. \& Greenfield, P. M. (1995). Attitudes toward computers, science, and technology. Journal of Cross-Cultural Psychology. 26:3, 229-242.

Sullivan, P. \& Porter, J. E. (1997). Opening Spaces: Writing Technologies and Critical Research Practices. Greenwich, Connecticut: Ablex Publishing Corporation.

Thurstone, L. L. \& Chave, E. J. (1929). The Measurement of Attitude: A Psychophysical Method and Some Experiments with a Scale for Measuring Attitude toward the Church. Chicago: The University of Chicago Press. 
Tuckman, B. W. (1999). Conducting Educational Research. Fort Worth: Harcourt Brace College Publishers.

Wagschal, K. (1997). I became clueless teaching the GenXers: Redefining the profile of the adult learner. Adult Learning. 8:4, 21-25.

Walters, J. E. \& Necessary, J. R. (1996). An attitudinal comparison toward computers between underclassmen and graduating seniors. Education. 116:4, 623-634.

WVU Extended Learning. (2002, October 20). Adult Learning. West Virginia University. http://www.wvu.edu/ exlearn/adultlearning/index.htm

Young, B. J. (2000). Gender differences in student attitudes toward computers. Journal of Research on Computing in Education. 33:2, 204-216.

Zakrajsek, T. D. \& Waters, L. K. (1990). Convergent validity of scales measuring computer-related attitudes. Educational and Psychological Measurement. 50:2, 343-349.

Zoltan, E. \& Chapanis, A. (1982). What do professional persons think about computers? Behavior Information Technology. 1, 55-68. 
Appendices 


\section{Appendix A}

\section{Attitude Toward Educational Use of the Internet}

For each statement, indicate the degree of either disagreement or agreement by circling one of the five options from 1 (Strongly Disagree) to 5 (Strongly Agree). This is a survey of people's attitudes toward the use of the Internet for educational purposes. Your responses to all questions will be held in strict confidence.

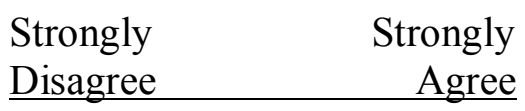

1. Knowledge of the Internet is essential for surviving college.

2. The Internet is as important as other research tools.

3. I prefer to use the Internet to do research.

4. I feel that the Internet contains mostly useless information.

5. The Internet is too difficult to use for school.

6. I feel the Internet is easier to use than the library.

7. Generally, I feel the Internet is as informative as the teacher.

8. I hate using the Internet for important educational projects.

9. I enjoy getting information from books and the Internet equally.

10. I feel overwhelmed when I try to use the Internet for my classes.

11. The Internet does not particularly excite me.

12. Using the Internet makes learning fun.

13. I feel the Internet is an integral part of the educational process.

14. I am indifferent about using the Internet for education.

15. I wish I did not have to use the Internet for educational purposes.

16. Using the Internet is as convenient as using the library.

17. Access to the Internet for educational purposes is not important to me.

18. Browsing the Internet confuses me.

\begin{tabular}{|c|c|c|c|c|}
\hline 1 & 2 & 3 & 4 & 5 \\
\hline 1 & 2 & 3 & 4 & 5 \\
\hline 1 & 2 & 3 & 4 & 5 \\
\hline 1 & 2 & 3 & 4 & 5 \\
\hline 1 & 2 & 3 & 4 & 5 \\
\hline 1 & 2 & 3 & 4 & 5 \\
\hline 1 & 2 & 3 & 4 & 5 \\
\hline 1 & 2 & 3 & 4 & 5 \\
\hline 1 & 2 & 3 & 4 & 5 \\
\hline 1 & 2 & 3 & 4 & 5 \\
\hline 1 & 2 & 3 & 4 & 5 \\
\hline 1 & 2 & 3 & 4 & 5 \\
\hline 1 & 2 & 3 & 4 & 5 \\
\hline 1 & 2 & 3 & 4 & 5 \\
\hline 1 & 2 & 3 & 4 & 5 \\
\hline 1 & 2 & 3 & 4 & 5 \\
\hline 1 & 2 & 3 & 4 & 5 \\
\hline
\end{tabular}

$\begin{array}{lllll}1 & 2 & 3 & 4 & 5\end{array}$ 


\section{Appendix B}

\section{Behavioral Correlates Questionnaire}

For each question, check the box or boxes that best represent your Internet-related behavior(s). Questions 17-19 ask for demographic information. This is a survey of people's behavior toward the Internet for educational purposes. Your responses to all questions will be held in strict confidence.

1. Do you own a personal computer?

2. Are you connected to the Internet?

3. Do you keep track of valuable educational sites?

4. If you could get all lecture and course information from the Internet, would you go to class?

5. Do you and your friends discuss/share class-related information found on the Internet?

6. Given a choice, would you take a course that required Internet use?

7. On average, how often do you browse the Internet?

$$
\square \text { Never }
$$

$\square$ Once a semester

$\square$ Once a month

$\square$ Once a week

$\square$ Daily

8. On average, how often do you search the Internet for English composition coursework, (for example, to find research material, consult with classmates or instructor, download class lessons/notes)?

\section{$\square$ Never}

$\square$ Once a semester

$\square$ Once a month

$\square$ Once a week

$\square$ Daily 
9. How did you initially learn to use the Internet? (Please check all that apply.)

$\square$ Class

$\square$ Journal/Book

$\square$ Conference/Presentation

$\square$ Friends/Colleagues

$\square$ Library/Instruction

$\square$ Self-taught

$\square$ Other (please specify)

10. Which of the following features for using the Internet apply to you? (Please check all that apply.)

$\square$ Electronic mail

$\square$ World Wide Web

$\square$ Newsgroups

$\square$ FTP

$\square$ LISTSERVs

$\square$ Chat rooms

$\square$ Telnet

$\square$ Forwarding

$\square$ Downloading

$\square$ Uploading

$\square$ Other (please specify)

11. How has using the Internet affected the length of your papers?

$\square$ I write much longer papers.

$\square$ I write somewhat longer papers.

$\square$ Using the Internet has had no effect on the length of my papers.

$\square$ I write somewhat shorter papers.

$\square$ I write much shorter papers.

12. How has using the Internet affected the quality of your writing?

$\square$ My writing is much better.

$\square$ My writing is somewhat better.

$\square$ The quality of my writing has not changed.

$\square$ My writing is somewhat worse.

$\square$ My writing is much worse.

Can you give specific ways in which using the Internet has affected your writing? 
13. How has using the Internet for research in English composition changed your attitude toward writing?

$\square$ I enjoy writing much more.

$\square$ I enjoy writing somewhat more.

$\square$ My attitude toward writing hasn't changed.

$\square$ I enjoy writing somewhat less.

$\square$ I enjoy writing much less.

14. How has using the Internet for research in English composition affected the ease or difficulty with which you write papers?

$\square$ It is much easier to write papers using the Internet for research.

$\square$ It is somewhat easier to write papers using the Internet for research.

$\square$ Using the Internet for research has no made difference in how hard or easy it is for me to write papers.

$\square$ It is somewhat more difficult to write papers using the Internet for research.

$\square$ It is much more difficult to write papers using the Internet for research.

15. On average, how often do you visit the library (building) to find research material?

$\square$ Never

$\square$ Once a semester

$\square$ Once a month

$\square$ Once a week

$\square$ Daily

16. For which of the following purposes do you use the Internet specific to English composition?

(Please check all that apply.)

$\square$ Consult with instructor

$\square$ Consult with classmates

$\square$ Homework assignments

$\square$ Search for research material for assigned papers

$\square$ Search WVU Libraries online

$\square$ Retrieve class lessons/lecture notes

$\square$ Peer review of papers

$\square$ Other (please specify)

17. Sex:

Male $\quad \square$ Female

18. Age:

19. Year in school: $\quad \square$ Freshman $\quad \square$ Sophomore $\quad \square$ Junior $\quad \square$ Senior

20. Is there anything else you would like to say about using the Internet for English composition? 


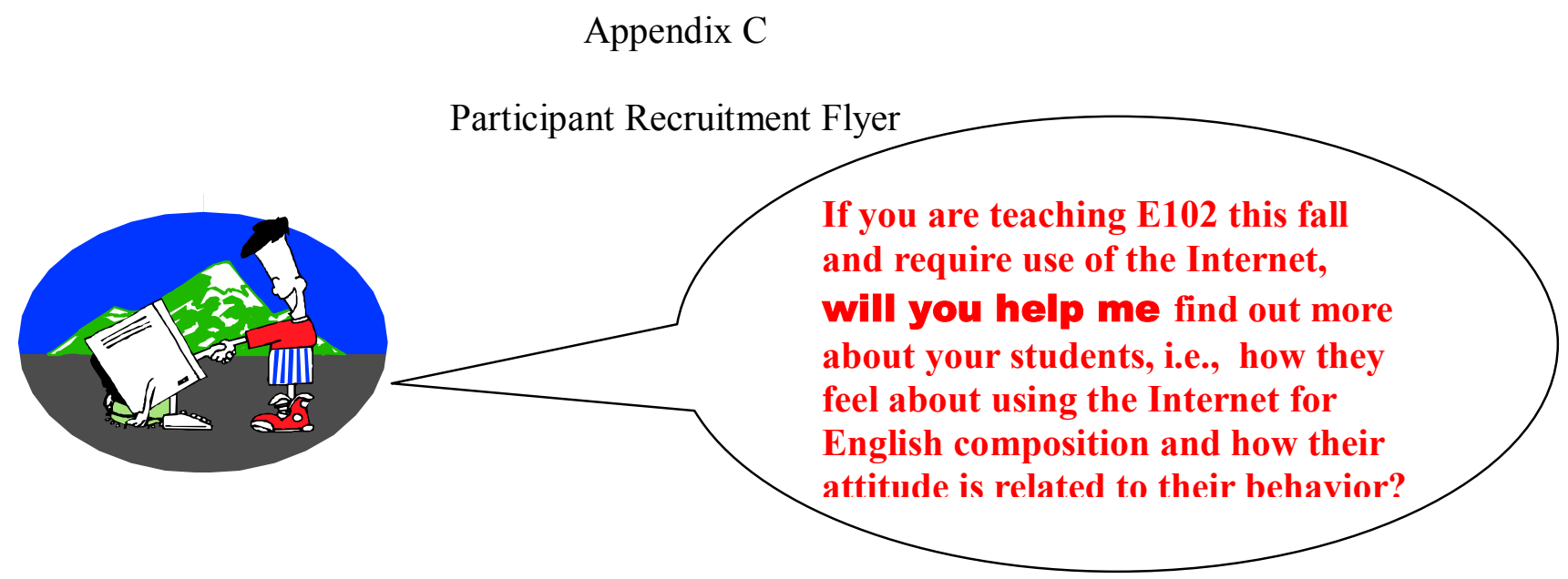

What: Doctoral dissertation

Measurement of Attitude Toward Educational Use of the Internet in an English Composition Course with a Comparison of Traditional and Non-traditional Aged Students

Who: Diana Duran, doctoral candidate in Educational Psychology at WVU, (B.A./M.A. in English)

When: Fall 2002 Semester (November)

Where: E102 classrooms during a regular class meeting (maximum time required, 10-15 minutes). I will administer: (1) an 18-item attitude scale and (2) a 16-item multiple-choice questionnaire of how students use the Internet. Basic demographic information also will be gathered, and there is one open-ended question. For control purposes, students should have no prior knowledge that they will be surveyed, nor should the research proposal be discussed with them. I would also like to conduct a brief interview with each instructor about course requirements for use of the Internet.

Why: To help me gather information for my doctoral dissertation.

Using the information gathered in the surveys, the study will measure attitudes toward educational use of the Internet (ATEUI) among English composition (E102) students at West Virginia University to determine any relationship between attitude and behavior, age, sex, or academic rank. SPSS ${ }^{\circledR}$ software will be used for the statistical analyses.

All aspects of the information collection and analysis will be kept confidential and anonymous and in the sole possession of the researcher (me). This research plan has been approved by the College of Human Resources and Education, and the West Virginia University Institutional Review Board. If you are interested in helping with this research by allowing me to survey your composition students and talk to you, or if you have any questions about the research, please notify me at 293-4191, ext. 5561 (w) or 864-6857 (h), or at d2duran@yahoo.com no later than Friday, November 5, 2002. Thank you for your prompt response. 


\section{Appendix D}

\section{Script for Study}

Good morning (afternoon, evening). Thank you for agreeing to participate in this study. The goal of this research is to measure English composition students' attitudes toward using the Internet for educational purposes, and to learn what behaviors are related to their attitudes. The information I gather will be used as part of the fulfillment for my doctorate in Educational Psychology at WVU.

I would like to advise you of the following:

1. Your participation is entirely voluntary, and you do not have to respond to every question.

2. Your responses will remain anonymous, and confidentiality will be maintained at all times during this study.

3. Neither your class standing, athletic status, nor grades will be affected by refusing to participate or by withdrawing from the study.

Procedures for the study:

- I will ask you to complete two surveys: 1) the Attitude Toward Educational Use of the Internet (18 items), and 2) a Behavioral Correlates questionnaire (20 questions).

- You will not put your name on the surveys or identify yourself in any way. Your identity is kept anonymous and your answers in strict confidence. No one besides the investigator (me) will see the surveys.

- After the surveys are collected, I will record the numbers to determine, for example, how frequently you as a group gave a certain answer to any question.

- Do you have any questions? 